\title{
Mammals from the earliest Uintan (middle Eocene) Turtle Bluff Member, Bridger Formation, southwestern Wyoming, USA, Part 2: Apatotheria, Lipotyphla, Carnivoramorpha, Condylartha, Dinocerata, Perissodactyla and Artiodactyla
}

\author{
Paul C. Murphey and Thomas S. Kelly
}

\begin{abstract}
The Turtle Bluff Member (TBM) of the Bridger Formation in southwestern Wyoming, formerly known as the Bridger $\mathrm{E}$, is designated as the stratotype section for the earliest Uintan or biochron Ui1a of the Uintan North American Land Mammal age. The TBM overlies the Twin Buttes Member of the Bridger Formation, upon which the Twinbuttean Subage or biochron $\mathrm{Br} 3$ of the Bridgerian North American Land Mammal age is characterized. For over a century, the TBM yielded only a few fragmentary specimens, but extensive field work over the last 23 years has resulted in the discovery of numerous mammal fossils from the member, which provides an unprecedented opportunity to better define this poorly known interval. This is the second in a series of three papers that provide detailed descriptions and taxonomic revisions of the fauna from the TBM. Here we document the occurrence of the following taxa from the TBM: Apatemys bellulus; Apatemys rodens; Scenopagus priscus; Scenopagus curtidens; Sespedectinae, genus undetermined; Entomolestes westgatei new species; Centetodon bemicophagus; Centetodon pulcher; Nyctitherium gunnelli new species; Nyctitherium velox; Pontifactor bestiola; an unnamed oligoryctid; an unnamed lipotyphlan; Viverravus gracilis; Hyopsodus lepidus; Uintatherium anceps; Wickia sp., cf. W. brevirhinus; Triplopus sp., cf. T. obliquidens; Epihippus sp., cf. E. gracilis; Homacodon sp., cf. H. vagans; and Merycobunodon? walshi new species. A greater understanding of the faunal composition of the TBM allows a better characterization of the beginning of the Uintan and further clarifies the Bridgerian-Uintan transition.
\end{abstract}

Paul C. Murphey. Research Associate, Department of Paleontology, San Diego Museum of Natural History, 1788 El Prado, San Diego, California 92101, USA, pmurphey@sdnhm.org Thomas S. Kelly. Research Associate, Vertebrate Paleontology Department, Natural History Museum of Los Angeles County, 900 Exposition Blvd., Los Angeles, California 90007, USA, tom@tskelly.gardnerville.nv.us 
MuRPhey \& Kelly: BRIDger TuRtLe Bluff Member mammals

Keywords: biostratigraphy, Eocene; mammals; new species; Uintan

Submission: 5 September 2016 Acceptance: 20 April 2017

\section{INTRODUCTION}

The Turtle Bluff Member (TBM) of the Bridger Formation of southwestern Wyoming, formerly known as the Bridger $E$, is one of only a few areas in North America that has yielded mammals of the earliest Uintan biochron (Ui1a) of the Uintan North American Land Mammal age (Evanoff et al., 1994; Murphey and Evanoff, 2007; Murphey and Dunn, 2009; Gunnell et al., 2009; Kelly and Murphey, 2016a). One of us (Murphey) has conducted over 15 years of field work in the TBM, including quarrying and screen washing of large amounts of matrix followed by heavy liquid separation of the fossils from the concentrates, which has resulted in a diverse sample of mammals from six localities in the TBM (Figure 1). Additional fossils were previously recovered from two other localities in the TBM (Figure 1) by West and Hutchison (1981) at Milwaukee Public Museum Locality 2960 and crews from the University of Colorado Natural History Museum (UCM) at UCM Locality 92189 (Donna's Locality). Together, these samples of fossil mammals offer an unprecedented opportunity to increase our knowledge of the faunal diversity of this poorly known interval. Faunal lists for the TBM have been published. However, with the exception of Hemiacodon engardae Murphey and Dunn, 2009 , the taxa were never formally described or illustrated in detail. This paper is the second in a series that provides a comprehensive taxonomic analysis and revision of the mammals from the Turtle Bluff Member and includes the Apatotheria, Lipotyphla, Condylartha, Dinocerata, Perissodactyla, and Artiodactyla. The first paper reported on the Primates and Rodentia from the TBM (Kelly and Murphey, 2016a) and included a detailed discussion of the history of investigations of the Turtle Bluff Member, which will not be repeated here. The third paper will document the marsupials from the TBM and provide a reevaluation of the BridgerianUintan North American Land Mammal age transition based faunal comparisons along with new radioisometric and paleomagnetic data for the TBM.

\section{METHODS}

Measurements of small mammal teeth were made with an optical micrometer to the nearest
$0.01 \mathrm{~mm}$, and those of large mammals were made with calipers to the nearest $0.1 \mathrm{~mm}$. Dental terminology follows Rose (2006) for lipotyphlans and apatemyids, Turnbull (2002) for uintatheres, Froehlich (2002) for perissodactyls, Golz (1976) for condylarths and artiodactyls, and Dashzeveg and Hooker (1997) for hyracodontids. Upper and lower teeth are designated by uppercase and lowercase letters, respectively. All specimens are curated in the research collections at the Department of Paleontology at the San Diego Museum of Natural History, the Paleontology Section of the Museum of Natural History, University of Colorado, and the Department of Earth Sciences, Denver Museum of Nature and Science. Detailed locality data are available at these institutions.

Biochrons or subbiozones of the Bridgerian and Uintan North American Land Mammal ages (e.g., $\mathrm{Br} 2, \mathrm{Br}$, Ui1a, Ui1b, Ui2, and Ui3) follow Gunnell et al. (2009). All older ${ }^{40} \mathrm{Ar} /{ }^{39} \mathrm{Ar}$ dates reported here have been recalculated relative to the astronomically calibrated age of $28.201 \mathrm{Ma}$ for the Fish Canyon sanidine standard (Kuiper et al., 2008) and include $\pm 2 \sigma$.

Abbreviations are as follows: ap, greatest anteroposterior length; $b$, broken tooth dimension measurement; $d$, deciduous; L, left; $m$, meters; Ma, megannum (one million years in the radioisotopic time scale); $p$, partial; $R$, right; tr, greatest transverse width; tra, anterior transverse (trigonid) width; trp, posterior transverse (talonid) width. Institutional abbreviations are as follows: AMNH, American Museum of Natural History; AMNH FM, American Museum of Natural History, Frick Collection; DMNS, Denver Museum of Nature and Science; MPM, Milwaukee Public Museum; SDNHM, San Diego Natural History Museum; SDSNH, San Diego Society of Natural History; TMM, Texas Memorial Museum; UCM, University of Colorado, Museum of Natural History.

\section{SYSTEMATIC PALEONTOLOGY}

Order APATOTHERIA Scott and Jepsen, 1936

Family APATEMYIDAE Matthew, 1909 Genus APATEMYS Marsh, 1872b Apatemys bellulus Marsh, 1872b

Figure 2.1-6, Table 1 


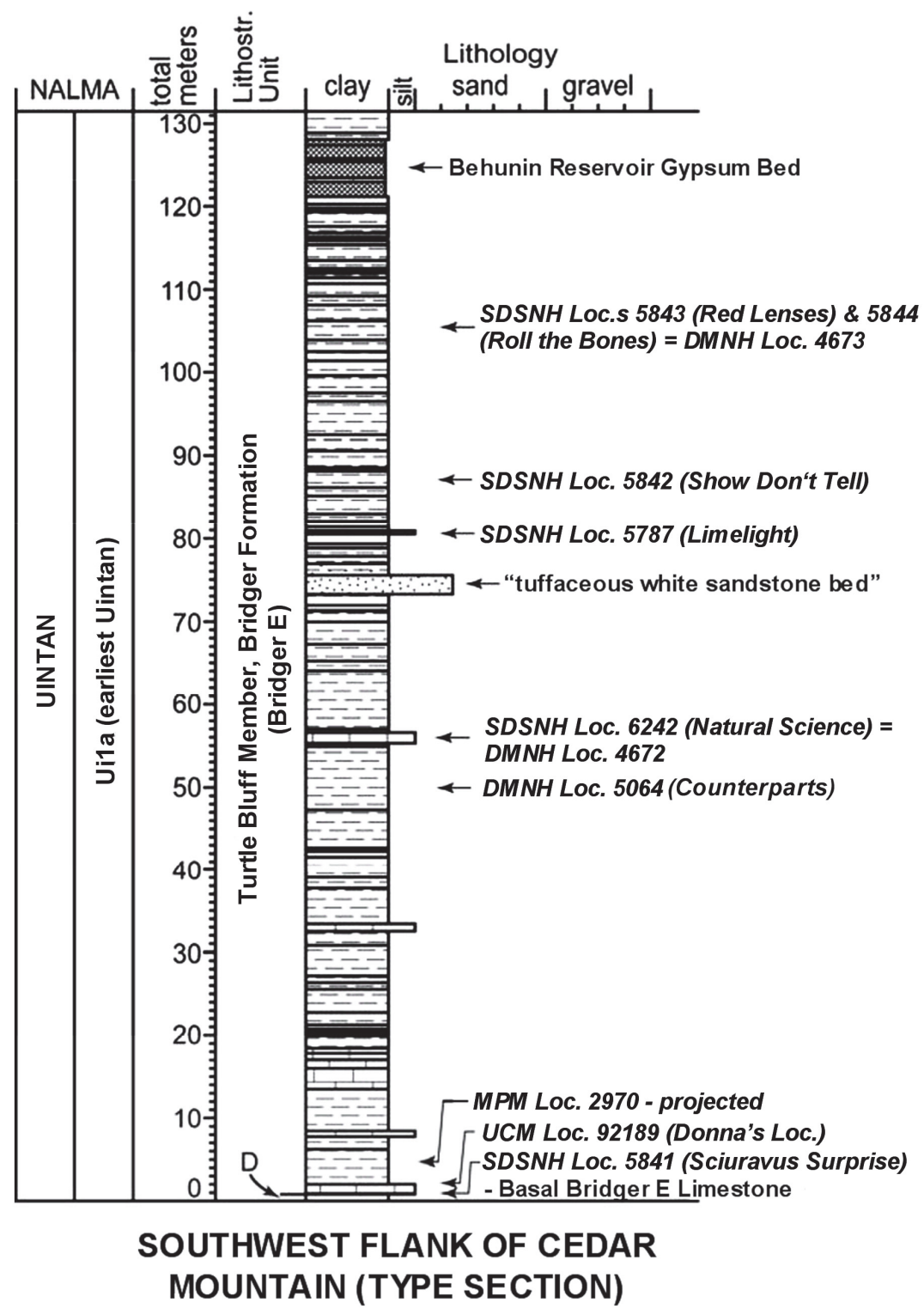

FIGURE 1. Schematic stratigraphic column of type section Turtle Bluff Member on southwest flank of Cedar Mountain, Bridger Formation, showing relative stratigraphic positions of SDSNH, DMNS and UCM localities (along with the locality names in parentheses) that yielded the fossils described in this paper (reproduced from Kelly and Murphey, 2016a, figure 1). MPM Locality 2970 occurs on southwest flank of Sage Creek Mountain, and its approximate relative stratigraphic position is projected onto type section. Abbreviations are: Lithostr., lithostratigraphic; NALMA, North American Land Mammal age.

Referred specimens. From UCM Locality 92189: RM1, UCM 70967; Lm1, UCM 95804; Lm2, UCM 68923; Rm3s, UCM 68424, 79676; Lm3, UCM 95807.

Description. The M1 paracone, metacone, and protocone have relatively tall, sharp apices with the protocone positioned anteriorly. The hypocone is distinct and positioned posterolabially of the protocone apex. The parastyle is robust and forms an anterior extension at the anterolabial corner of the stylar shelf. The labial border along the stylar shelf between the paracone and metacone (ectoflexus) is moderately concave. The postmetacrista extends posterolabially in a gentle arc from the metacone to terminate at a distinct metastyle on the posterolabial corner of the stylar shelf. The anterior and posterior cingula are weak.

The $\mathrm{m} 3$ differs from $\mathrm{m} 1-2$ by having a more anteroposteriorly elongated talonid, and the $\mathrm{m} 1$ differs from the $\mathrm{m} 2$ by having a more anteroposteri- 


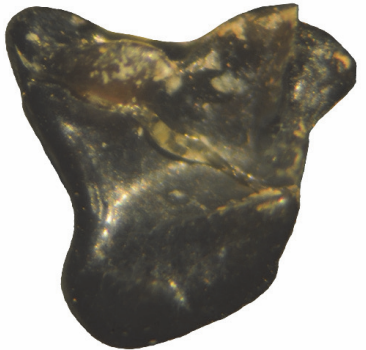

1

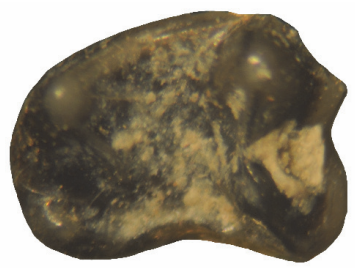

4

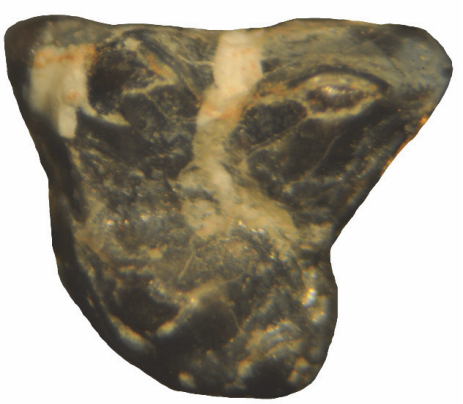

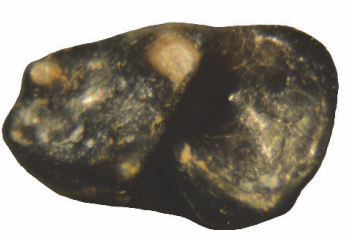

2

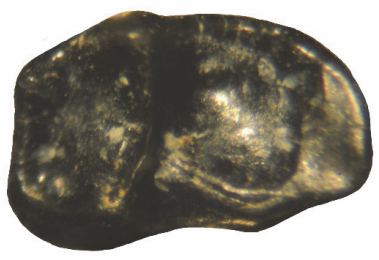

5

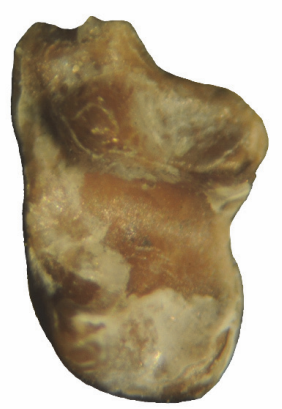

8

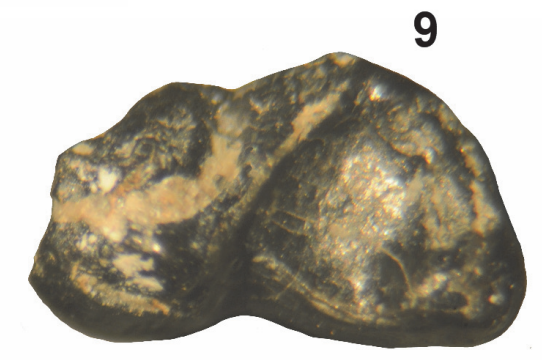

11
10

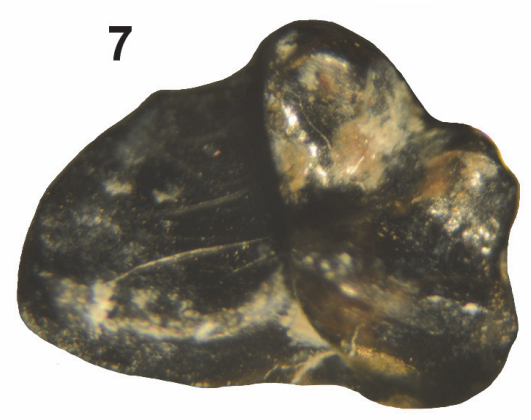

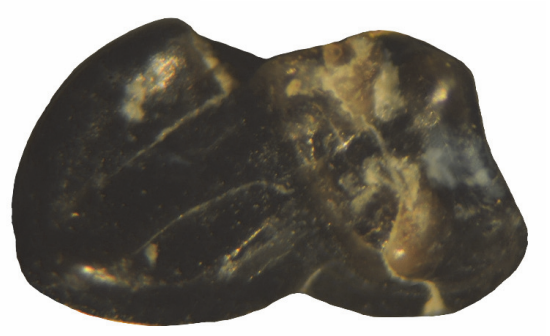

12

FIGURE 2. Apatemyidae from TBM. 1-6, Apatemys bellulus: RM1, UCM 70967 (1); Lm1, UCM 95804 (2); Lm2, UCM 68923 (3); partial Rm3, UCM 68424 (4); Lm3, UCM 95807 (5); Rm3, UCM 70676 (6). 7-12, Apatemys rodens: LM1, UCM 68580 (7); LM3, SDSNH 110342 (8); LM3, UCM 68970 (9); Rm3, UCM 95805 (10); partial Lm3, UCM 66324 (11). Rm3, 95801 (12). All occlusal views. Scale bar equals $1 \mathrm{~mm}$. 
TABLE 1. Measurements (in mm) of Apatemyidae from TBM. Abbreviations are: ap = greatest anteroposterior length; $b$ = broken dimension; $p .=$ partial; $\operatorname{tr}=$ greatest transverse width; tra = anterior transverse (trigonid) width; trp = posterior transverse (talonid) width.

\begin{tabular}{lccccc}
\hline \multicolumn{1}{c}{ Taxon/Specimen number } & Position & ap & tr & tra & trp \\
\hline Apatemys bellulus & & & & & \\
UCM 70967 & $\mathrm{M} 1$ & 1.96 & 1.90 & - & - \\
UCM 95804 & $\mathrm{~m} 1$ & 1.87 & - & 1.08 & 1.13 \\
UCM 68923 & $\mathrm{m} 2$ & 1.85 & - & 1.39 & 1.31 \\
UCM 68424 & p. m3 & 1.97 & - & - & 1.21 \\
UCM 70676 & $\mathrm{m} 3$ & 1.92 & - & 1.23 & 1.05 \\
UCM 95807 & $\mathrm{m} 3$ & 2.00 & - & 1.26 & 1.16 \\
Apatemys rodens & & & & - & - \\
UCM 68580 & $\mathrm{M} 1$ & 2.48 & 2.08 & - & - \\
UCM 68970 & $\mathrm{M} 3$ & 1.36 & 2.37 & - & - \\
SDSNH 110342 & p. M3 & $1.37 \mathrm{~b}$ & $2.06 \mathrm{~b}$ & - & 1.74 \\
UCM 66324 & p. m3 & 2.79 & - & - & 1.80 \\
UCM 95801 & p. m3 & 2.90 & - & - & 1.74 \\
UCM 95805 & $\mathrm{m} 3$ & 2.82 & - & 2.13 &
\end{tabular}

orly expanded trigonid with the paraconid positioned slightly further from the metaconid. The lower molars have an accessory cuspid present at the anterolabial corner of the trigonid, giving it a trapezoidal occlusal outline. The metaconid is larger than the other cusps of the trigonid and positioned posterior of the protoconid apex. The entoconid varies from a weakly expressed bump to a small distinct cuspid. The hypoconid is broad with the cristid obliqua extending anterolabially from its apex to join the posterior wall of the trigonid just labial of the notch between the protoconid and metaconid. A moderately distinct anterior cingulid is present that extends from the accessory cuspid to the paraconid.

Remarks. Apatemys is a relatively rare taxon in the middle Eocene (West, 1973b). Three species have been described from the Bridger Formation; A. bellus Marsh, 1872b, A. bellulus Marsh, 1872b, and $A$. rodens Troxell, 1923b. These species are differentiated primarily by size and minor differences in dental occlusal morphology (Marsh, 1872b; Troxell, 1923b; Jepsen, 1934; McKenna, 1963; Gazin, 1976). However, West (1973b), in a revision of the North American Apatemyidae, placed $A$. bellulus, $A$. rodens and a number of other apatemyid taxa including Labidolemur kayi Simpson, 1929, in synonymy with $A$. bellus, resulting in a geochronologic range for the species from the late Paleocene to the middle Eocene. This excessive taxonomic lumping also resulted in extreme dental size ranges with high coefficients of variation for $A$. bellus. Most recent investigators have not accepted most of West's (1973b) synonymies (e.g., Gazin, 1976; Gunnell and Bartels, 1999; Koenigswald et al., 2005; Gunnell et al., 2008a; Silcox et al., 2010) and recognize the three originally described species from the Bridger Formation.

The Apatemys specimens from the TBM at UCM Locality 92189 are represented by two distinct dental size groups. The smaller sized group of teeth (Figure 2.1-6) are well within the observed ranges of those of Apatemys bellulus and are referred to the species. Although both groups exhibit similar occlusal morphology, the $A$. bellulus specimens differ by the following: 1) a more concave labial border along the M1 stylar shelf between the paracone and metacone; 2) a slightly less developed M1 hypocone; 3 ) a slightly more weak and slightly more lingually positioned $\mathrm{m} 3$ paraconid; and 4) a slightly more squared off posterior border of the $\mathrm{m} 3$ talonid (less pointed).

\section{Apatemys rodens Troxell, 1923b}

Figure 2.7-12, Table 1

Referred specimens. From SDSNH Locality 5841: partial LM3, SDSNH 110342. From UCM Locality 92189: LM1, UCM 68580; LM3, UCM 
68970; Rm3s, UCM 95801, 95805; Lm3, UCM 66324.

Description. All of the referred teeth are very large compared to those of other species of Apatemys (Marsh, 1872b; Troxell, 1923b; Matthew, 1921, 1929; Jepsen, 1934; Gazin, 1958; Robinson, 1966b; West, 1973b). The M1 is in early wear. Its metacone is larger than the paracone with its apex positioned slightly more lingually than that of the metacone. The protocone is large and positioned anteriorly, just posterior of the paracone apex. The hypocone is robust. A distinct parastyle is present on the anterolabial corner of the stylar shelf and the labial border of stylar shelf is relatively straight. The postmetacrista extends posteriorly from the metacone apex to terminate at an indistinct metastyle at the posterolabial corner of the stylar shelf. The anterior and posterior cingula are weak.

The M3 is transversely expanded, that is its length is significantly narrower than its width. The paracone is slightly larger than the metacone and positioned slightly more labially. The protocone is large and positioned anteriorly, below the paracone apex. The hypocone is weakly developed as a bulge on the posterior cingulum. The parastylar lobe is robust, elongated, and projects nearly straight labially. The parastyle is a moderately distinct cusp, positioned near the central, labial edge of the parastylar lobe. The anterior cingulum is weak. A distinct metastyle is lacking.

Three $\mathrm{m} 3 \mathrm{~s}$ are identified. One is complete, whereas the other two are missing portions of the trigonids. They exhibit a trapezoidal trigonid occlusal outline with a well-developed accessory cuspid positioned at the anterolabial corner of the trigonid. All of the trigonid primary cusps (paraconid, metaconid, and protoconid) are robust. The talonid has a relatively shallow basin and is wide anteriorly, but tapers posteriorly, giving it a somewhat tear-drop occlusal outline. The entoconid is small, but distinct. The hypoconid is expressed as a weak bulge along the posterolabial edge of the talonid, and the cristid obliqua extends anteriorly from it to join the posterior wall of the trigonid labial of the notch between the protoconid and metaconid.

Remarks. A second group of very large Apatemys teeth are present at UCM Locality 92189 and SDSNH Locality 6242 (Figure 2.7-12) that exhibit some minor occlusal differences from those referred to $A$. bellulus (see above). These teeth are within the size range of those of the $A$. rodens (Troxell, 1923b; West, 1973b) and are referred to the species.
Grandorder LIPOTYPHLA Haeckel, 1866

Order ERINACEOMORPHA Gregory, 1910

Family SESPEDECTIDAE Novacek, 1985

Subfamily SCENOPAGINAE Novacek, 1985

Genus SCENOPAGUS McKenna and Simpson, 1959

Scenopagus priscus Marsh, $1872 \mathrm{~b}$

Figure 3.9-11, Table 2

Referred specimens. From UCM Locality 92189: partial Rm1 or 2, UCM 95683. From SDSNH Locality 5841: Rm3, SDSNH 110345.

Description. The $\mathrm{m} 3$ and the $\mathrm{m} 1$ or 2 have similar occlusal morphologies, except that the $\mathrm{m} 3$ talonid is much narrower relative to the trigonid width, and its trigonid is slightly more anteroposteriorly compressed between the metaconid and paracristid. The talonids of the lower molars are about half the height of the trigonids. The metaconid and protoconid are robust and connected by a postprotocristid that is notched centrally and lower in height. The paracristid is lower in height than the metaconid and protoconid, and extends lingually from the anterolabial corner of the protoconid to terminate near the anterior base of the metaconid. A distinct paraconid is lacking at the lingual terminus of the paracristid. The talonid consists of a robust entoconid and hypoconid, and a distinct, centrally positioned hypoconulid. The cristid obliqua extends from the hypoconid to terminate on the posterior wall of the trigonid at a point just slightly labial of the central notch of the postprotocristid. The anterior cingulid is moderately robust.

Remarks. Four species of Scenopagus are recognized from the Bridger Formation; $S$. priscus (Marsh, 1872b), S. curtidens (Marsh, 1872b), S. edenensis (McGrew, 1959), and S. mcgrewi McKenna and Simpson, 1959. They are differentiated primarily by size and slight differences in the occlusal morphologies of M1-2 and p4 (McGrew, 1959; Robinson, 1966a; McKenna and Simpson, 1959; McGrew and Sullivan, 1970; West, 1973a; Krishtalka, 1975, 1976a; Gunnell et al., 2008b). The two molars from the TBM agree well in size and occlusal morphology to those of Scenopagus priscus and are referred to the species.

Scenopagus curtidens (Matthew, 1909) Figure 3.1-8, Table 2

Referred specimens. From SDSNH Locality 5841: Ldp4, SDSNH 110344. From UCM Locality 92189: LM1, UCM 68966; partial Rm1 or 2, UCM 70677; Rm1 or 2, UCM 95684; Lm1 or 2, UCM 95685; Rm3, UCM 68968. 


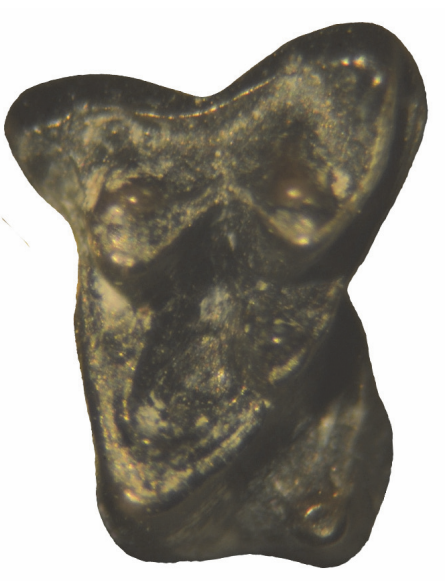

1

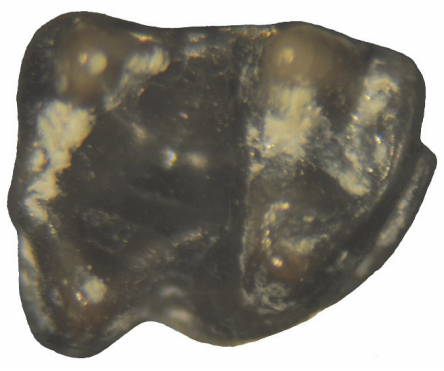

6

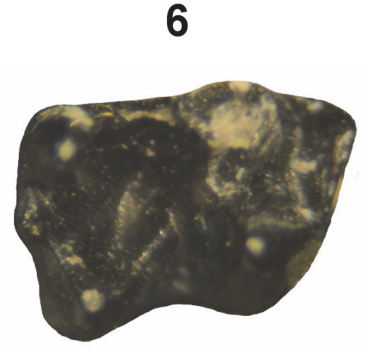

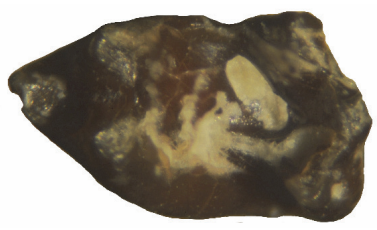

2

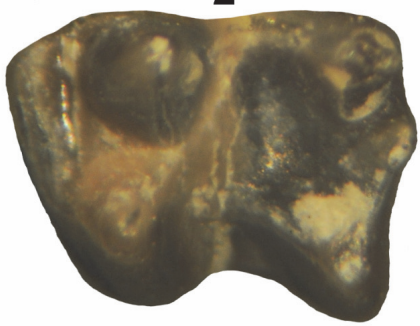

4
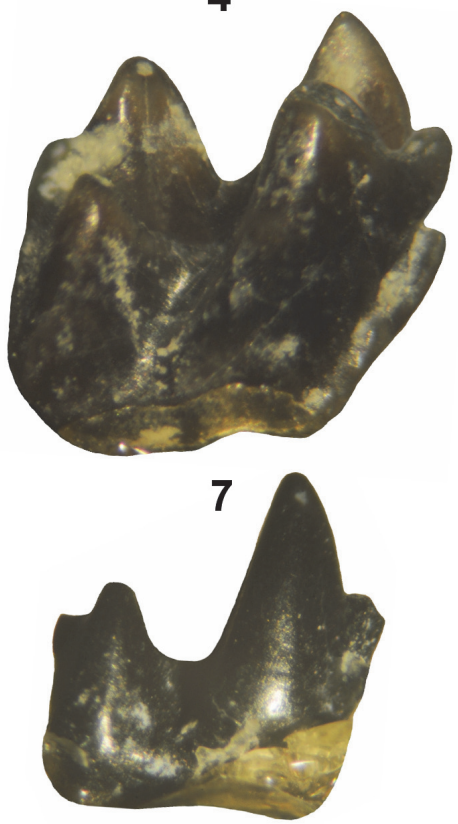

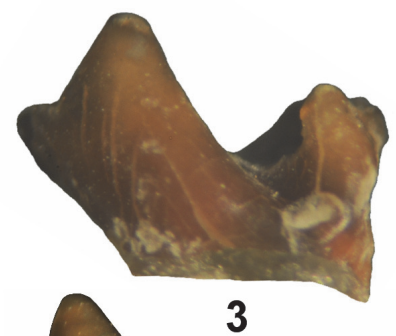

3

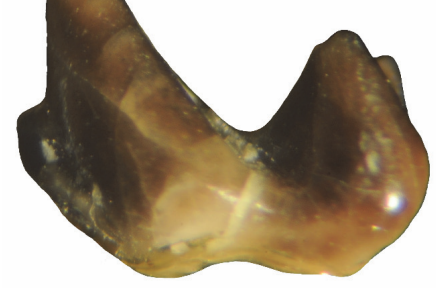

5

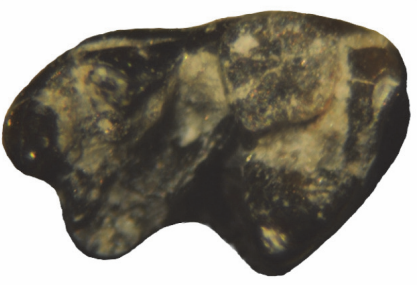

8

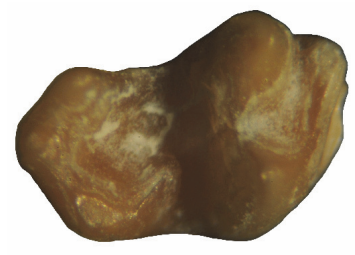

11
9

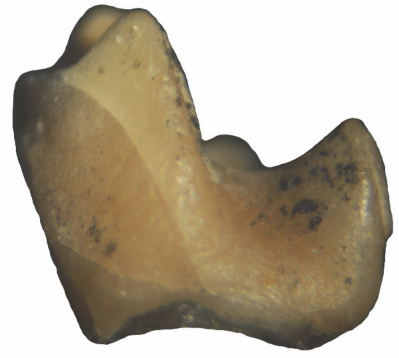

12
10

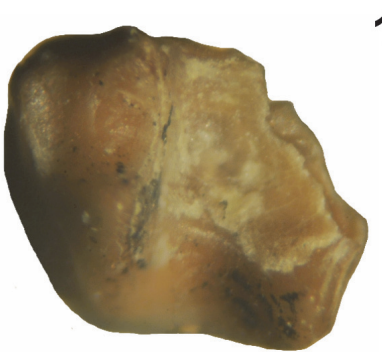

13

FIGURE 3. Sespedectidae from TBM. 1-8, Scenopagus curtidens: LM1 (UCM 68966) in occlusal view (1); Ldp4 (UCM 110344) in occlusal (2) and labial (3) views; Lm1 or 2 (UCM 95685) in occlusal (4) and labial (5) views; Rm1 or 2 (UCM 95684) in occlusal (6) and labial (7) views; partial Rm3 (UCM 68968) in occlusal view (8). 9-11, Scenopagus priscus: Rm1 or 2 (UCM 95683) in occlusal (9) and labial (10) views; Rm3 (SDSNH 110345) in occlusal view (11). 1213, Sespedectidae, genus undetermined, partial Lm1 or 2 (SDSNH 110343) in labial (12) and occlusal (13) views. Scale bar equals $1 \mathrm{~mm}$. 
TABLE 2. Measurements (in $\mathrm{mm}$ ) of Lipotyphla and Carnivoramorpha from TBM. Abbreviations are: ap = greatest anteroposterior length; $b=$ broken dimension; $\mathrm{p}$. = partial; $\mathrm{tr}=$ greatest transverse width; tra = anterior transverse (trigonid) width; trp = posterior transverse (talonid) width.

\begin{tabular}{|c|c|c|c|c|c|}
\hline Taxon/Specimen number & Position & ap & $\operatorname{tr}$ & tra & $\operatorname{trp}$ \\
\hline \multicolumn{6}{|l|}{ Scenopagus priscus } \\
\hline UCM 95683 & $\mathrm{~m} 1$ or 2 & 1.40 & - & $1.02 b$ & 1.05 \\
\hline SDSNH 110345 & m3 & 1.35 & - & 0.85 & 0.67 \\
\hline \multicolumn{6}{|l|}{ Scenopagus curtidens } \\
\hline UCM 68966 & M1 & 1.77 & 2.49 & - & - \\
\hline SDSNH 110344 & $\mathrm{dp} 4$ & 1.60 & - & 0.91 & 1.00 \\
\hline UCM 70677 & p. $\mathrm{m} 1$ or 2 & 1.88 & - & 1.32 & - \\
\hline UCM 95684 & $\mathrm{~m} 1$ or 2 & 1.80 & - & 1.49 & 1.51 \\
\hline UCM 95685 & $\mathrm{~m} 1$ or 2 & 1.74 & - & 1.46 & 1.49 \\
\hline UCM 68968 & m3 & 1.60 & - & 1.12 & 0.94 \\
\hline \multicolumn{6}{|l|}{ Sespedectinae, genus undet. } \\
\hline SDSNH 110343 & p. $\mathrm{m} 1$ or 2 & $1.36 \mathrm{~b}$ & - & 1.44 & - \\
\hline \multicolumn{6}{|l|}{ Entomolestes westgatei $\mathrm{n} . \mathrm{sp}$. } \\
\hline UCM 68540 & $\mathrm{p} 4$ & 0.90 & - & 0.67 & 0.62 \\
\hline \multirow[t]{2}{*}{ UCM 95686} & $\mathrm{p} 4$ & 0.95 & - & 0.71 & 0.58 \\
\hline & $\mathrm{m} 1$ & 1.56 & - & 0.93 & 0.95 \\
\hline \multirow[t]{2}{*}{ UCM 95687 (holotype) } & $\mathrm{p} 4$ & 0.90 & - & 0.72 & 0.62 \\
\hline & $\mathrm{m} 1$ & 1.59 & - & 0.94 & 0.95 \\
\hline \multirow[t]{3}{*}{ UCM 67884} & p. $\mathrm{m} 1$ & - & - & 0.90 & 0.88 \\
\hline & $\mathrm{m} 2$ & 1.41 & - & 0.93 & 0.93 \\
\hline & m3 & 1.08 & - & 0.64 & 0.57 \\
\hline UCM 78746 & p. $\mathrm{m} 1$ & - & - & 0.93 & - \\
\hline UCM 68423 & $\mathrm{~m} 2$ & 1.39 & - & 0.91 & 0.93 \\
\hline UCM 68973 & $\mathrm{~m} 2$ & 1.36 & - & 0.95 & 0.87 \\
\hline \multicolumn{6}{|l|}{ Centetodon bemicophagus } \\
\hline UCM 68681 & P4 & 1.46 & 1.49 & - & - \\
\hline SDSNH 110347 & M3 & 0.93 & 1.90 & - & - \\
\hline SDSNH 110391 & $\mathrm{p} 4$ & 1.21 & - & 0.67 & 0.67 \\
\hline UCM 68899 & $\mathrm{~m} 1$ or 2 & 1.49 & - & 1.00 & 0.85 \\
\hline UCM 71128 & $\mathrm{~m} 1$ or 2 & 1.34 & - & 0.77 & 0.70 \\
\hline DMNH 75256 & $\mathrm{~m} 1$ or 2 & 1.50 & - & 0.85 & 0.70 \\
\hline DMNH 75257 & m3 & 1.46 & - & 0.85 & 0.70 \\
\hline \multicolumn{6}{|l|}{ Centetodon pulcher } \\
\hline UCM 67889 & $\mathrm{p} 4$ & 1.55 & - & 0.92 & 0.87 \\
\hline UCM 68534 & $\mathrm{p} 4$ & 1.59 & - & 0.93 & 0.87 \\
\hline \multirow[t]{2}{*}{ UCM 95767} & $\mathrm{p} 4$ & 1.79 & - & 0.93 & 0.93 \\
\hline & $\mathrm{m} 1$ & 2.01 & - & 1.28 & 1.18 \\
\hline
\end{tabular}


TABLE 2 (continued).

\begin{tabular}{|c|c|c|c|c|c|}
\hline Taxon/Specimen number & Position & ap & $\operatorname{tr}$ & tra & $\operatorname{trp}$ \\
\hline UCM 95768 & $\mathrm{~m} 1$ or 2 & 1.83 & - & 1.25 & 1.16 \\
\hline \multirow[t]{5}{*}{ UCM 68963} & $\mathrm{p} 1$ & 1.19 & 0.52 & - & - \\
\hline & $\mathrm{p} 4$ & 1.59 & - & 1.10 & 0.93 \\
\hline & $\mathrm{m} 1$ & 1.75 & - & 1.31 & 1.20 \\
\hline & $\mathrm{m} 2$ & 1.70 & - & $1.21 b$ & 1.15 \\
\hline & m3 & 1.68 & - & $1.10 b$ & 0.90 \\
\hline DMNH 75327 & $\mathrm{~m} 2$ & 1.65 & - & 1.03 & 0.87 \\
\hline UCM 69968 & m3 & 1.55 & - & 1.03 & 0.93 \\
\hline UCM 95682 & m3 & 1.59 & - & 1.05 & 0.87 \\
\hline \multicolumn{6}{|l|}{ Nyctitherium gunnelli $\mathrm{n} . \mathrm{sp}$. } \\
\hline UCM 95769 & $\mathrm{P} 4$ & 2.08 & 2.54 & - & - \\
\hline \multirow[t]{3}{*}{ SDSNH 110393 (holotype) } & $\mathrm{p} 4$ & 2.09 & - & 0.93 & 1.00 \\
\hline & $\mathrm{m} 1$ & 2.23 & - & 1.14 & 1.22 \\
\hline & $\mathrm{m} 2$ & 2.08 & - & 1.23 & 1.27 \\
\hline \multicolumn{6}{|l|}{ Nyctitherium velox } \\
\hline DMNH 75292 & M2 & 1.71 & 2.27 & - & - \\
\hline UCM 68581 & M2 & 1.58 & 2.13 & - & - \\
\hline UCM 95771 & M2 & 1.62 & 2.11 & - & - \\
\hline DMNH 75290 & p. M1 or 2 & - & $2.10 b$ & - & - \\
\hline DMNH 75291 & M3 & 1.21 & 1.90 & - & - \\
\hline UCM 68967 & $\mathrm{~m} 1$ & 1.72 & - & 1.08 & 1.13 \\
\hline SDSNH 110409 & p. $m 2$ & 1.60 & - & 1.13 & 1.18 \\
\hline DMNH 75317 & p. m2 & 1.74 & - & - & 1.23 \\
\hline UCM 67899 & p. m2 & $1.59 b$ & - & - & 1.25 \\
\hline \multicolumn{6}{|l|}{ Pontifactor bestiola } \\
\hline UCM 71129 & M1 & 1.58 & 1.78 & - & - \\
\hline \multicolumn{6}{|l|}{ unnamed apternodontid sp. } \\
\hline SDSNH 110348 & p. M1 or 2 & $0.49 b$ & $1.05 b$ & - & - \\
\hline SDSNH 110349 & p. $\mathrm{m} 1$ or 2 & $0.79 b$ & $0.63 b$ & - & - \\
\hline \multicolumn{6}{|l|}{ unnamed lipotyphlan sp. } \\
\hline DMNH 75258 & $\mathrm{p} 4$ & 0.80 & - & 0.54 & 0.54 \\
\hline \multicolumn{6}{|l|}{ Viverravus gracilis } \\
\hline UCM 95809 & M2 & 2.60 & 4.15 & - & - \\
\hline
\end{tabular}

Description. To the best of our knowledge, the dp4 of Scenopagus curtidens has not been previously described. It exhibits an anteriorly inclined trigonid that is about twice as tall as the height of the talonid, a relatively tall paracristid, a centrally positioned hypoconulid and is lacking a distinct paraconid, characters that are typical of Scenopagus. It is further characterized by the following: 1) molariform; 2) a rounded protoconid and metaconid, about equal in height; 3 ) a robust, deeply basined talonid with a distinct entoconid, hypoconid, and hypoconulid, all nearly equal in height; 4) a 
moderately tall cristid obliqua, extending from the anterior edge of the hypoconid to terminate at the posterior wall of the trigonid, just lingual of the protoconid apex; 5) a deep lingual talonid notch; and 6) a shallow ectoflexid.

The lower molars are very similar morphologically to those referred above to Scenopagus priscus, but differ by being significantly larger in size and by having a slightly stronger anterior cingulid and a slightly straighter paracristid and postprotocristid. Otherwise, the above description of the lower molars of $S$. priscus also applies to those referred above to $S$. curtidens.

Based on a well-preserved partial maxilla with P3-M3 from the Aycross Formation of the Absaroka Range, Wyoming, Bown (1982) described in detail the upper cheek teeth of $S$. curtidens. The referred M1 (UCM 68966) from the TBM is nearly identical in size and occlusal morphology to that of $S$. curtidens from the Aycross Formation. The TBM M1 differs from that of the Aycross specimen only by having a slightly larger hypocone and slightly less developed anterior cingulum, differences that can be attributed to individual variation.

Remarks. The five molars from the TBM are indistinguishable in size and occlusal morphology to those of Scenopagus curtidens (Bown, 1982) and are referred to the species. One isolated tooth, which is identified as a dp4, is tentatively referred to the species because it is compatible in size and general occlusal morphology to the cheek teeth of S. curtidens.

\section{Subfamily SESPEDECTINAE Novacek, 1985 Sespedectinae, genus undetermined} Figure 3.12-13, Table 2

Referred specimen. From SDSNH Locality 5841 , partial Lm1 or 2, SDSNH 110343.

Description. The partial $\mathrm{m} 1$ or 2 is broken with the posterolingual corner of the tooth missing, so the development of the entoconid or hypoconulid cannot be determined. However, even in its broken state, the following characters can still be discerned. The trigonid is robust, anteroposteriorly compressed, about one-half the height of the talonid and projects slightly anteriorly. The protoconid and metaconid are bunodont, about equal in size and height, and connected by a relatively tall postprotocristid. The paracristid is a short shelf, slightly lower in height than the postprotocristid, that extends from the anterior base of the protoconid to terminate near the anterior base of the metaconid, resulting in the trigonid being almost closed off lingually. A parastylid is lacking at the lingual terminus of the paracristid. Although the entoconid is missing, the entocristid is moderately tall and extends anteriorly from the posterolingual broken edge of the tooth to terminate on the posterior wall of the metaconid, resulting in a talonid that is blocked off lingually. The hypoconid is bunodont and well developed with the cristid obliqua extending anteriorly from its apex to terminate at the posterior wall of the trigonid, at a point below the protoconid apex. The anterior cingulid is very weak, extending only a short distance labially from the anterolabial base of the protoconid as a slight ridge on the enamel surface that fades out about halfway across the middle of the anterior face of the protoconid. Labial and posterior cingulids are lacking.

Remarks. The partial $\mathrm{m} 1$ or 2 (SDSNH 110343) from the TBM exhibits an occlusal morphology that is most similar to those of the Sespedectidae, including the following: 1) an anteriorly inclined and anteroposteriorly compressed trigonid, about half the height of the talonid; 2) a blade-like paracristid terminating close to the metaconid and lacking a distinct paraconid at its lingual terminus; and 3) relatively connate (bunodont) primary cusps. However, SDSNH 110343 also exhibits certain differences from all known sespedectid genera. It can be easily distinguished from Scenopagus by the following: 1) a much more weakly developed metaconid and protoconid; 2) a weaker paracristid positioned slightly higher on the crown with its lingual terminus positioned slightly higher and closer to the metaconid, almost closing off the trigonid lingually; 3) a more anteroposteriorly expanded hypoconid; 4) a taller cristid obliqua, terminating anteriorly slightly more labially and higher on the posterior wall of the protoconid; and 5) a much weaker anterior cingulid. SDSNH 110343 is significantly smaller than Proterixoides davisi Stock, 1935, larger than Sespedectes davisi Stock, 1935, and similar in size to Sespedectes stocki Novacek, 1985. It differs from the m1-2 of Proterixoides and Sespedectes by the following: 1) higher crowned; 2) a more anteroposteriorly compressed trigonid with its height taller relative to the talonid height; 3 ) a more weakly developed paracristid; 4) much less bulbous (swollen) primary cusps; and 5) less exodaenodont. It differs from Patriolestes novaceki Walsh, 1998, by the following: 1) much smaller size; 2) a more anteroposteriorly compressed trigonid; 3) a paracristid positioned relatively higher on the crown; 4) a taller postprotocristid with a much shallower central notch; and 5) a taller and more robust cristid obliqua. It differs from the putative sespedectid Macrocranion Weitzel, 1949, by the 
following: 1) trigonid more anteriorly inclined and anteroposteriorly compressed with the trigonid significantly taller relative to the trigonid height; 2) a relatively taller postprotocristd with a much shallower central notch; 3 ) a taller cristid obliqua; 4) a taller, more distinct entocristid, closing off the talonid lingually; and 5) a weaker anterior cingulid. Of all sespedectid taxa, SDSNH 110343 is most similar in size and occlusal morphology to the m1-2 of Crypholestes vaughni (Novacek, 1976; see also Novacek, 1980) from early Uintan faunas (Murray Canyon and Mesa Drive local faunas, and Poway Fauna) of southern California (Novacek, 1976; Walsh, 1996b), but differs by the following: 1) a relatively higher positioned paracristid on the crown; 2 ) a slightly more anteroposteriorly compressed trigonid; 3) a slightly taller and more robust entocristid; and 4) a much weaker anterior cingulid.

SDSNH110343 appears to represent a previously unknown sespedectid species, and probably also a new genus most closely related to the early Uintan Crypholestes, but until additional material of this taxon becomes available to better characterize it, we refer it to an undetermined genus of the Sespedectinae.

Family ERINACEIDAE Fisher von Waldheim, 1817

Genus ENTOMOLESTES Matthew, 1909

Entomolestes westgatei new species

Figures 4 and 5 , Table 2

zoobank.org/EEE540D5-BB9D-411D-B1CD-0CCF3E7729E7

Holotype. Partial dentary with Lp4-m1, UCM 95687.

Hypodym. From UCM Locality 92189: Lp4, UCM 68540; partial dentary with Lp4-m1, UCM 95686; partial dentary with partial Lp4 and $\mathrm{m} 1$, UCM 78746; partial dentary with partial $\mathrm{Rm} 1$ and $\mathrm{m} 2-3$, UCM 67884; Rm2, UCM 68423; Lm2, UCM 68973. Type locality. UCM 92189, $2 \mathrm{~m}$ above the base of the Turtle Bluff Member, Bridger Formation, Wyoming.

Distribution and age. Known only from type locality. Earliest Uintan (Ui1a).

Diagnosis. Entomolestes westgatei differs from Entomolestes grangeri Matthew, 1909, by having the following: 1) a smaller, more reduced p4; 2) p4 talonid lacking a central cristid from posterior wall of trigonid; and 3) a smaller, more reduced $\mathrm{m} 3$.

Etymology. Patronym for James Westgate of the Department of Earth and Space Sciences, Lamar University, in honor of his many contributions on Eocene mammals.

Description. Robinson (1968b) and Novacek et al. (1985) regarded the lower antemolars of Entomo- lestes grangeri to consist of 3 incisors, a canine and 4 premolars, whereas Krishtalka and West (1977) regarded its lower antemolars to consist of 3 incisors and 5 premolars ( $p 1$ or dp1 and p2-p5) with the canine lacking. It should be noted that in our descriptions below, we follow the more traditional antemolar assignments of Robinson (1968b) and Novacek et al. (1985).

Two of the partial dentaries preserve alveoli anterior to p4. UCM 95686 has three alveoli and one partial alveolus anterior to p4 (Figure 5.1-2). The two alveoli directly anterior to p4 are positioned close together with the anterior alveolus slightly smaller than the posterior. These two alveoli appear to represent those of the roots of $p 3$, indicating its anterior root was smaller than its posterior root. The third alveolus anterior to $p 4$ is circular and separated from the first two alveoli by a space. The most anterior partial alveolus has a circular posterior border and is separated from the third alveolus by a space. The partial alveolus and third alveolus anterior to $p 4$ may represent those of the p2 or possibly those of two separate, single rooted teeth (p1-2?). UCM 95687 has two alveoli anterior to $\mathrm{p} 4$ (Figure 5.3-4). The one directly anterior to $\mathrm{p} 4$ is hourglass shaped with the anterior portion slightly narrower, indicating that it held a p3 with two roots or two closely appressed roots. The second alveolus anterior to $\mathrm{p} 4$ is circular in shape and appears to represent that of the posterior root of $\mathrm{p} 2$ or possibly that of a single rooted $\mathrm{p} 2$. Thus, the p3 appears to have been two rooted, as in Entomolestes grangeri Matthew, 1909 (Robinson, 1968b; Krishtalka and West, 1977), however, whether the p2 was single or two rooted is uncertain. If the p2 was two rooted then it would have been relatively large because the two circular alveoli anterior of the p3 alveoli are large and separated by a short space. It appears more likely that the two circular alveoli anterior of $p 3$ represent two separate, single rooted teeth.

The mental foramen of UCM 95686 is positioned below and between the roots of $\mathrm{p3}$, whereas that of UCM 95687 is positioned slightly more anteriorly, below the anterior root of p3 (Figure 5.2 and 5.4).

The $\mathrm{p} 4$ is reduced relative to the $\mathrm{m} 1$ with a mean $\mathrm{p} 4 \mathrm{ap} / \mathrm{m} 1$ ap ratio of 0.59 . The $\mathrm{p} 4$ paraconid is relatively strong and projects anterolingually forming a distinct notch between it and the protoconid in labial view. The protoconid is robust, but moderate in height, slightly lower than that of the $\mathrm{m} 1$ protoconid. The talonid is very short with a shallow basin. The anterior cingulid ascends 


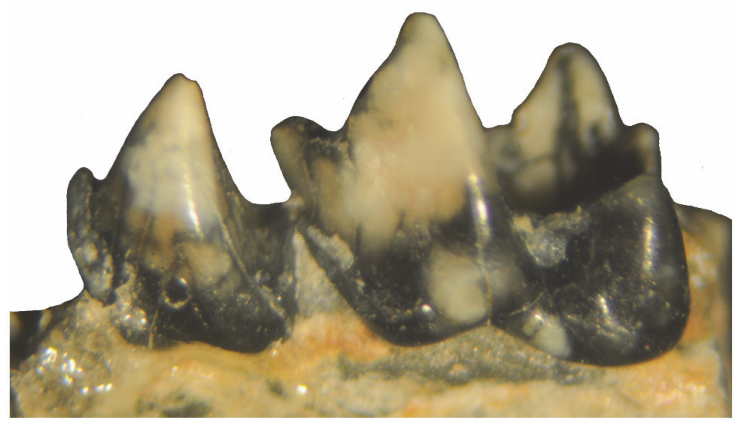

1

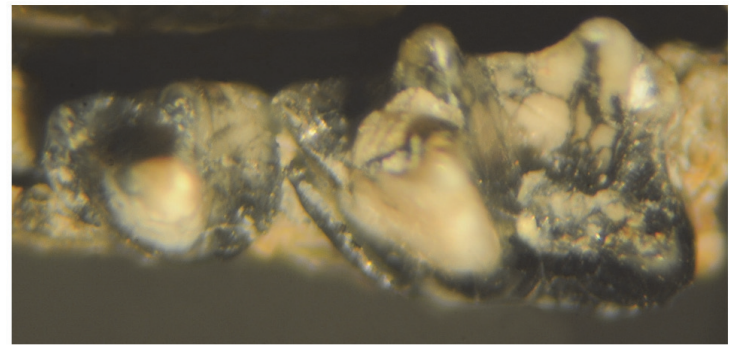

2
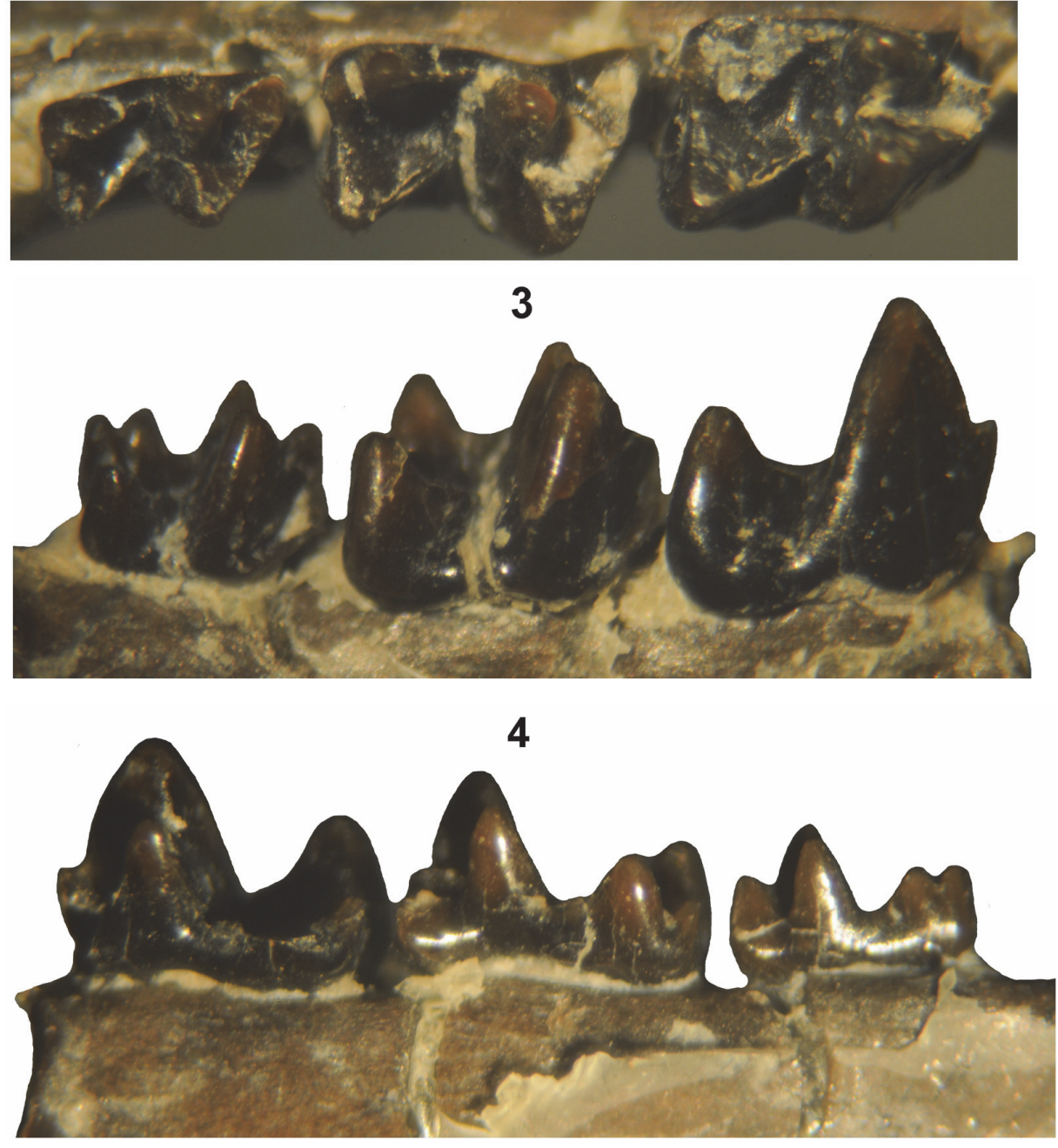

5

FIGURE 4. Entomolestes westgatei new species from TBM. 1-2, partial dentary with Lp4-m1 (UCM 95687, holotype) in labial (1) and occlusal (2) views. 3-5, partial dentary with partial Rm1 and m2-3 (UCM 67884) in occlusal (3), labial (4), and lingual (5) views. Scale bar equals $1 \mathrm{~mm}$. 


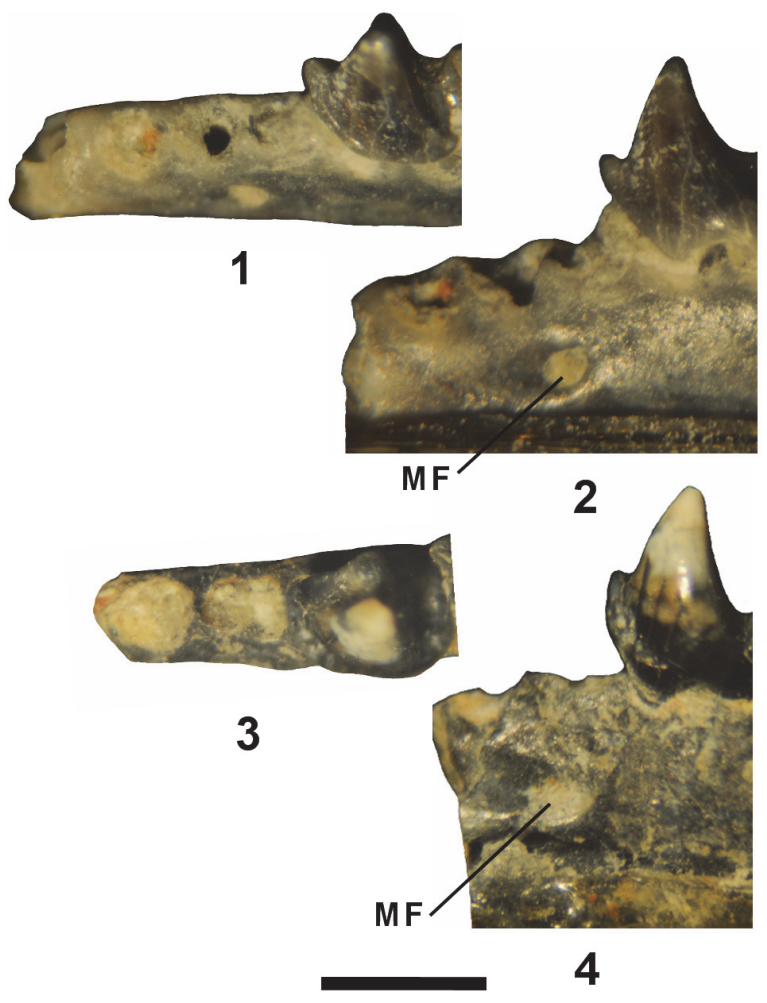

FIGURE 5. Entomolestes westgatei new species from TBM. Specimens showing position of mental foramen (MF) and alveoli for antemolars anterior of p4. See text for proposed alveolar homologies. 1-2, partial dentary with Lp4-m1 (UCM 95686, m1 not shown) in occlusal (1) and labial (2) views. 3-4, partial dentary with Lp4-m1 (UCM 95687, holotype, m1 not shown) in occlusal (3) and labial (4) views. Scale bar equals $1 \mathrm{~mm}$.

steeply from the anterolabial base of the protoconid to the apex of the paraconid.

The molars decrease in size posteriorly. The talonid and trigonid are V-shaped with the talonid only moderately lower in height than the trigonid, especially on $\mathrm{m} 3$. The paraconid is anterolingually projecting, low, and blade-like. The conical metaconid is lower in height than the protoconid on m1-2 and about equal in height on $\mathrm{m} 3$. The entoconid is anteroposteriorly elongated and tall, but progressively flattens with wear. The entocristid is robust and relatively tall, extending from the entoconid to the metaconid. The small hypoconulid is positioned labially, close to the entoconid, giving these cusps a twinned appearance. The $\mathrm{m} 1$ cristid obliqua extends anterolingually from the hypoconid to terminate just labial of the notch between the protoconid and metaconid, whereas the m2-3 cristids obliqua extend towards the metaconids, terminating near the bases of the metaconids. The anterior cingulid is distinct, extending lingually from the anterolabial base of the protoconid to the anterolingual base of the paraconid.

Remarks. Entomolestes grangeri was first described by Matthew (1909) from the lower part of the Bridger Formation (Br2). Subsequently, other investigators have reported its occurrence in the TBM (e.g., Evanoff et al., 1994; Murphey, 2001; Gunnell et al., 2009). The Entomolestes specimens from the TBM exhibit occlusal morphologies that are very similar overall to those of $E$. grangeri, including the following (Matthew, 1909; Robinson, 1968b; Delson, 1971; Krishtalka, 1976a; Krishtalka and West, 1977; Novacek et al., 1985; Gunnell et al., 2008b): 1) a premolariform p4 with a projecting paraconid forming a characteristic notch between it and the protoconid in labial view, a protoconid of moderate height, a short talonid, and a distinct anterior cingulid; and 2) lower molars that decrease in size posteriorly with low, blade-like paraconids, V-shaped trigonids and talonids, exodaenodont labial margins, tall, anteroposteriorly elongated entoconids, robust, relatively tall entocristids, and labially positioned hypoconulids that are smaller and lower in height than the entoconids. However, the TBM specimens exhibit differences from the holotype and topotypic sample of $E$. grangeri (Robinson, 1968b; Krishtalka and West, 1977) from lower in the Bridger Formation. Most significant are the sizes of $\mathrm{p} 4$ relative to $\mathrm{m} 1$ and $\mathrm{m} 3$ relative to $\mathrm{m} 2$. In E. grangeri, the mean $\mathrm{p} 4 \mathrm{ap} / \mathrm{m} 1$ ap ratio for seven intact dentitions is 0.702 (Robinson, 1968b; Krishtalka and West, 1977), whereas that of the two TBM intact dentitions is 0.588 , a $16 \%$ difference. Also, the TBM p4s are absolutely smaller than those of $E$. grangeri with a mean $\mathrm{p} 4$ ap of $0.92 \mathrm{~mm}$, whereas the mean $\mathrm{p} 4$ ap for seven specimens of $E$. grangeri (Robinson, 1968b; Krishtalka and West, 1977) is $1.23 \mathrm{~mm}$, a $26 \%$ difference. In E. grangeri, the mean $\mathrm{m} 3 \mathrm{ap} / \mathrm{m} 2$ ap ratio is 0.85 , whereas that of the only TBM intact dentition with m1-3 is 0.77 , a $9 \%$ difference. Also, the TBM $\mathrm{m} 3$ is absolutely smaller than that of $E$. grangeri with an ap of $1.08 \mathrm{~mm}$, whereas the mean of three m3s of E. grangeri (Robinson, 1968b; Krishtalka and West, 1977) is $1.27 \mathrm{~mm}$, a $15 \%$ difference. Although the TBM specimens appear to have a two rooted $\mathrm{p} 3$, like that of $E$. grangeri, the p2 may have had a single, relatively large, circular root, whereas that of $E$. grangeri is two rooted (Krishtalka and West, 1977). In the holotype of $E$. grangeri and referred specimens, a central cristid is present in the p4 talonid that extends from the posterior wall of the trigonid to the posterior border 
of the talonid (Krishtalka and West, 1977; Novacek et al., 1985), whereas on the TBM p4s this central talonid cristid is lacking. All of the above differences are significant enough to specifically separate the TBM specimens from E. grangeri, and, as such, they are assigned to the new species, $E$. westgatei.

\section{Grandorder SORICOMORPHA Fischer von Waldheim, 1817 \\ Family GEOLABIDIDAE McKenna, 1960b Genus CENTETODON Marsh, 1872b \\ Centetodon bembicophagus Lillegraven, McKenna, and Krishtalka, 1981 \\ Figure 6.1-4, Table 2}

Referred specimens. From SDSNH Locality 5841: LM3, SDSNH 110347; Lp4, SDSNH 110391. From DMNH Locality 4672: Lm1 or 2, DMNH 75256; Lm3, DMNH 75257. From UCM Locality 92189: LP4, UCM 68681; Lm1 or 2, UCM 68899; Rm1 or 2, 71128.

Description. The cheek teeth from the TBM have occlusal morphologies typical of Centetodon. All of the lower molars are missing a portion of the anterolabial cingulid. Lillegraven et al. (1981) previously provided comprehensive descriptions of the upper and lower cheek teeth of Centetodon bemicophagus. The new specimens from the TBM do not provide any new information regarding the species, so detailed descriptions are not necessary.

Remarks. Three species of Centetodon, C. bemicophagus, C. pulcher Marsh, 1872b, and C. bacchanalis (McGrew, 1959), have been recognized from the Bridger Formation in the Bridger Basin (McKenna et al., 1962; West, 1973a; Lillegraven et al., 1981; Gunnell et al., 2008b). Lillegraven et al. (1981) noted that the holotype of C. bucchanalis from the Bridger Formation at Tabernacle Butte (McGrew, 1959) consists of a partial dentary with heavily worn $\mathrm{m} 2-3$ and is probably a synonym of $C$. pulcher, but could also be regarded as an indeterminate species (nomen dubium) of the genus. All of the Bridgerian species exhibit similar occlusal morphologies and are differentiated primarily by size. Centetodon bemicophagus is the smallest of the Bridgerian species (Lillegraven et al., 1981). The eight teeth from the TBM agree well in size and occlusal morphology to those of $C$. bemicophagus and are referred to the species.

Centetodon pulcher Marsh, 1872b

Figure 6.5-10, Table 2

Referred specimens. From DMNH Locality 4672 : Rm2, DMNH 75327. From UCM Locality 92189: Lp4, UCM 68534; partial dentary with Lp4-m1,
UCM 95767; partial dentary with Lp1 and p4-m3, UCM 68963; Rp4, UCM 67889; Rm1 or 2, UCM 95768; Rm3s, UCM 69968, 95682.

Description. The p4-m3 of Centetodon pulcher have been well described in the literature (McKenna, 1960b; McKenna et al., 1962; West, 1973a; Lillegraven et al., 1981) and the new specimens from the TBM do not provide any additional information, so detailed descriptions of them are not necessary. However, to the best of our knowledge, the $\mathrm{p} 1$ of $C$. pulcher has not been previously described. The $\mathrm{p} 1$ is moderately worn. It has two roots that are about equal in size and inclined anteriorly. The crown is anteroposteriorly elongated, transversely compressed, and procumbent with the apex of the primary cusp positioned anteriorly. A short ridge is present that extends anteriorly from the primary cusp to terminate as what appears to be an incipient cuspid, but this may just be an artifact of wear. A long, wedge-shaped, slightly convex ridge extends posteriorly from the apex of the primary cusp to terminate at a small posterior accessory cuspid. A labial cingulid is lacking.

Remarks. The eight Centetodon specimens from the TBM are significantly larger than those referred above to $C$. bemicophagus (Table 2). In size and occlusal morphology, they are indistinguishable from those of C. pulcher (Lillegraven et al., 1981) and are referred to the species.
Family NYCTITHERIIDAE Simpson, 1928
Genus NYCTITHERIUM Marsh, 1872b Nyctitherium gunnelli new species
Figures 7, 8.8-10, Table 2

zoobank.org/22943145-6062-4D3F-92F9-A7A5CE48453B

Holotype. Associated Lp4-m2, SDSNH 110393. Hypodym. From UCM Locality 92189: LP4, UCM 95769.

Type Locality. SDSNH Locality 5843, $105 \mathrm{~m}$ above the base of the Turtle Bluff Member, Bridger Formation, Wyoming.

Distribution and Age. Type locality and SDSNH Locality 92189 at $2 \mathrm{~m}$ above the base of the Turtle Bluff Member, Bridger Formation, Wyoming. Earliest Uintan (Ui1a).

Diagnosis. Nyctitherium gunnelli is larger than Nyctitherium velox, Nyctitherium serotinum, Nyctitherium krishtalkai, and Nyctitherium celatum. It further differs from $N$. velox and $N$. serotinum by having $\mathrm{m} 1-2$ talonid width slightly more expanded transversely relative to trigonid width $(\mathrm{m} 1 \mathrm{tra} / \mathrm{trp}=$ 0.93 and $\mathrm{m} 2$ tra/trp $=0.97$ versus mean $\mathrm{m} 1$ tra/trp $=0.96$ and mean $\mathrm{m} 2$ tra/trp $=0.98$ for $N$. velox , and mean $\mathrm{m} 1$ tra/trp $=0.95$ and mean $\mathrm{m} 2$ tra/trp $=1.05$ for $N$. serotinum), m1-2 anterior (precingulid) and 

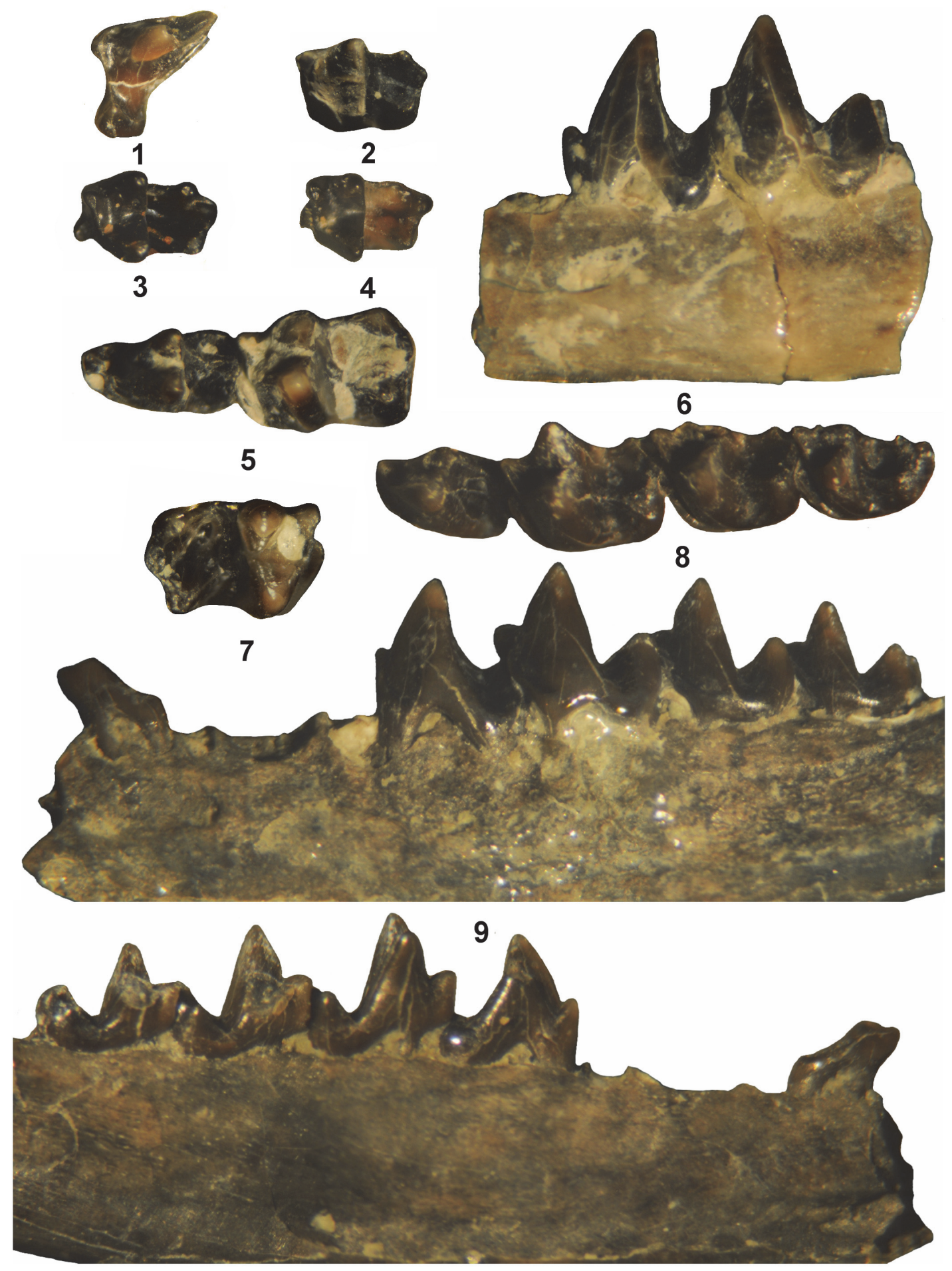

10

FIGURE 6. Geolabididae from TBM. 1-4, Centetodon bembicophagus: LP4 (UCM 68681) in occlusal view (1); partial Lm1 or 2 (UCM 68899) in occlusal view (2); Lm1 or 2 (DMNH 75256) in occlusal view (3); Lm3 (DMNH 75257) in occlusal view (4). 5-10, Centetodon pulcher: partial dentary with Lp4-m1 (UCM 95767) in occlusal (5) and labial (6) views; Rm1 or 2 (UCM 95768) in occlusal view (7); partial dentary with Lp1 and p4-m3 (UCM 68963) in occlusal (8), labial (9), and lingual (10) views. Scale bar equals $1 \mathrm{~mm}$. 


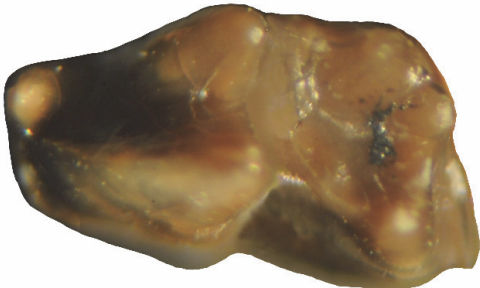

1

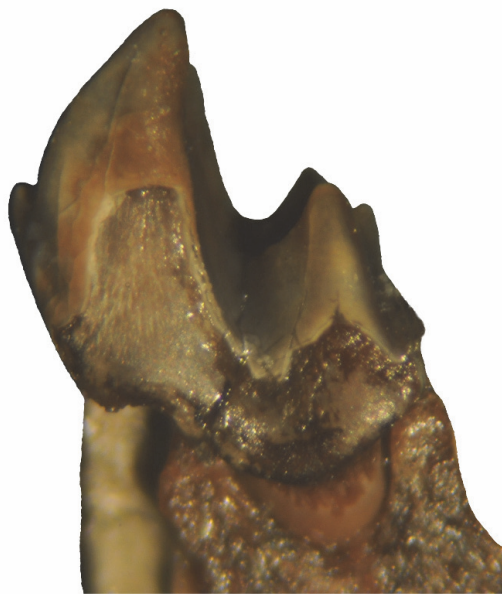

4

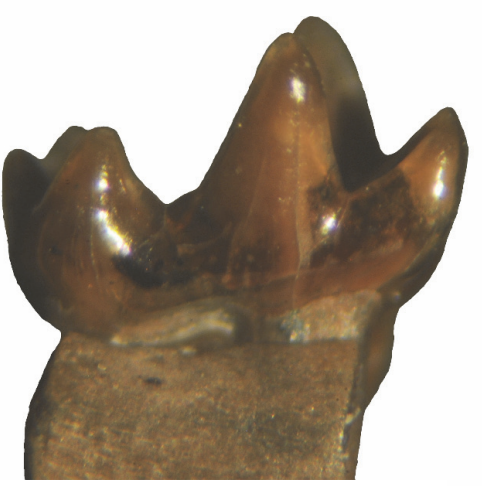

7

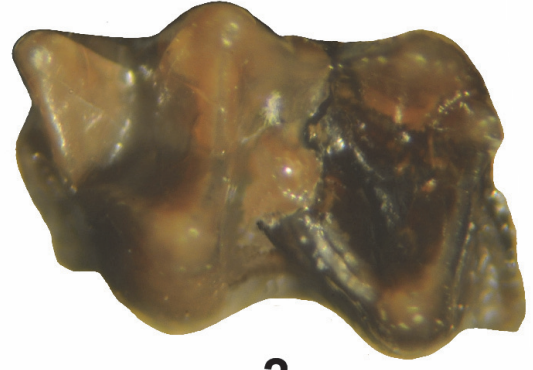

2

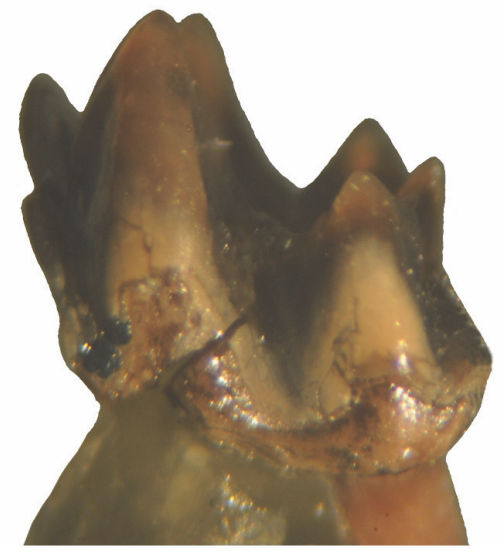

5

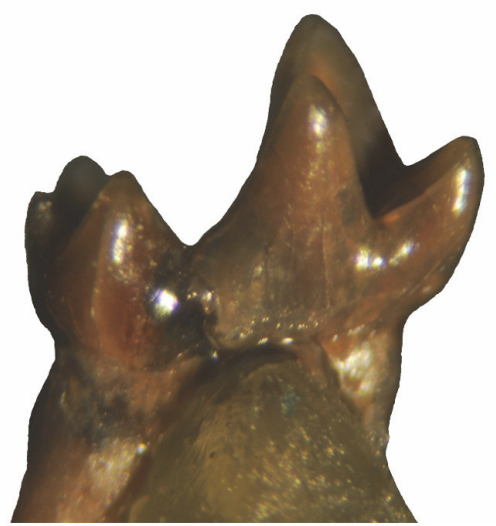

8

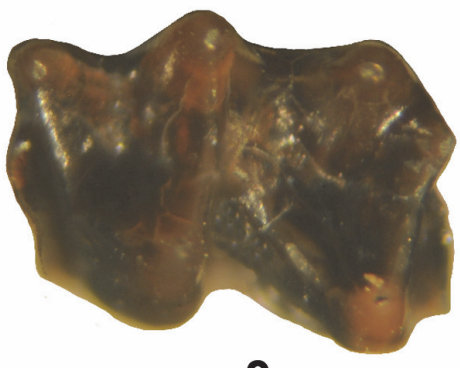

3

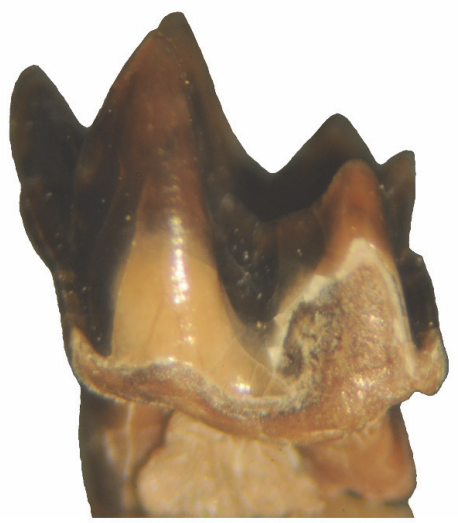

6

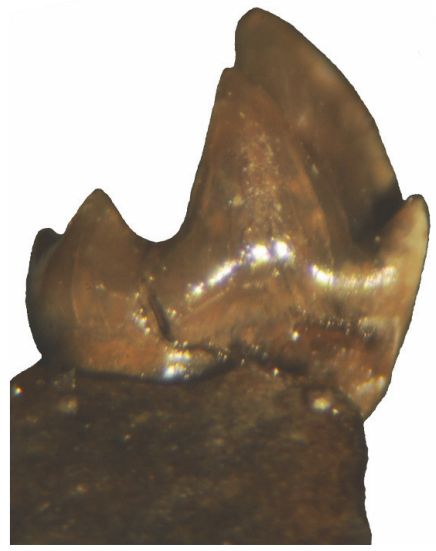

9

FIGURE 7. Nyctitherium gunnelli new species from TBM, associated Lp4-m2 (SDSNH 110393, holotype): Lp4 in occlusal (1), labial (4), and lingual (7) views; Lm1 in occlusal (2), labial (5), and lingual (8) views; Lm2 in occlusal (3), labial (6), and lingual (9) views. Scale bar equals $1 \mathrm{~mm}$. 

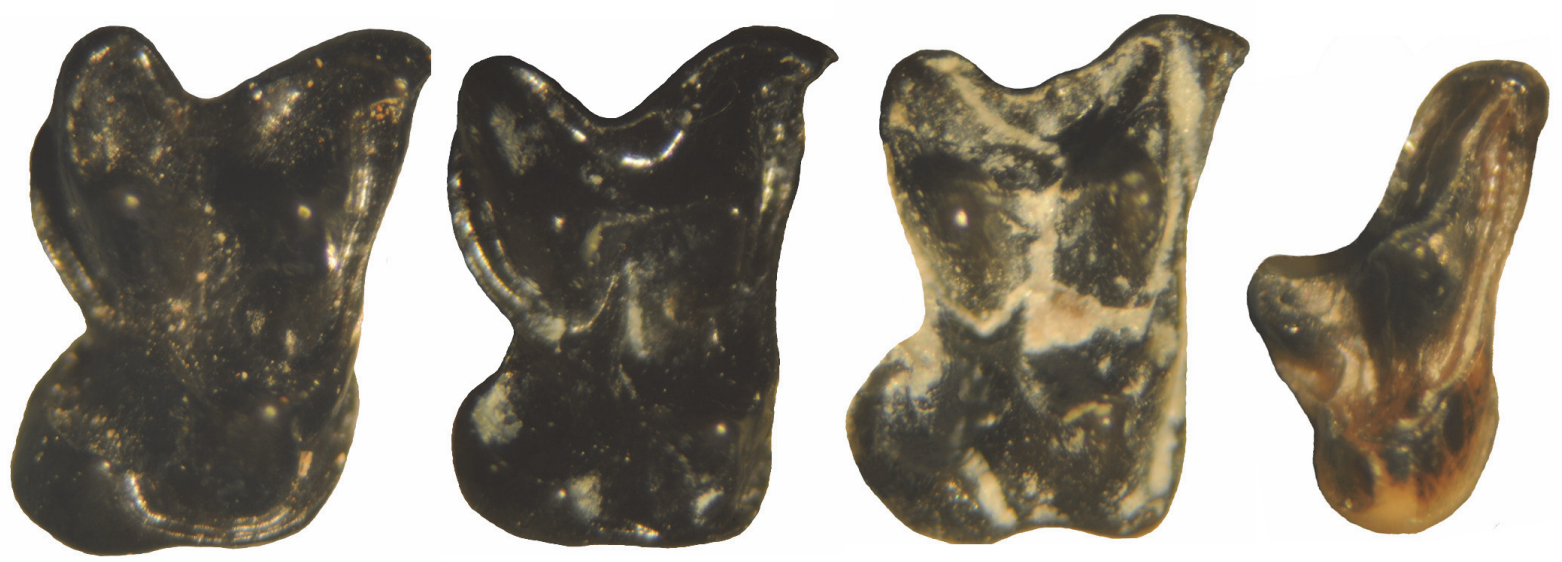

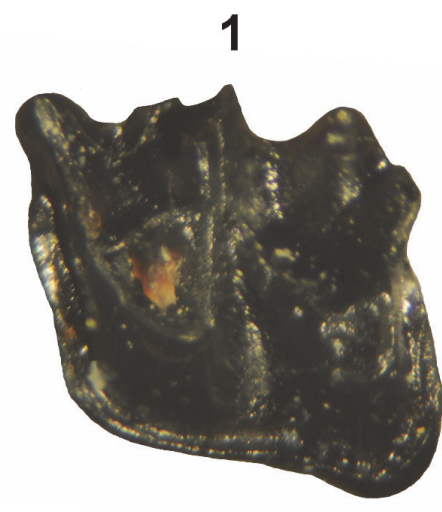

5

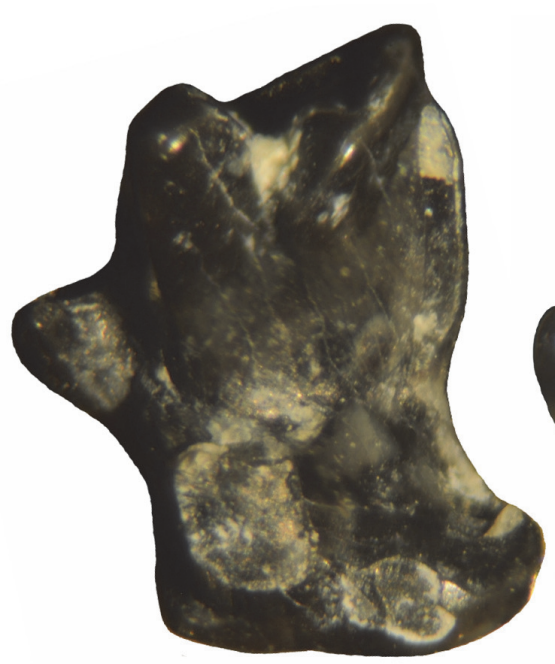

8
2

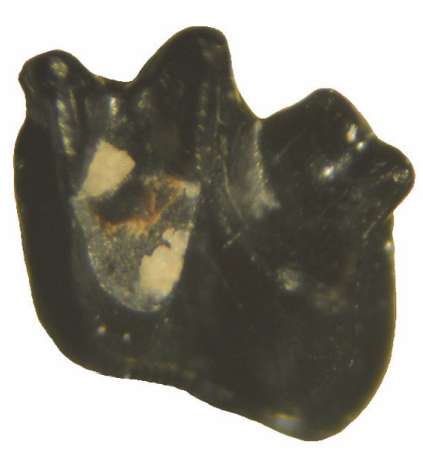

6

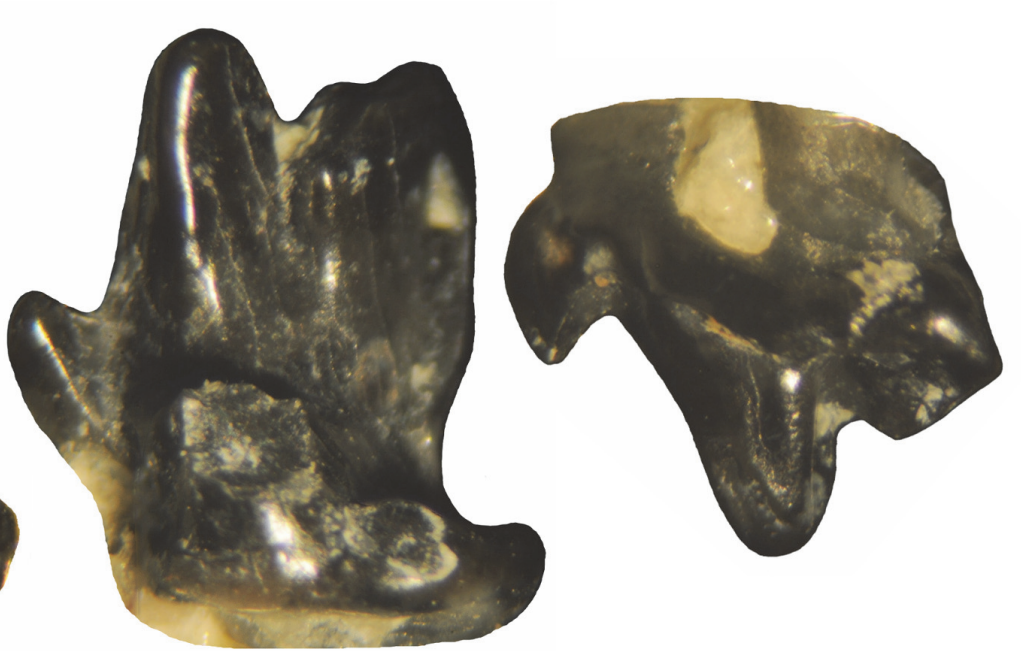

9
3

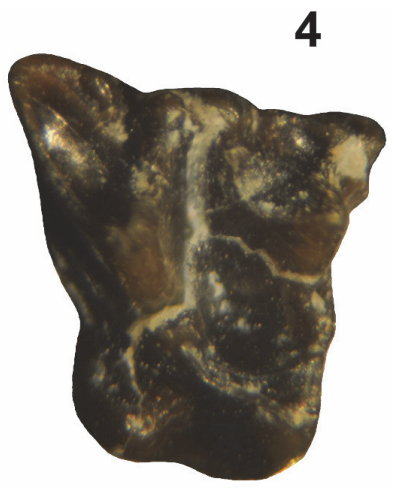

7

10

FIGURE 8. Nyctitheriidae from TBM. 1-6, Nyctitherium velox: RM2 (DMNH 75292) in occlusal view (1); RM2 (UCM 95771) in occlusal view (2); RM2 (UCM 68581) in occlusal view (3); RM3 (DMNH 75291) in occlusal view (4); partial Lm2 (DMNH 75317) in occlusal view (5); partial Lm2 (SDSNH 110409) in occlusal view (6). (7), Pontifactor bestiola, RM1 (UCM 71129) in occlusal view. 8-10, Nyctitherium gunnelli new species, LP4 (UCM 95769) in occlusal (8), labial (9), and lingual (10) views. Scale bar equals $1 \mathrm{~mm}$. 
posterior (postcingulid) portions of labial cingulid more strongly developed, and m1-2 hypoconulid more reduced in size relative to size of entoconid resulting in these two cuspids being slightly more weakly twinned. It further differs from $N$. krishtalkai and $N$. serotinum by having the p4 hypoconulid slightly better developed. It further differs from $N$. krishtalkai by having m1-2 cristid obliqua terminating higher on the postvallid (posterior wall of trigonid) and p4 talonid width more expanded transversely relative to trigonid width (talonid wider than trigonid). It further differs from $N$. serotinum and $N$. celatum by having a complete labial cingulid. Nyctitherium gunnelli differs from Nyctitherium christopheri by having $\mathrm{P} 4$ with slightly more transverse expansion, a much straighter ectocingulum, a more conical parastyle, a weaker metacone and metastyle, and less posterior expansion of hypoconal shelf. The lower molars of Nyctitherium gunnelli cannot be compared directly to much younger (late Uintan-Duchesnean) $N$. christopheri because it is only known from upper dentitions, but they appear to be larger (see Remarks below).

Etymology. Patronym for Gregg Gunnell of the Division of Fossil Primates, Duke Lemur Center, Duke University, in honor of his many contributions on Eocene mammals.

Description. The three TBM teeth from SDSNH Locality 5843 are regarded as associated, that is represent a single individual, because they were recovered from the same small batch of matrix, their preservation exhibits the same patterns of coloration, they are all in the same wear stage (unworn), are compatible in size and occlusal morphology, and all exhibit very similar abrasion patterns on the enamel along their ventrolabial borders. Although the ventrolabial enamel is abraded off these teeth, they all apparently had a continuous labial cingulid because the underlying dentine surfaces have a distinct ridge still present that outlines the labial cingulid. Moreover, the anterior and posterior cingulids (pre and postcingulids) are very robust, and the ridged dentine outline merges anteriorly and posteriorly with their broken edges (Figure 7.4-6), indicating that the cingulid was continuous, extending from the anterolabial base of the protoconid across the entire ventrolabial border and terminating at the posterolabial base of the hypoconulid.

The p4 is molariform with the talonid wider transversely than the trigonid. The cuspate paraconid is small, but distinct, positioned slightly lingual of the midline and significantly lower in height than the metaconid and protoconid. The protoconid is large, vertically orientated and larger and slightly taller than the metaconid. The talonid is well developed with a moderately deep basin. The hypoconid is robust and about equal in height to the entoconid. The hypoconulid is distinct, smaller than the entoconid, and positioned close to the entoconid (twinned condition). The cristid obliqua is tall, extending anterolingually from the hypoconid to join the postvallid (posterior wall of the trigonid) at a level about a third the way up the base of the protoconid.

The TBM lower molars are very similar in occlusal morphology, but the $\mathrm{m} 1$ can be distinguished from the $\mathrm{m} 2$ by being slightly larger in size, having the length slightly longer relative to the talonid width $(\mathrm{m} 1 \mathrm{trp} / \mathrm{ap}=0.54$ versus $\mathrm{m} 2 \mathrm{trp} / \mathrm{ap}=$ 0.61 ), and the protoconid is slightly taller than the metaconid, whereas in the $\mathrm{m} 2$, they are about equal in height. Their trigonids are narrower and taller than the talonids, and open lingually (not compressed). The paraconid is cuspate and lower in height than the protoconid and metaconid. The protoconid is the largest trigonid cusp with its apex positioned slightly anterior of the metaconid apex. The talonid is deeply basined. The hypoconid and entoconid are robust with the latter being slightly lower in height. The hypoconulid is smaller than the entoconid and positioned lingually, close to the entoconid, and slightly lower in height than the entoconid and hypoconid. The preentoconid cristid is moderately strong, extending anteriorly from the entoconid to join the metaconid about a third the way up from its base. The cristid obliqua is tall, extending anterolingually towards the metaconid, where it terminates about halfway up the postvallid, near the posterolabial edge of the metaconid. There is a slight swelling on the cristid obliqua (incipient mesoconid?), near the anterolingual terminus of the cristid obliqua.

A partial P4 (UCM 95769) was recovered from UCM Locality 92189 that is significantly larger than those of Nyctitherium velox, but compatible in size with the p4-m2 of $N$. gunnelli and is tentatively assigned to the species (Figure 8.8-10, Table 2). Although the protoconid of UCM 95769 is broken off and a small portion of the enamel on the anterior face of the hypocone is missing, the following characters can still be discerned. The paracone is tall and robust with a moderately developed, centrally positioned rib on its labial face. The metacone is represented by a slight bulge on the short, but tall, blade-like postmetacrista, and is positioned slightly more lingually than the paracone apex. The 
paracone and metacone are separated by a relatively deep notch, thus a distinct centrocrista is lacking. The parastyle projects anteriorly as a robust, conical cusp with a sharp apex, and it is significantly lower in height than the paracone. The metastyle is very small and positioned at the labial termination of the postmetacrista. The protocone appears to have been relatively large based on the diameter of its broken base. The hypocone is low and moderate in size with a relatively large, posteriorly expanded hypoconal shelf. The anterior cingulum is weak and extends lingually from the anterior base of the protocone, then continues as a slight ridge around its lingual base, terminating at about the middle of the lingual base of the protocone. The posterior cingulum extends labially as a thin ridge from the hypocone and then, as it reaches the level of the base of the metacone, expands to become robust, terminating at the posterior base of the postmetacrista. The labial margin of the ectocingulum is relatively straight, wherein it extends anteriorly as a ridge from the posterolabial corner of the tooth and then descends and narrows to terminate at the anterolabial base of the paracone, resulting in a moderately developed metastylar shelf between the ectocingulum and the metacone. A paraconule and metaconule are lacking.

Remarks. The lower molars of nyctitheriids exhibit some occlusal similarities with those of early marsupials (especially Herpetotherium Cope, 1873c), including the twinned condition of the entoconid and hypoconulid. In fact, the holotype of Entomacodon minutus Marsh, 1872b (= Centracodon delicatus Marsh, 1872b) was first mistakenly identified as an insectivore (Marsh, 1872b; Matthew, 1909), but was later shown to be a synonym of Herpetotherium knighti (McKenna, 1960a; Robinson, 1968a). The dp3 of didelphids and the p4 of Nyctitherium are molariform and also exhibit similarity in their occlusal morphology. In contrast, the p3 of didelphids can be easily distinguished from the p4 of nyctitheriids because it is not molariform. So when first examining the three associated TBM teeth, the question arose, could these teeth represent dp3m2 of a didelphid marsupial instead of Nyctitherium? Although rarely recovered, dp3s have been described for Herpetotherium and Copedelphys Korth, 1994, including Herpetotherium sp., cf. $H$. knighti from San Diego area of California (Lillegraven, 1976), Herpetotherium sp., cf. H. knighti from the Lac Pelletier Lower Fauna of Saskatchewan (Storer, 1996), Herpetotherium sp., cf. H. marsupium from the Lac Pelletier Lower Fauna (Storer,
1996), and Copedelphys. sp., cf. C. innominatum (Simpson, 1928) from the Badwater Creek area of Wyoming (Setoguchi, 1975; Krishtalka and Stucky, 1983; Korth, 2008). In all of these samples of Herpetotherium and Copedelphys, the dp3 is reduced relative to $\mathrm{m} 1$ with its length significantly shorter than that of the $\mathrm{m} 1$ (observed range of $\mathrm{dp} 3 \mathrm{ap} / \mathrm{m} 1$ $\mathrm{ap}=0.70-0.81$ and mean $\mathrm{dp} 3 \mathrm{ap} /$ mean $\mathrm{m} 1 \mathrm{ap}=$ 0.72 ). A similar situation exists for the relative size of the dP3 and M1 in Herpetotherium and other Eocene didelphids (Setoguchi, 1975; Krishtalka and Stucky, 1983; Storer, 1996). In samples of Nyctitherium velox and $N$. serotinum from the Bridger Formation (Robinson, 1968a; Krishtalka, 1976b), the p4 is much less reduced relative to the $\mathrm{m} 1$, where it is subequal to or slightly longer than the $\mathrm{m} 1$ (observed range of $\mathrm{p} 4 \mathrm{ap} / \mathrm{m} 1 \mathrm{ap}=0.93-1.06$ for $N$. velox and $N$. serotinum, mean $\mathrm{p} 4 \mathrm{ap} /$ mean $\mathrm{m} 1$ ap $=1.03$ for $N$. velox and mean $\mathrm{p} 4 \mathrm{ap} /$ mean $\mathrm{m} 1$ ap $=0.98$ for $N$. serotinum). The TBM premolar is significantly less reduced relative to $\mathrm{m} 1$ ( $\mathrm{p} 4 \mathrm{ap} / \mathrm{m} 1$ $a p=0.94$ ) than those of the dp3 of Herpetotherium or Copedelphys and within the observed range for those of Nyctitherium.

Additional characters also support the referral of the TBM teeth to Nyctitherium rather than Herpetotherium. In Herpetotherium and Copedelphys, the dp3 paraconid is more shelf-like, whereas in the p4 of Nyctitherium it is more cuspate, as in the TBM premolar. The p4-m2 hypoconulids of Nyctitherium and those of the TBM teeth are cuspate and positioned just slightly posterior of the entoconid, whereas in Herpetotherium and Copedelphys, the dp3-m2 hypoconulids are more shelf-like and positioned slightly further posteriorly from the entoconid. In fossil and extant marsupials, the only deciduous premolar that is replaced (diphyodont) is p3, whereas in eutherians, all of the deciduous premolars are usually diphyodont (Flower, 1867; Cifelli, 1993; Cifelli et al., 1996; Cifelli and Muizon, 1998; Nievelt and Smith, 2005). In the extant shorttailed opossum (Monodelphis Burnett, 1830), the crypt for the successor permanent $\mathrm{p} 3$ is present within the bone of the dentary below dp3 by 57 days of age, a well-developed, calcified p3 protoconid cap is present within the p3 crypt by 65 days of age, and p3 erupts at about 109 days of age (Cifelli et al., 1996; Nievelt and Smith, 2005). The TBM premolar is embedded with a section of the dentary and has a large, long, well-developed posterior root and an anterior alveolus for the anterior root that is also large and long. There is no indication within the bone of the dentary below the TBM premolar of a successor crypt or premolar, further 
indicating that it is not deciduous. In Herpetotherium and Copedelphys, the $\mathrm{m} 1$ differs from the $\mathrm{m} 2$ by having the $\mathrm{m} 1$ paraconid positioned relatively further anteriorly resulting in its trigonid being more widely open lingually. In Nyctitherium and the TBM molars, the m1-2 paraconids are similarly positioned with the $\mathrm{m} 1$ lacking the more anteriorly positioned paraconid and widely open trigonid seen in Herpetotherium or Copedelphys. Based on the above evidence, the TBM teeth agree well with those of Nyctitherium and can be eliminated as possibly representing those of a marsupial.

Nyctitheriids have also sometimes been mistaken for bats because of similarities in their molar occlusal morphologies (e.g., Matthew, 1918; Gingerich, 1987) and some investigators have suggested that chiropterans may have arisen from an early nycitheriid (Matthew, 1918; Robinson, 1968a; Rose, 1981; but for conflicting opinions, see also Smith, 1995; Smith et al., 2012; and Manz and Block, 2015). Where known for primitive Eocene bats, the dp4 is molariform and significantly smaller than m1 (Sigé, 1991; Sigé et al., 1998), whereas the p4 is usually not molariform (Jepsen, 1966; Smith et al., 2007, 2012). As noted above, the TBM premolar is not deciduous and is only slightly smaller than the associated $\mathrm{m} 1$, eliminating it as a molariform chiropteran dp4. In the early Eocene bat Icaronycteris Jepsen, 1966, from the Green River Formation of Wyoming, the p4 is pre-molariform with a three-cusped trigonid and a wide rounded, basined talonid (Jepsen, 1966; Smith et al., 2012). The TBM premolar differs from the p4 of Icaronycteris by having a much better developed metaconid (relatively larger and taller) and a fully developed, V-shaped talonid with three distinct cuspids (hypoconid, hypoconulid, and entoconid), like that of the p4 of Nyctitherium. Therefore, the associated TBM teeth can also be eliminated as representing a bat instead of Nyctitherium.

The phylogenetic relationships and content of the Nyctitheriidae have long been debated (e.g., Marsh, 1872b; Matthew, 1909, 1918; Simpson, 1928; Robinson, 1968a; West, 1974; Krishtalka, 1976b; Bown and Schankler, 1982; Gingerich, 1987; Butler, 1988; Smith, 1995; Sigé, 1997; Lopatin, 2006; Secord, 2008; Beard and Dawson, 2009, Rose et al., 2012; Christiansen and Stucky, 2013; Manz and Bloch, 2015). Recently, Christiansen and Stucky (2013) and Manz and Bloch (2015) provided cladistic analyses of the Nyctitheriidae, which significantly increased our understanding of the systematics of the family. The p4-m2 from the TBM are assigned to Nyctitherium because they exhibit the following characters (Robinson, 1968a; Krishtalka, 1976b; Gunnell et al., 2008b; Manz and Block, 2015): 1) small size; 2) p4 molariform with a well developed talonid and a low paraconid; and 3) m1-2 with sharp, vertically orientated primary cusps, a relatively uncompressed, lingually open trigonid, a cuspate paraconid, a cristid obliqua tending towards the metaconid (vespiform condition), and a hypoconulid positioned close to the entoconid (twinned condition).

The taxonomy of the Bridgerian nyctitheriids has a complicated history with many species previously assigned to Nyctitherium now referred to different genera. Marsh (1872b) named a number of 'insectivores' from the Bridger Formation, including Nyctitherium velox, Nyctitherium priscum, Nyctilestes serotinus, Entomacodon angustidens, Entomacodon minutus, Centracodon delicatus, and Talpavus nitidens. Matthew (1909) transferred Nyctilestes serotinus to Nyctitherium as N. serotinum, transferred Talpavus nitidens to Nyctitherium as $N$. nitidus, placed Centracodon delicatus as a junior synonym of Entomacodon minutus, and described two new taxa from the Bridger Formation, Myolestes dasypelix and Nyctitherium curtidens. Robinson (1968a) regarded M. dasypelix as an aberrant representative of Nyctitherium and $E$. angustidens as a junior synonym of $N$. serotinum, which was followed by later investigators (e.g., Gazin, 1976). McKenna (1960a) first noted that the material referred to $E$. minutus may actually represent a marsupial, which was confirmed by later investigators (Robinson, 1968a; Gazin, 1976; Kristhtalka and Stucky, 1983). McKenna (1960b), Krishtalka (1976b), and Bown and Schankler (1982) regarded Myolestes as generically and familially distinct from Nyctitherium and referred it to the Geolabididae. McKenna and Haase (1992) replaced Myolestes with Marsholestes because the name Myolestes was preoccupied. McGrew (1959) named Diacodon edenensis from the Bridger Formation at Tabernacle Butte. Robinson (1966a) transferred $N$. priscum and $D$. edenensis to the geolabidid genus Scenopagus McKenna and Simpson, 1959, as S. priscus and S. edenensis, respectively. Based on a partial maxilla with M1-3 and isolated upper teeth, West (1974) described Pontifactor bestiola from the Twin Buttes Member of the Bridger Formation. Most recently, Christiansen and Stucky (2013) described a third species of Nyctitherium, N. krishtalkai, from the late Wasatchian Lost Cabin Member of the Wind River Formation, Wyoming. Thus, prior to the discovery of Nyctitherium gunnelli from the TBM, only three 
nyctitheriid species were recognized from the Bridger Formation; Nyctitherium velox, Nyctitherium serotinum and Pontifactor bestiola.

Based on a partial dentary with m1-3, Cope (1875) described Diacodon celatus from the late Wasatchian San Jose Formation of New Mexico. Matthew (1918) transferred the holotype of $D$. celatus along with a referred, associated partial upper and lower dentition (originally cited as $\mathrm{AMNH}$ 15103, but subsequently reassigned to AMNH FM 113783) from the Wasatchian Willwood Formation of Wyoming to Nyctitherium, as N. celatum. Subsequently, AMNH FM 113783 was reassigned to Pontifactor sp. by Krishtalka (1976b), leaving $N$. celatum known only from the holotype. However, Gingerich (1987) described a new genus, Wyonycteris, which he first regarded as a chiropteran, but is now regarded by most recent investigators to belong to a Wyonycteris-Pontifactor clade nested well within Nyctitheriidae (e.g., Beard and Dawson, 2009; Christiansen and Stucky, 2013; Manz and Bloch, 2015). It now seems most likely that AMNH FM 113783 actually represents a species of Wyonycteris rather than Pontifactor (Gingerich, 1987), which makes Pontifactor a monotypic genus that is known only from upper teeth.

One species of Nyctitherium, N. christopheri from late Uintan and early Duchesnean localities of the Badwater Creek area of Wyoming was described by Krishtalka and Setoguchi (1977), and is based only on upper teeth (holotype partial maxilla with P4-M3, three isolated upper molars and a P4). The upper cheek teeth of Nyctitherium christopheri differ from those of Bridgerian N. velox and N. serotinum (Krishtalka and Setoguchi, 1977) by the following: 1) slightly larger size; 2) relatively more transversely expanded molars, especially M2; 3) a more expanded hypoconal shelf on P4M2; 4) a more reduced precingulum (anterior cingulum) on P4-M2; and 5) a deeper M2 ectoflexus. In $N$. velox and $N$. serotinum, where larger samples of both upper and lower molars are available (Robinson, 1968a; Krishtalka, 1976b), the $\mathrm{m} 1$ ap is 5$9 \%$ longer than the M1 ap, and the $\mathrm{m} 2$ ap is $4-5 \%$ longer than the M2 ap. Assuming the upper and lower molar proportions of $N$. christopheri are similar to those of $N$. velox and $N$. serotinum, then the extrapolated $\mathrm{m} 1$ ap for $N$. christopheri would be about 1.8-1.9 mm and that for its $\mathrm{m} 2$ ap would be about $1.7 \mathrm{~mm}$. Although speculative, these extrapolated dimensions suggest that the m1-2 of Nyctitherium gunnelli are probably significantly larger than those of $N$. christopheri because its $\mathrm{m} 1 \mathrm{ap}=$ $2.23 \mathrm{~mm}$ and $\mathrm{m} 2 \mathrm{ap}=2.08 \mathrm{~mm}$. In N. velox, the M1 ap is smaller than the P4 ap (mean M1 ap $=81 \%$ of mean P4 ap), whereas in N. christopheri the M1 ap is slightly less reduced relative to that of the P4 (M1 ap $=87 \%$ of P4 ap). The M1 tr is equal to the $\mathrm{P} 4 \mathrm{tr}$ in $N$. christopheri, but slightly smaller in $N$. velox (M1 tr $=97 \%$ of $\mathrm{P} 4 \mathrm{tr}$ ). Thus, the P4 of $N$. christopheri differs from that of $N$. velox by being slightly larger anteroposteriorly and transversly relative to the M1 (Figure 8.8-10). The tentatively referred P4 (UCM 95769) of $N$. gunnelli is similar in size to that of $N$. christopheri and, based on the large sizes of the m1-2 of $N$. gunnelli, the relative sizes of its M1-2 to its P4 are speculated to be similar to those of $N$. velox. Moreover, if the referral of UCM 95769 to $N$. gunnelli is correct, then the following additional differences distinguish the P4 of $N$. gunnelli from that of $N$. christopheri (Krishtalka and Setoguchi, 1977): 1) slightly more transversely expanded (P4 ap/P4 tr $=0.82$, whereas that of $N$. christopheri $=0.87) ; 2$ ) the ectocingulum is nearly straight, whereas that of $N$. christopheri exhibits a distinct concavity along the labial edge of the metastylar shelf; 3) a more conical parastyle, whereas that of $N$. christopheri is expanded slightly anteroposteriorly; 4) a more weakly-developed metacone and metastyle; 5) and a less posteriorly expanded hypoconal shelf. In addition, $N$. christopheri is significantly younger (late Uintan to early Duchesnean, <44 Ma) than $N$. gunnelli (earliest Uintan, $\sim 47 \mathrm{Ma}$ ).

As noted above, $P$. bestiola is known only from upper dentitions, so a direct comparison of the lower cheek teeth of $N$. gunnelli cannot be made. However, based on unambiguous synapomorphies of the upper dentition of $P$. bestiola and species of Wyonycteris, Manz and Bloch's (2015) cladistic analysis placed Wyonycteris as the closest sister taxon to $P$. bestiola in a Wyonycteris-Pontifactor clade. Their data strongly suggests that the lower molars of $P$. bestiola should be similar to those of Wyonycteris. The lower molars of $N$. gunnelli differ from those of Wyonycteris by the following: 1) p4 paraconid lower in height; 2) p4 anterior cingulid (precingulid) much better developed; 3 ) m1-2 paraconid cuspate and unreduced; 4) m1-2 trigonid much less compressed and more open lingually; 5) m1-2 hypoconulid positioned more lingually and twinned with entoconid; 6) m1-2 cristid obiqua tends more towards the metaconid resulting in a more vespiform constriction between the trigonid and talonid; and 7) m1-2 labial cingulid more complete, extending across the hypoconid. Therefore, it is very doubtful that the lower molars of $N$. gunnelli could instead represent the lower molars 
of $P$. bestiola. Furthermore, the tentatively referred P4 of $N$. gunnelli is quite different from that of $P$. bestiola (West, 1974, figure 1), including the following: 1) a quadrate occlusal outline due to an expanded hypoconal shelf; 2) a more anteroposteriorly compressed paracone; 3) a straighter ectocingulum; 4) a more lingually positioned protocone; and 5) a small parastyle present (lacking in P. bestiola).

In summary, Nyctitherium gunnelli can be easily distinguished from Wasatchian and Bridgerian species of Nyctitherium by the differences listed above in the diagnosis. Despite acknowledging that we cannot directly compare the p4-m2 of $N$. gunnelli to $N$. christopheri or $P$. bestiola until their lower cheek teeth are known, we believe the circumstantial evidence strongly supports recognizing $N$. gunnelli as distinct from these nyctitheriids. Furthermore, assuming that the tentative referral of the P4 to $N$. gunnelli is correct, then additional differences can be recognized that distinguish $N$. gunnelli from $N$. christopheri and P. bestiola.

\section{Nyctitherium velox (Marsh, 1872b) \\ Figure 8.1-6, Table 2}

Referred specimen. From UCM Locality 92189: RM2s, UCM 68581, 95771; Lm1, UCM 68967; partial dentary with partial Lm2 and m3, UCM 67899. From SDSNH Locality 5787: partial Lm2, SDSNH 110409. From DMNH Locality 4672: RM2, DMNH 75292; partial RM1 or 2, DMNH 75290; RM3, DMNH 75291. From DMNH Locality 4673: partial Lm2, DMNH 75317.

Description. The M2 paracone and metacone are tall with sharply tapered apices (sectorial condition of Robinson, 1968a) and the protocone is robust. The preprotocrista is well defined and extends anterolabially from the protocone apex to terminate at a distinct $\mathrm{V}$-shaped protoconule. The postprotocrista is also well defined and extends posterolabially from the protocone apex to terminate at a distinct, V-shaped metaconule. The hypocone is very large and expanded, giving it a protruding, circular occlusal outline. A small mesostyle (or stylocone) is present along the stylar shelf posterior of the paracone apex. The parastyle is distinct and positioned at the anterolabial corner of a prominent parastylar lobe. The ectoflexus is moderately concave between the parastylar lobe and the robust, labially projecting metastylar lobe. The anterior cingulum is moderately robust.

The M3 paracone is taller and slightly larger in size than the metacone with a long preparacrista extending labially to join a small, but distinct, parastyle. The stylar shelf extends anterolabially as a long rapidly ascending projection from the labial base of the metacone to the anterolabial corner of the tooth. A very small mesostyle (or stylocone) is present on the labial edge of the stylar shelf that is positioned above the paracone apex. The protocone is robust, but a hypocone is lacking. The paraconule and metaconule are well developed with distinct parastylar and metastylar wings. The anterior and posterior cingula are weak.

The $\mathrm{m} 1$ and $\mathrm{m} 2$ trigonids are anteroposteriorly compressed with a large protoconid and a cuspate paraconid that is slightly smaller and lower in height than the metaconid. The talonid is wider than the trigonid with a large hypoconid and a distinct entoconid that is positioned close to a distinct hypoconulid (twinned condition). The cristid obliqua extends anterolingually from the hypoconid towards the metaconid and terminates just lingual of the notch between the metaconid and protoconid, resulting in a deep ectoflexid. The anterior, labial, and posterior cingulids are joined as a continuous, well-developed cingulid that extends from the anterior base of the protoconid across the labial bases of the protoconid and hypoconid to terminate near the posterior base of the hypoconulid.

The occlusal morphology of the $\mathrm{m} 3$ is very similar to that of the $\mathrm{m} 1$ and $\mathrm{m} 2$, but differs by having a narrower talonid and smaller hypoconid.

Remarks. Prior to the discovery of Nyctitherium gunnelli, only two other species of Nyctitherium, $N$. serotinum and $N$. velox, were previously recognized from the Bridger Formation. Nyctitherium velox is easily distinguished from $N$. serotinum by its larger size and the presence of a complete, well-developed labial cingulid on the lower molars (Robinson, 1968a; Krishtalka, 1976b). Nyctitherium velox can also be easily distinguished from $N$. gunnelli by its significantly smaller size (Figure 9 ) and certain other dental characters listed above. The referred specimens from the TBM agree well in their occlusal morphology and size to those of $N$. velox and are referred to the species.

\section{Genus PONTIFACTOR West, 1974 \\ Pontifactor bestiola West, 1974}

Figure 8.7, Table 2

Referred specimens. From UCM Locality 92189: RM1, UCM 71129.

Description. The M1 paracone, metacone, and protocone are conical and tall and with sharp apices. The protocone is the largest primary cusp and the metacone is slightly larger than the paracone. The preparacrista, postmetacrista, and centrocrista are strongly developed, forming a W-shaped ectoloph. The hypocone is small, but distinct, and posi- 


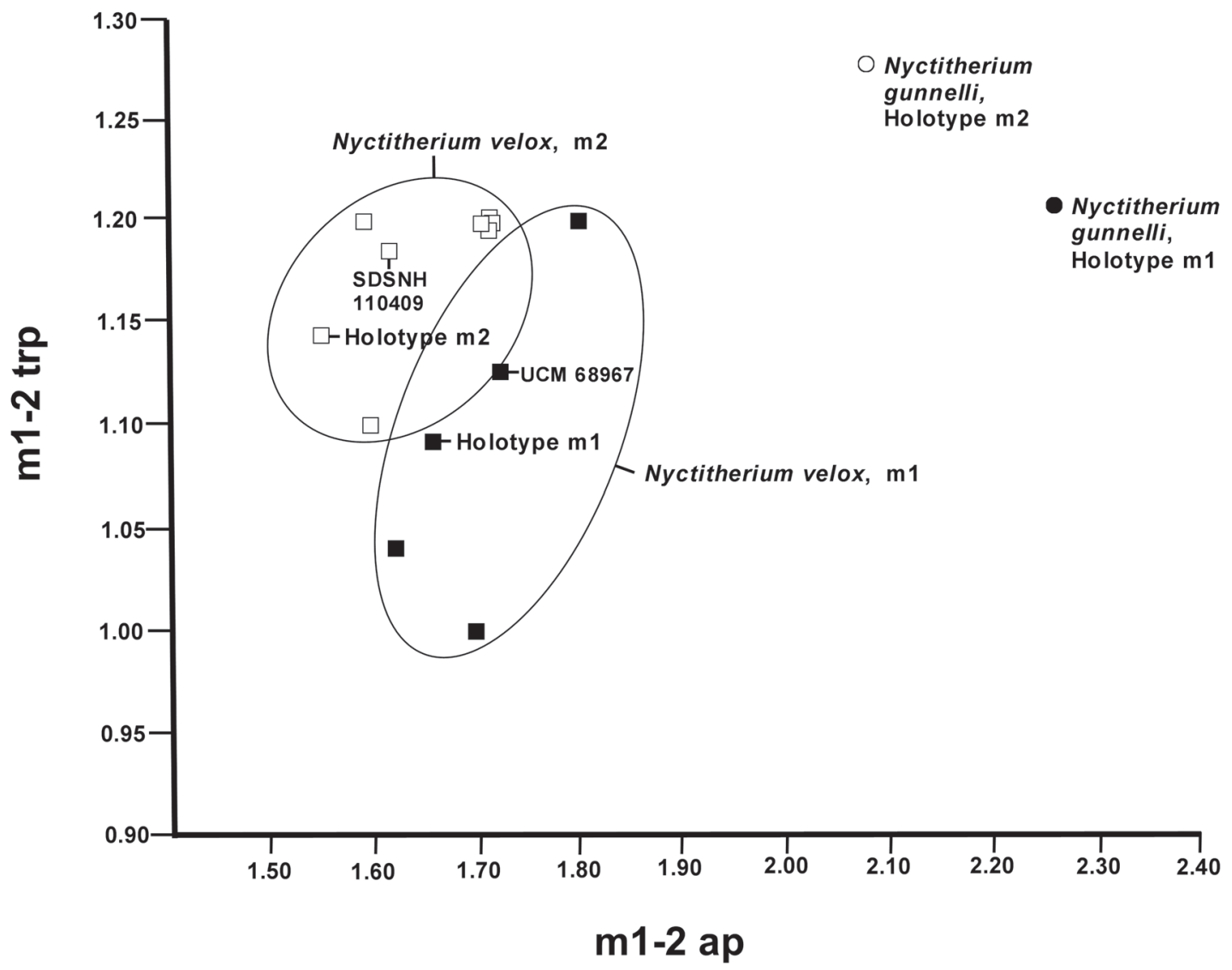

FIGURE 9. Chart comparing m1-2 anteroposterior length (ap) versus m1-2 talonid width (trp) in mm of specimens of Nyctitherium velox (including two referred specimens from TBM, SDSNH 110409 and UCM 68967) and holotype m12 (SDSNH 110393) of Nyctitherium gunnelli new species. Black solid filled squares/circles are $\mathrm{m} 1 \mathrm{~s}$ and white filled squares/circles are m2s. Except for SDSNH 110409 and UCM 68967, measurements of other specimens of N. velox from Robinson (1968a) and Krishtalka (1976b).

tioned lower and posterolingually of the protocone apex. A large, distinct mesostyle is positioned at the center of the centrocrista between and labial of the paracone and metacone apices. The parastyle is large and projects anterolabially. A small stylocone is present at the labial terminus of the premetacrista. The stylar shelf extends posterolabially to join a distinct metastyle. A distinct paraconule and metaconule are present at the labial terminus of the preprotocrista and postprotocrista, respectively. The anterolingual cingulum is weak, extending labially from the anterolingual base of the protocone.

Remarks. UCM 71129 is indistinguishable in size and occlusal morphology to the M1 of Pontifactor bestiola (West, 1974; Gunnell et al., 2008b) and is confidently be assigned to the species.

Family OLIGORYCTIDAE Asher, McKenna, Emry, Tabrum, and Kron, 2002 unnamed apternodontid sp.

Figure 10.1-4, Table 2

Referred specimens. From SDSNH Locality 5841: partial LM1 or 2, SDSNH 110348; partial Rm1 or 2, SDSNH 110349. From UCM Locality 92189: partial dentary with Rm1-2, UCM 68965.

Description. The partial M1 or 2 is broken, missing the parastylar lobe of the stylar shelf and the labial portion of the anterior cingulum. Even in its broken state, certain characters can still be distinguished. It is zalambdodont with a sharp, tall, large paracone and lacking a metacone. The protocone is robust with a sharp apex, but is significantly lower in height than the paracone. The anterior cingulum is moderately strong and extends labially from the protocone to the point where the tooth is broken off. The ectoflexus is deep with a distinct concave labial border. A paraconule and metaconule are lacking. 

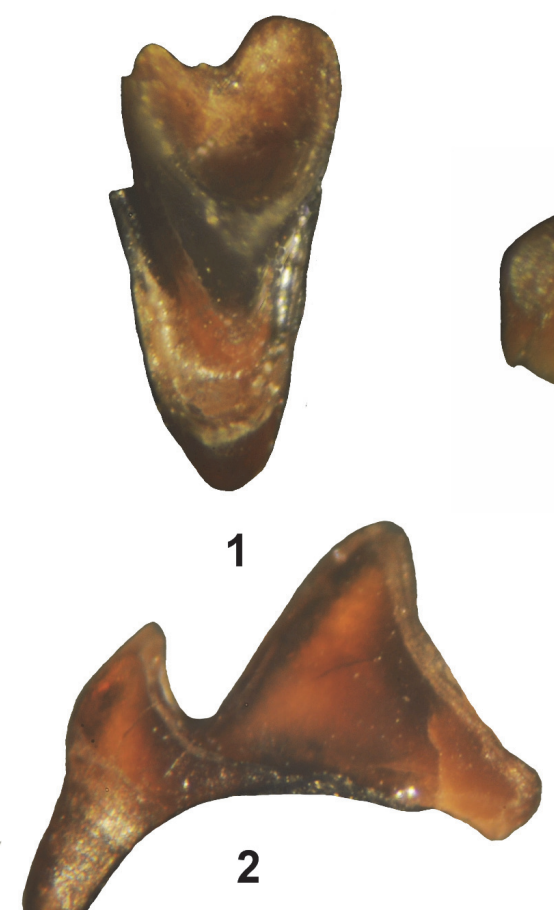

3

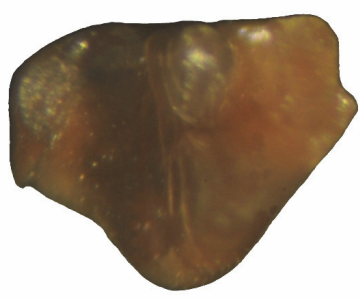

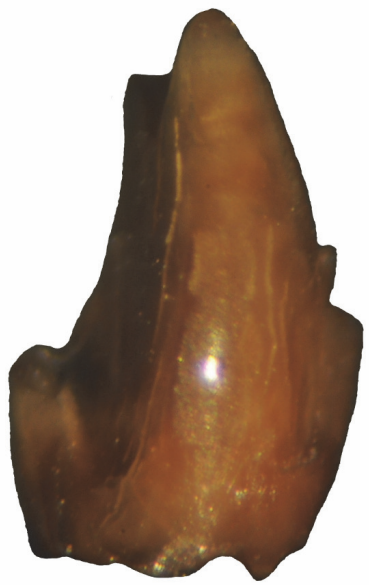

4

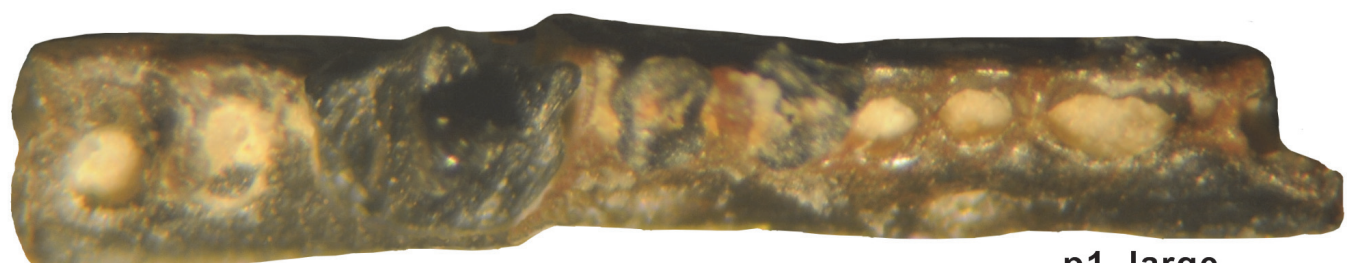

p1, large

5 p3, two large small

p2, two

alveolus,

slightly

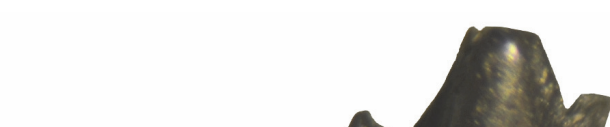

roots

hourglass

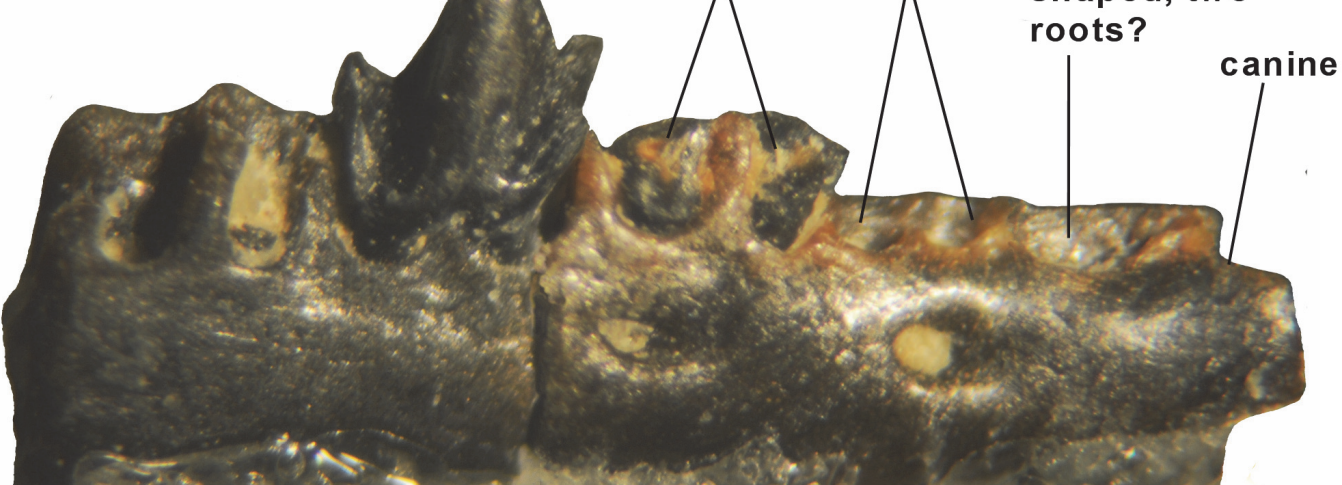

6

FIGURE 10. Oligoryctidae and unnamed lipotyphlan from TBM. 1-4, unnamed apternodontid sp.: partial LM1 or 2 (SDSNH 110348) in occlusal (1) and anterior (2) views; partial Rm1 or 2 (SDSNH 110349) in occlusal (3) and labial (4) views. 5-6, unnamed lipotyphlan sp., partial dentary with Rp4 (DMNH 75258) in occlusal (5) and labial (6) views. Scale bars equals $1 \mathrm{~mm}$. 
The partial dentary with m1-2 was not available at the time of our study (G.F. Gunnell, personal communication, 2015). The partial $\mathrm{m} 1$ or 2 is missing most of the tip of the paraconid, but the following characters can still be distinguished. The trigonid is very tall and compressed anteroposteriorly with the metaconid only slightly lower in height than the protoconid. The talonid is extremely reduced, only represented by an incipient entoconid and narrow shelf (unbasined) that does not extend to the labial corner of the tooth. The anterior cingulid is moderately strong, extending lingually from the anterolabial base of the protoconid and terminating near the anterior base of the paraconid.

Remarks. Asher et al. (2002) provided a brief description and illustration of a very small, unnamed apternodontid from the middle Eocene of the western Interior (see also McKenna et al., 1962; Emry, 1990), including specimens from the Bridger Formation at Tabernacle Butte and the TBM. Based on their cladistic analysis, Asher et al. (2002) found the new unnamed apternodontid was most closely related to Oligoryctes Hough, 1956. The TBM specimens agree well in size and occlusal morphology with this unnamed taxon.

Family undetermined unnamed lipotyphlan sp.

Figure 10.5-6, Table 2

Referred specimens. From DMNH Locality 4672: partial right dentary with $\mathrm{p} 4$, roots of $\mathrm{p} 3$ and alveoli for c-p2 and $\mathrm{m} 1$ plus associated partial left, edentulous dentary with alveoli for c-p3, DMNH 75258.

Description. The dentary is extremely small and shallow (depth below p4 $=1.13 \mathrm{~mm}$ ). Two large mental foramina are present, an anterior one below the middle of $\mathrm{p} 2$ and a posterior one below the level of the posterior root of p3. DMNH 75258 has one premolariform tooth present, here identified as p4 (Figure 10.5-6). Posterior to the p4 are two alveoli and anteriorly there are two, closely spaced alveoli with two large broken roots followed by two small alveoli, one moderate slightly hourglass shaped alveolus, and the posterior half of one large alveolus. Recognizing that determining the tooth positions from alveoli is difficult, the following scenario is proposed. The two larger alveoli posterior to the p4 are those of $\mathrm{m} 1$. They are relatively straight and larger than those of the p4, indicating that the $\mathrm{m} 1$ was larger than the $\mathrm{p} 4$. Directly anterior to the p4 are two relatively large roots, which are presumed to be those of $\mathrm{p} 3$. These roots do not appear to represent two separate, single rooted teeth because they are so closely appressed that there would not be any room for two separate crowns above them, especially if they were procumbent. Anterior to the p3 roots are two smaller alveoli, presumably those of $\mathrm{p} 2$, and one larger, slightly anteriorly inclined alveolus. The anteriorly inclined alveolus exhibits a slight constriction near its middle (slightly hourglass shaped) that appears to indicate that the $\mathrm{p} 1$ had two closely appressed or fused roots. At the anterior tip of the partial dentaries is one large, partial alveolus, presumably that of the canine. Thus, the proposed antemolar formula for DMNH 75258 is a moderately large canine, a two rooted or fused two rooted $\mathrm{p} 1$, a two rooted smaller $\mathrm{p} 2$, and a two rooted larger p3-4.

The p4 is slightly worn. It has a well-developed trigonid consisting of a robust protoconid of moderate height, a distinct metaconid that is slightly lower in height than the protoconid, and a crest-like paraconid that is about two-thirds the height of the protoconid. The talonid is very reduced and shelf-like, wherein the posterior margin steeply declines labially from a small cuspid (incipient entoconid) positioned at its posterolingual corner to terminate at the posterior base of the protoconid. The anterior cingulid is moderately strong, extending lingually from the anterolabial base of the protoconid to terminate about halfway up the anterior wall of the paraconid.

Remarks. DMNH 75258 is enigmatic because it does not agree well morphologically with any previously known Bridgerian species. The p4 occlusal morphology and delicate horizontal ramus indicates that it is a lipotyphlan, but it can be eliminated as representing most previously recognized Bridgerian lipotyphlans by its miniscule size. The reduced p4 talonid exhibits similarities to those of Entomolestes, Batodonoides Novacek, 1976, and Oligoryctes. DMNH 75258 differs from Entomolestes grangeri by the following (Robinson, 1968b; Krishtalka and West, 1977): 1) smaller size (p4 ap $31 \%$ smaller and p4 tr $35 \%$ smaller); 2) p3 roots and alveoli significantly larger, similar in size to those of the p4 (in E. grangeri, p3 crown procumbent and significantly smaller than p4); and 3) two large mental foramina (in E. grangeri, only one large mental foramen present below the posterior root of p2). DMNH 75258 differs from Entomolestes sp. from the TBM by its smaller size (p4 ap is $14 \%$ smaller) and by having a slightly more reduced $\mathrm{p} 4$ talonid with a $\mathrm{p} 4$ tra/p4 ap ratio of 0.68 , whereas that of Entomolestes sp. is 0.77 , a $14 \%$ difference. Entomolestes sp. from the TBM appears to further differ from DMNH 75258 because it lacks an anterior mental foramen below the alveolus of what is assumed to be p2. DMNH 
75258 differs from Oligoryctes by the following (Asher et al., 2002; Gunnell et al., 2008b): 1) smaller size; 2) the p4 protoconid relatively shorter in height with the metaconid nearly as tall as protoconid (in Oligoryctes, the p4 protoconid very tall and metaconid shorter relative to the protoconid); 3 ) the anterior mental foramen positioned slightly more anteriorly (in Oligoryctes, the posterior mental foramen smaller and positioned slightly more posteriorly); and 4) the ventral border of the horizontal ramus relatively straight (in Oligoryctes, ventral border more convex). The p4 of DMNH 75258 is similar in size to those of the diminutive soricomorph Batodonoides powayensis Novacek, 1976, but it differs by the following: 1) a more reduced talonid that lacks a posterior, centrally positioned cuspid; 2) a more robust, relatively shorter protoconid (not as tall relative to the talonid height); and 3) a better developed, more anterolabially projecting paraconid. Although B. powayensis also has two mental foramina, they are positioned differently than those of DMNH 75258 with the anterior one below the posterior root of $\mathrm{p} 2$ and the posterior one below the posterior root of $\mathrm{p} 4$. The p4 of the very small, unnamed apternodontid (see above) has not yet been described, but if it is like that of Oligoryctes, as implied by the character state matrix of Asher et al. (2002), then it would be expected to differ from DMNH 75258 by having a much taller trigonid relative to the talonid height.

The two large mental foramina positioned below $p 2$ and $p 3$, respectively, presumably $p 1-p 3$ with two roots and $\mathrm{p} 4$ with an anterolingually projecting paraconid, reduced talonid and a relatively low difference between the trigonid and talonid heights suggests that DMNH 75258 may represent an erinaceomorph (Novacek et al., 1985; Gunnell et al., 2008b). The distinctive characters of DMNH 75258 indicate that it probably represents a new lipotyphlan species not previously recognized from the Bridger Formation. However, definitive familial and generic identification cannot be made without additional knowledge of the lower cheek teeth, so DMNH 75258 is referred to an unnamed lipotyphlan.

$$
\begin{gathered}
\text { Unranked clade CARNIVORAMORPHA sensu } \\
\text { Bryant, 1996 } \\
\text { Family VIVERRAVIDAE Wortman and Matthew, } \\
1899 \\
\text { Genus VIVERRAVUS Marsh, 1872a } \\
\text { Viverrravus gracilis Marsh, 1872a } \\
\text { Figure 11.1, Table } 2
\end{gathered}
$$

Referred specimen. From UCM Locality 92189: LM2, UCM 95809.
Description. The M2 paracone is slightly larger and taller than the metacone, and both cusps have relatively sharp apices. The preparacrista extends labially from the paracone apex to a small parastyle. The centrocrista between the paracone and metacone is deep and almost straight. The protocone is tall and positioned anteriorly, nearly in line with the paracone. The preprotocrista extends labially in a gentle arc from the protocone apex to terminate near the anterolingual base of the paracone. The postprotocrista extends posterolabially from the protocone to terminate at the lingual base of the metacone. A small, low ridge is present just anterior to the preprotocrista that extends anterolingually from near the lingual base of the metacone to terminate short of the labial base of the protocone. The stylar shelf is moderately strong, inclined posteriorly, and bounded by a labial cingulum. An anterior cingulum, posterior cingulum, metastyle, paraconule, metaconule, and hypocone are lacking.

Remarks. The M2 agrees well in size and occlusal morphology of those of Viverravus gracilis (Matthew, 1909; Robinson, 1966a; Flynn and Galliano, 1982; Flynn, 1998) and is referred to the species.

Order "CONDYLARTHA" Cope, 1881

Family HYOPSODONTIDAE Trouessart, 1879 Genus HYOPSODUS Leidy, 1870

Hyopsodus lepidus Matthew, 1909

Figure 11.2-3, Table 3

Referred specimens. From UCM Locality 92189 : RM1 or 2, UCM 67956; Rm1 or 2, UCM 67958.

Description. The two molars from the TBM have typical hyopsodontid morphology. The upper molar (M1 or 2) has a quadrate occlusal outline with a subselenodont paracone and metacone that are connected centrally by a strong centrocrista. The hypocone is robust and only slightly smaller than the protocone with these cusps connected labially by a cristid. A distinct parastyle, protoconule, and metaconule are present. The anterior and posterior cingula are well developed. The ectocingulum is distinct and shelf-like, extending between the bases of the paracone and metacone.

The $\mathrm{m} 1$ or 2 has a rectangular occlusal outline. The trigonid is two-cusped (paraconid lacking), consisting of a conical protoconid and metaconid that are obliquely orientated and connected both anteriorly and posteriorly by a paracristid and postprotocristid, respectively. The entoconid and hypoconid are large and slightly obliquely orientated to one another. The hypoconulid is relatively large and positioned along the posterior border of the talonid, slightly lingual of its 

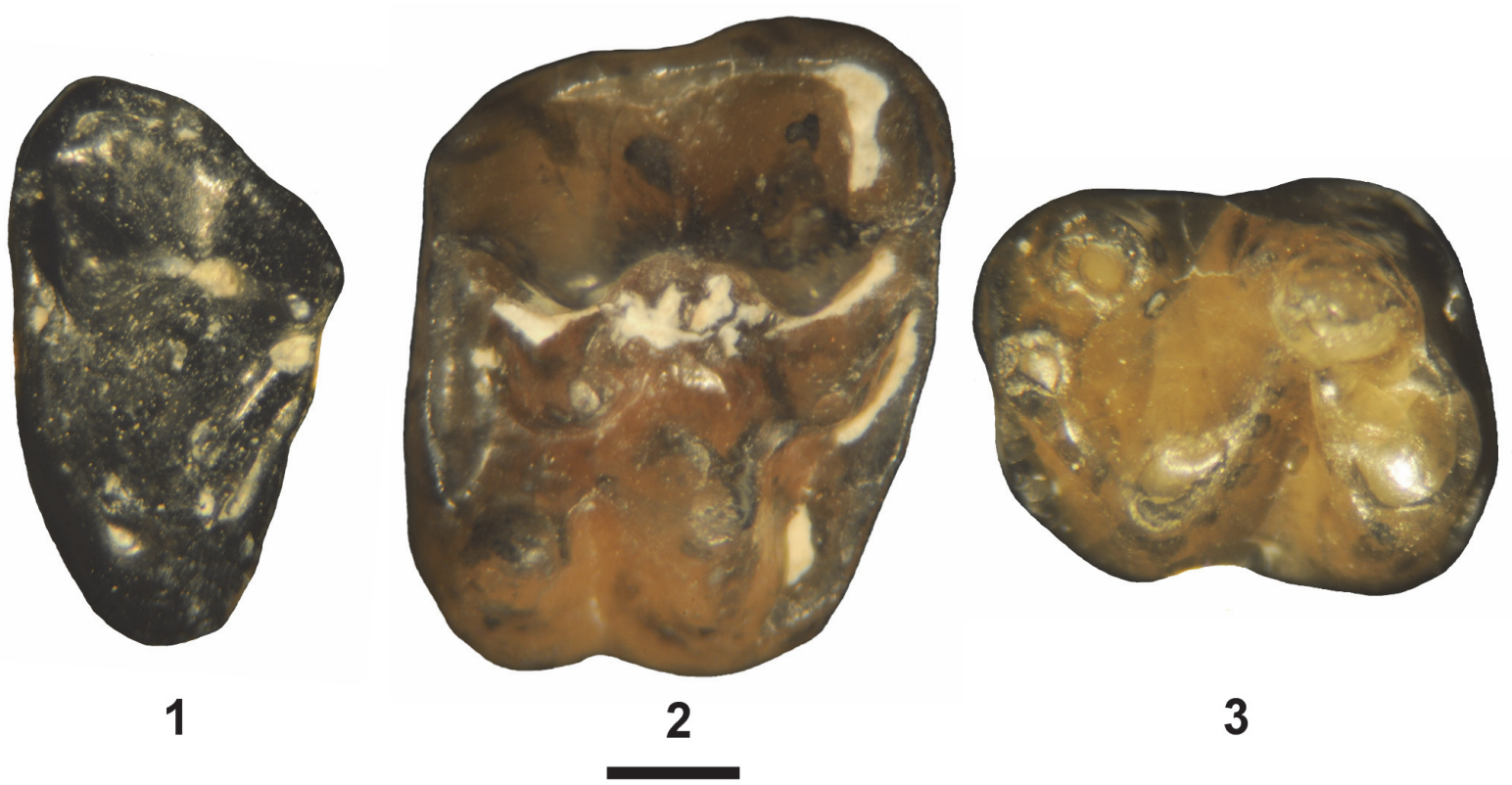

FIGURE 11. Carnivoramorpha and Condylartha from TBM. 1, Viverravus gracilis, LM2 (UCM 95809). 2-3, Hyposodus lepidus: RM1 or 2, UCM 67958 (2); Rm1 or 2, UCM 67956 (3). All occlusal views. Scale bar = $1 \mathrm{~mm}$.

center. A moderately tall cristid obliqua extends from the hypoconid apex to terminate on the posterolabial wall of the metaconid. The anterior, labial, and posterior cingulids are joined as a continuous cingulid.

Remarks. Gazin (1968) provided the first comprehensive review of Hyopsodus wherein he recognized five species from the Bridger Formation based on size. West (1979) reevaluated the systematics of Hyopsodus from the Bridger Formation using a stratophenetic analysis (Gingerich, 1974a, 1974b, 1976) on large, stratigraphically controlled samples, and provided evidence that only three species occur in the formation $(H$. paulus Leidy, 1870 [ $=H$. despiciens Matthew, 1909, and H. marshi Gazin, 1968]; $H$. minusculus Leidy, 1873; and H. lepidus Matthew, 1909). In West's (1979) phylogeny, $H$. paulus and $H$. minusculus are the only species of Hyopsodus present low in the Bridger (Br2, or Bridger B of Matthew [1909]). Hyopsodus minusculus, the smallest species, is not known from higher in the Bridger Formation. However, samples of $H$. paulus progressively exhibited increased size through the upper Bridger $(\mathrm{Br} 3$, or Bridger C-D of Matthew [1909]). Moreover, West (1979) regarded $H$. paulus to have given rise to the smaller $H$. lepidus during the upper Bridger (lower part of Bridger $C$ of Matthew [1909]), with the last occurrence of $H$. lepidus occurring in the lowermost part of Matthew's Bridger $D_{1}$.

The two Hyopsodus specimens from the TBM agree well with the dental measurements provided by West (1979, table 9 ) for $H$. lepidus. West (1979) also utilized the $\log _{10}$ of the M1-2 and m1-2 area (ap x greatest transverse width) to differentiate $H$. paulus from $H$. lepidus from equivalent stratigraphic levels in the lower half of the upper Bridger (Bridger $C-D_{1}$ of Matthew [1909]). The measurements of the M1 or 2 from the TBM are very near the means for the M1 of $H$. lepidus and only slightly smaller than those of the means for the M2 of $H$. lepidus (West, 1979, table 13). The mean $\log _{10}$ for the area of the M1 of $\mathrm{H}$. lepidus is 1.25 and for M2 is 1.36 , and that of the TBM M1 or 2 is 1.29 , whereas the $\log _{10}$ of the M1 and M2 for samples of $H$. paulus from stratigraphically equivalent samples from the upper Bridger (Bridger C-D of Matthew [1909]) are 1.34 and 1.44, respectively. Similarly, the $\mathrm{m} 1$ or 2 from the TBM differs from those of stratigraphically lower samples of $H$. paulus from high in the Bridger $D\left(D_{4}-D_{5}\right.$ of Matthew [1909]) by being smaller (over three standard deviations smaller than the mean $\mathrm{m} 1$ ap and over seven standard deviations smaller than the mean $\mathrm{m} 2 \mathrm{ap}$ ). The $\log _{10}$ of the area of the $\mathrm{m} 1$ or 2 from the TBM is 1.05 , similar to that of $H$. lepidus (mean $\mathrm{m} 1 \log _{10}=$ 1.02, mean $\mathrm{m} 2 \log _{10}=1.08$ ), but significantly 
TABLE 3. Measurements (in mm) of Hyopsodus sp., Uintatherium anceps, Wickia sp., cf. W. brevirhinus, Triplopus sp., cf. T. obliquidens, Epihippus sp., cf. E. gracilis, and Merycobunodon? walshi new species from TBM. Abbreviations are: $a p=$ greatest anteroposterior length; $b=$ broken dimension; $p .=$ partial; $t r$ = greatest transverse width; tra = anterior transverse (trigonid) width; trp = posterior transverse (talonid) width.

\begin{tabular}{|c|c|c|c|c|}
\hline Taxon/Specimen number & Position & ap & tra & $\operatorname{trp}$ \\
\hline \multicolumn{5}{|l|}{ Hyopsodus lepidus } \\
\hline UCM 67956 & M1 or 2 & 3.92 & 4.97 & 4.67 \\
\hline UCM 67958 & $\mathrm{~m} 1$ or 2 & 3.71 & 3.05 & 2.99 \\
\hline \multicolumn{5}{|l|}{ Uintatherium anceps } \\
\hline DMNH 75308 & P3 or 4 & 20.4 & 29.3 & 26.8 \\
\hline DMNH 75310 & p2 & 20.9 & 11.7 & 14.1 \\
\hline DMNH 75309 & $\mathrm{~m} 2$ & 32.3 & 28.3 & 24.1 \\
\hline \multicolumn{5}{|l|}{ Wickia sp., cf. W. brevirhinus } \\
\hline DMNH 75312 & 13 & 21.8 & 22.3 & - \\
\hline DMNH 75306 & $\mathrm{C}$ & 21.2 & 18.1 & \\
\hline DMNH 75311 & $\mathrm{P} 2$ & 20.4 & 19.8 & - \\
\hline DMNH 75305 & M1 & 40.6 & 39.3 & - \\
\hline DMNH 75304 & M3 & 50.8 & 49.1 & - \\
\hline DMNH 75314 & p. p4 & - & - & 27.1 \\
\hline DMNH 75307 & $\mathrm{~m} 1$ & 47.8 & 28.1 & 28.7 \\
\hline \multicolumn{5}{|l|}{ Triplopus sp., cf. T. obliquidens } \\
\hline \multirow[t]{4}{*}{ UCM 69053} & p2 & 7.85 & 4.00 & 4.09 \\
\hline & p3 & 9.94 & - & - \\
\hline & p4 & 10.55 & 6.52 & 7.38 \\
\hline & $\mathrm{m} 1$ & 13.10 & 8.15 & - \\
\hline \multirow[t]{2}{*}{ DMNH 75320} & $\mathrm{p} 4$ & 10.07 & 6.20 & 6.56 \\
\hline & p. m2 & - & - & 8.52 \\
\hline DMNH 75315 & $\mathrm{~m} 1$ & 13.45 & 6.77 & 7.52 \\
\hline \multicolumn{5}{|l|}{ Epihippus sp., cf. E. gracilis } \\
\hline SDSNH 110408 & p3 & 7.40 & 4.35 & 4.70 \\
\hline \multicolumn{5}{|l|}{ Homacodon sp., cf. H. vagans } \\
\hline UCM 95810 & p. p3 & $3.36 \mathrm{~b}$ & $1.51 \mathrm{~b}$ & - \\
\hline \multicolumn{5}{|l|}{ Merycobunodon? walshi n. sp. } \\
\hline UCM 69053 (holotype) & M1 or 2 & 5.98 & 7.71 & 7.19 \\
\hline
\end{tabular}

smaller than that of stratigraphically equivalent samples of $H$. paulus (mean $\mathrm{m} 1 \log _{10}=1.16$, mean $\left.\mathrm{m} 2 \log _{10}=1.25\right)$. The above data strongly supports referral of the two TBM molars to $\mathrm{H}$. lepidus.

Additional species of Hyopsodus have been recognized from the Bridgerian and Uintan of North America as follows: 1) early Uintan (Ui1b) $H$. despiciens Matthew, 1909, from the Washakie Formation, Sand Wash Basin, Colorado (= H. markmani Abel and Cook, 1925, vide West and Dawson, 1975); 2) middle to late Uintan (Ui2-3) $H$. uintensis Osborn, 1902, from the Uinta Formation, Utah; 3) late Uintan (Ui3) H. fastigatus Russell and Wickenden, 1933, of the Swift Current Creek Local Fauna of Saskatchewan $(=H$. uintensis vide Krishtalka [1979], but see also Storer [1984]); 4) 
middle Bridgerian (Br2) Hyopsodus tonksi Eaton, 1982, from the Wapiti Formation of Carter Mountain, Absaroka Range, Wyoming; and 5) early Uintan (Ui1b) H. lovei Flynn, 1991, from the type Tepee Trail Formation, East Fork Basin, Wyoming. Although it should be noted that West (1979) regarded $H$. despiciens as a junior synonym of $H$. paulus, whereas Archibald (1998) and Tsukui (2016) retained $H$. despiciens as a distinct species. West (1979) further regarded $H$. marshi as a junior synonym of $H$. paulus, whereas Tsukui (2016) retained $H$. marshi as a distinct species. Tsukui (2016) also recognized $H$. despiciens as occurring in the Bridger Formation from the Bridger $B_{2}$ through $D_{4}$ of Matthew (1909). Archibald (1998) followed Krishtalka (1979) and regarded $H$. fastigatus as a junior synonym of $H$. uintensis, despite the fact that Storer (1984) resurrected $H$. fastigatus based on a larger sample from the Swift Current Creek Local Fauna. Gazin (1968), Krishtalka (1979), and Storer (1984) noted that $H$. uintensis and $H$. fastigatus are more derived than representatives of Hyopsodus from the Bridger Formation by having the following: 1) a greater degree of molarization of the upper premolars; 2) a greater tendency towards formation of transverse lophs in the upper molars with a deeper valley between the protocone and hypocone (less connection of the protocone and hypocone) and the protoconule and metaconule more strongly connected to the protocone and hypocone, respectively; 3) more obliquely orientated crescentic lower molar cristids (the trigonid and talonid cristids more obliquely angled relative to the anteroposterior axis of the tooth); and 4) a relatively larger m1-3 entoconid. The TBM molars are significantly smaller than those of $H$. uintensis and $H$. fastigatus, and like those of $H$. lepidus, lack the derived states seen in these species wherein the upper molar protocone and hypocone are connected by a cristid labially with a shallower valley between them, the lower molar transverse cristids are less obliquely orientated, and the lower molar entoconids are not as enlarged. Flynn (1991) reported that $H$. lovei shares some of the derived dental characters seen in $H$. uintensis and $H$. sholemi Krishtalka, 1979, including well-developed molar lophodonty, high crowned upper molars, M1-2 with a squared occlusal outline, M1-2 with a large hypocone, a deep lingual valley separating the M1-2 protocone and hypocone, and a reduced hypoconulid on m1-3. The TBM molars are significantly smaller than those of $H$. lovei and lack the derived dental characters seen in the species. The TBM molars differ from those of $H$. despiciens and $H$. marshi by their smaller size (Matthew, 1909; Abel and Cook, 1925; West and Dawson, 1975; West, 1979; Tsukui, 2016). The TBM lower molar further differs from the lower molars of $H$. despiciens by lacking a cingulid between the metaconid and entoconid (Tsukui, 2016). The TBM molars can be easily distinguished from those of $H$. tonksi by the following (Eaton, 1982): 1) less lophidont; 2) much more transverse, with the width larger relative to the length (in $H$. tonksi, molars extremely narrow relative to their lengths); and 3) much less obliquely orientated lower molar cristids.

In summary, based on size and dental proportions, the TBM molars cannot be distinguished from those of $H$. lepidus, but can be eliminated as representing $H$. paulus, $H$. despiciens, $H$. marshi, $H$. uintensis, $H$. fastigatus, and $H$. lovei. They can be further distinguished from those of $H$. uintensis, $H$. fastigatus, $H$. tonksi, $H$. lovei, and $H$. sholemi by lacking the derived molar character states seen in these species. Thus, the TBM molars are referred to $H$. lepidus. In his study, West (1979) did not find any specimens representing $H$. lepidus above the lower level of Bridger $D_{1}$ of Matthew (1909) and considered its lineage had gone extinct. However, Tsukui (2016) reported $H$. lepidus from as high as the Bridger $D_{4}$ of Matthew (1909). Assuming our referral of TBM molars to $H$. lepidus is correct, then the geochronologic range of the species is extended into the earliest Uintan (Ui1a).

$$
\text { Order DINOCERATA Marsh, } 1873
$$

Family UINTATHERIIDAE Flower, 1876

Genus UINTATHERIUM Leidy, 1872a

Uintatherium anceps (Marsh, 1871)

Figure 12.1-3, Table 3

Referred specimens. From DMNH Locality 4673: RP3 or 4, DMNH 75308; Lp2, DMNH 75310; Lm2, DMNH 75309.

Description. Whether the upper premolar is a P3 or 4 cannot be determined because Turnbull (2002) found that these two teeth overlap in dimensions almost completely. The lower molar can be confidently identified as $\mathrm{m} 2$ because it fits well within the non-overlapping observed ranges for this tooth position (Turnbull, 2002).

The P3 or 4 has an oval occlusal outline with an anteroposteriorly compressed V-shaped talon. The paracone is the tallest primary cusp and is connected to the large protocone by a well-developed, tall protoloph. The metacone is compressed anteroposteriorly and connected to the protocone by a moderately strong, tall metaloph. The anterior and posterior cingula are robust. The hypocone is 

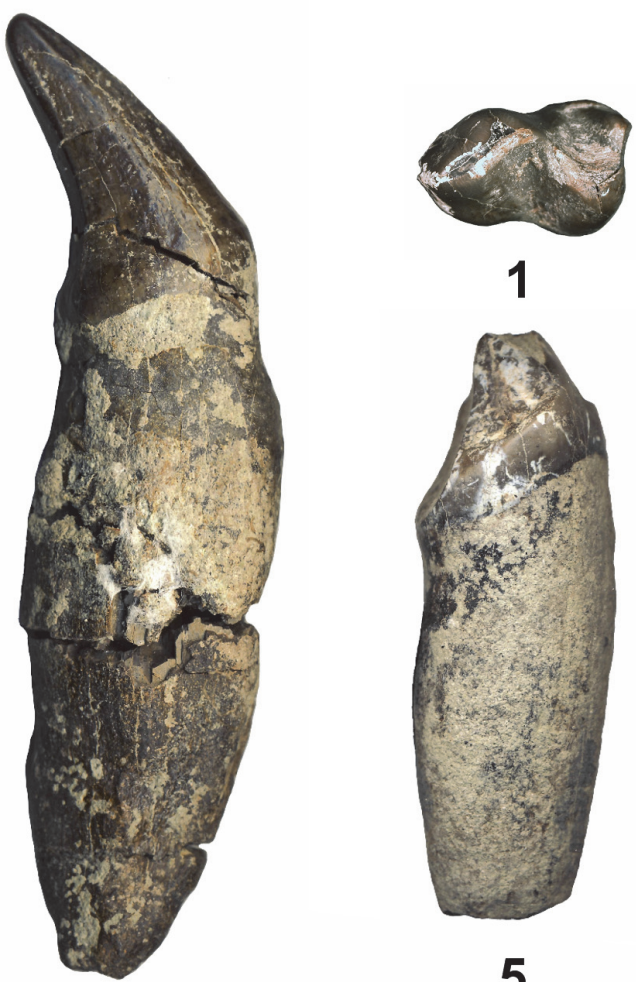

5

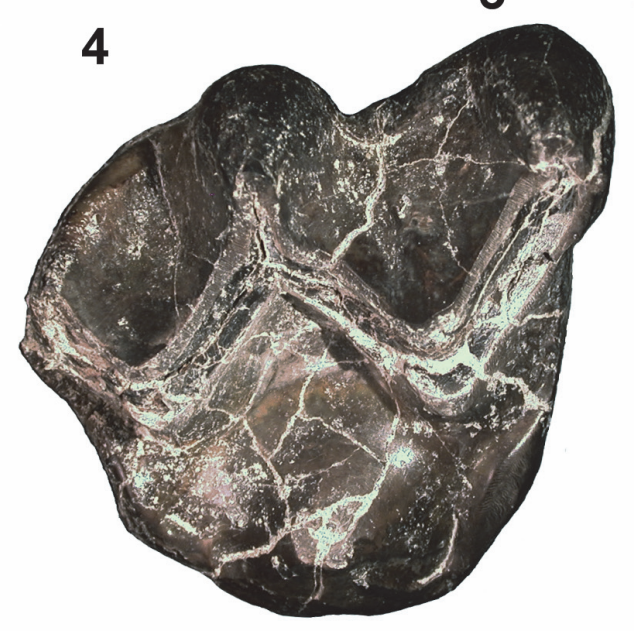

8

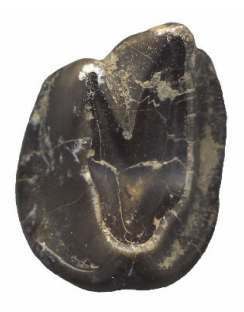

2

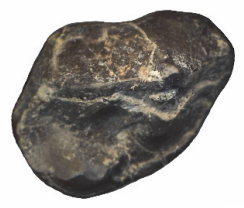

6

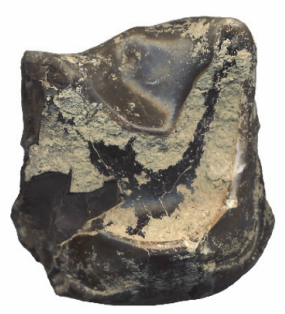

9

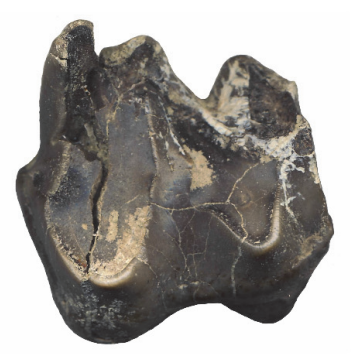

3

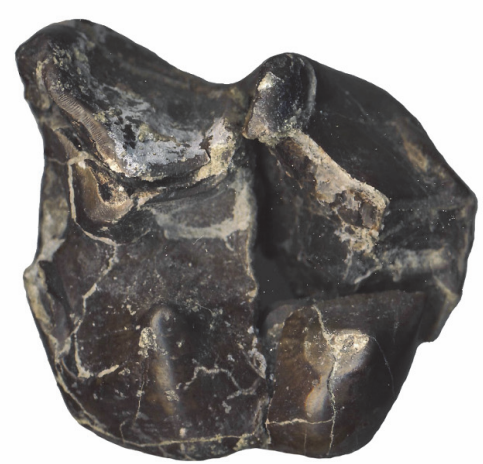

7

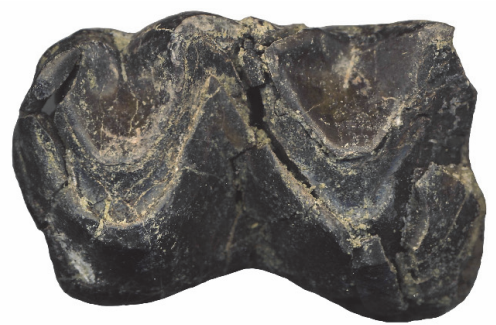

10

FIGURE 12. Dinocerata and Perissodactyla from TBM. 1-3, Uintatherium anceps: Lp2, (DMNH 75310) in occlusal view (1); RP3 or 4 (DMNH 75308) in occlusal view (2); Lm2 (DMNH 75309) in occlusal view (3). 4-10, Wickia sp., cf. W. brevirhinus: LC (DMNH 75306) in labial view (4); RI3 (DMNH 75312) in lingual view (5); RP2 (DMNH 75311) in occlusal view (6); LM1 (DMNH 75305) in occlusal view (7); RM3 (DMNH 75304) in occlusal view (8); partial Lp4? (DMNH 75314) in occlusal view (9); Lm1 (DMNH 75307) in occlusal view (10). Scale bar equals $10 \mathrm{~mm}$.

small and positioned on the posterior cingulum below the level of the lingual portion of the metaloph.

The enamel of the $\mathrm{p} 2$ is broken off at the anterior most portion of the tooth. It has a short, tall, obliquely orientated metalophid that is connected anterolabially to a weak protoconid and posterolingually to a weak metaconid. The hypoconid is relatively distinct and connected anterolingually to the posterior base of the protoconid by a hypolophid, both of which are about three-quarters the height of the metalophid. The entoconid is small, lower in 
height than the hypoconid, and connected to the latter by a low cristid.

The $\mathrm{m} 2$ exhibits the following characters: 1 ) an incipient paraconid; 2) a very tall, slender metaconid; 3) a distinct metastylid connected to the metaconid posteriorly; 4) a strong metalophid, connecting the large protoconid to the metaconid and metastylid; 5) a robust hypoconid, hypolophid, and entoconid; 6) a sharply cuspate hypoconulid, positioned at the middle of the posterior margin of the talonid; and 7) weak anterior and labial cingulids.

Remarks. The three teeth from the TBM are indistinguishable from those Uintatherium anceps (Marsh, 1886; Wheeler, 1961; Lucas and Schoch, 1998; Turnbull, 2002) and are referred to the species. Uintherium anceps is known from the late Bridgerian $(\mathrm{Br} 3)$ through the early Uintan (Ui2), so its occurrence in the TBM is not surprising.

Order PERISSODACTYLA Gray, 1821

Family BRONTOTHERIIDAE Marsh, 1873

Genus WICKIA Mihlbachler, 2008

Wickia sp., cf. W. brevirhinus Mihlbachler, 2008

Figure 12.4-10

Referred specimens. From DMNH Locality 4673: RI3, DMNH 75312; upper left canine, DMNH 75306; RP2, DMNH 75311; LM1, DMNH 75305; RM3, DMNH 75304; partial Lp4?, DMNH 75314; Lm1, DMNH 75307.

Description. The brontothere teeth were recovered from DMNH Locality 4673 (= SDSNH 5844), which is the highest fossil yielding level within the TBM. Considering the similar degree of wear on the teeth, these specimens may represent a single individual. The upper incisor is large and caniform with a distinct lingual cingulum. The upper canine is moderately robust with a weak lingual cingulum that extends along the lingual base to the posterior base of the crown, and is also comparatively short in length, indicating that it may represent a female.

The P2 has an oblique, ovoid occlusal outline. The paracone is the tallest and largest primary cusp. The metacone is distinct and positioned relatively close to the paracone. The protocone is a low cusp positioned posteriorly, below the level of the metacone apex. The preparacrista is a weak ridge that descends rapidly from the paracone apex to join a small parastyle. The anterior, lingual, and posterior cingula are continuous, extending from the parastyle to the lingual base of the protocone and continuing to the posterolabial corner of the tooth.

In the upper molars the paracone and metacone are well developed, tilted lingually, and $\mathrm{V}$-shaped, which together gives the ectoloph a wide W-shaped occlusal outline (selenodont). The parastyle and metastyle are robust, and the protocone is large and conical (bunodont). The anterior cingulum is prominent with a distinct cuspule present on its anterolingual portion (= anterolingual cingular cusp of Mihlbachler [2008]). A paraconule and metaconule are lacking. The M1 differs from the $\mathrm{M} 3$ by being smaller and relatively more transverse posteriorly due the presence of a large, conical hypocone, which is lacking on $\mathrm{M} 3$, and by having slightly weaker lingual and posterior cingula.

The $\mathrm{m} 1$ is almost complete, missing only a small portion of the posterior wall of the tooth. The occlusal outline is rectangular. The trigonid and talonid are well developed and, with wear, form a Wshaped lophid pattern in labial view (= M-shaped in lingual view). The protoconid and hypoconid are robust. The paraconid is weak, slightly obliquely compressed and connected to the protoconid by a strong paralophid. The metaconid is distinct, tall, and connected to the protoconid by a strong metalophid. A thick cristid obliqua extends anterolingually from the hypoconid to posterior wall of the metaconid. The hypolophid is well developed and extends posterolingually from the protoconid to the entoconid. The anterior, lingual, and posterior cingulids are connected, forming a continuous cingulid. A second partial cheek tooth, which probably represents $\mathrm{p} 4$, is only represented by the talonid, which is indistinguishable from the $\mathrm{m} 1$ talonid except for its slightly smaller size.

Remarks. The taxonomy of the Brontotheriidae was convoluted until Mihlbachler (2008) provided a comprehensive revision of the family. The only moderately large brontothere from the Twin Buttes Member $(\mathrm{Br} 3)$ of the Bridger Formation is Telmatherium validus Marsh, 1872a, which co-occurs with the smaller Mesatirhinus junius (Leidy, 1872b). Telmatherium validus is also known from the lower Adobe Town Member of the Washakie Formation (Washakie A of Granger [1909]). The teeth of Telmatherium validus are very similar in size and occlusal morphology to those of Metatelmatherium ultimum (Osborn, 1908) from the late Uintan of Utah and Wyoming and Wickia brevirhinus from the early Uintan of Wyoming (Mihlbachler, 2008). These three taxa differ in certain cranial characters, but share a number of dental characters, including the following (Mihlbachler, 2008): 1) large caniform upper incisors; 2) a simple $\mathrm{P} 1$; 3) a distinct P2 metacone; 3) upper premolars with a weak preprotocrista and lacking hypocones; 4) upper molars with weak labial ribs, thinned enamel on the 
lingual side of the ectoloph, a V-shaped paracone and metacone, and lacking a central fossa and cingular parastylar shelf; 5) large submolariform lower incisors; 6) an elongated p2 trigonid; 7) p2-3 lacking a metaconid; 8) p4 with a metaconid; 9) lower molars with shallow basins; and 10) a slender m3. Upper molar paraconules and metaconules are lacking in $M$. ultimum and $W$. brevirhinus, and are usually also lacking in $T$. validus. Wickia brevirhinus differs from $T$. validus by having upper molars with anterolingual cingular cusps present and a more poorly developed p2 talonid. Metatelmatherium ultimum also has upper molar anterolingual cingular cusps present, but differs from $W$. brevirhinus by having a better developed $\mathrm{p} 2$ talonid.

Mihlbachler (2008) noted that early Uintan $W$. brevirhinus appears to be morphologically intermediate between late Bridgerian $T$. validus and early Uintan M. ultimum. The TBM brontothere teeth exhibit the shared dental characters seen in $T$. validus, W. brevirhinus, and M. ultimum, and its M1 and $\mathrm{M} 3$ have a very distinct cusp on the anterolingual cingulum, which is lacking in $T$. validus. For this reason, we regard the TBM brontothere to represent a form that is more closely related to $W$. brevirhinus and $M$. ultimum than to $T$. validus. Since M. ultimum is not known to occur in the early Uintan, it would seem reasonable to tentatively assign the TBM brontothere to early Uintan Wickia, as Wickia sp., cf. $W$. brevirhinus. Although we recognize that this referral is speculative until additional more complete specimens of the TBM brontothere are available, including cranial material, the presence of distinct anterolingual cingular cusps on the upper molars of the TBM brontothere eliminates its referral to $T$. validus. Assuming that the generic assignment is correct, then Wickia sp., cf. W. brevirhinus would represent another taxon first appearance for the TBM, occurring high in the section at DMNH Locality 4673.

Family HYRACODONTIDAE Cope, 1879

Genus TRIPLOPUS Cope, 1880

Triplopus sp., cf. T. obliquidens (Scott and Osborn, 1887)

Figure 13.1-4, Table 3

Referred specimens. From UCM Locality 92189 : partial left dentary with $\mathrm{p} 2$, partial $\mathrm{p} 3$, and $\mathrm{p} 4-\mathrm{m} 1$, UCM 69053. From DMNH Locality 5064: partial left dentary with $p 1$ alveolus, roots of $p 3$, complete $p 4$, partial $\mathrm{m} 1-2$, and unerupted $\mathrm{m} 3, \mathrm{DMNH} 75320$. From DMNH Locality 4673: partial m1, DMNH 75315.

Description. UCM 69053 consists of a partial dentary with the alveolus for $\mathrm{p} 1$, a complete $\mathrm{p} 2$ and $\mathrm{p} 4$, a p3 that is missing a portion of the labial edge of the tooth, including the protoconid and hypoconid, and a partial $\mathrm{m} 1$ that is missing the labial half of the hypoconid. DMNH 75320 is a partial dentary with a complete $\mathrm{p} 4$, the posterior half of $\mathrm{m} 2$ and an unerupted $\mathrm{m} 3$ positioned deep in the alveolar crypt, indicating that it represents a juvenile. The enamel surfaces on the teeth of DMNH 75320 are somewhat eroded and etched, especially along the labial side of the p4. DMNH 75315 is a partial $\mathrm{m} 1$ that is missing a portion of the enamel along the metalophid.

The dentary is moderately deep with a depth below $\mathrm{m} 1$ of $19.6 \mathrm{~mm}$ for DMNH 75320 and 22.6 $\mathrm{mm}$ for UCM 69053. Three mental foramina are present with the largest one positioned below the posterior root of $\mathrm{p3}$, whereas the other two are smaller with one positioned below the anterior root of $\mathrm{m} 1$ (or just slightly posterior of the anterior root) and one below the anterior root of $p 2$. An alveolus is present anterior to p2 on both specimens, indicating that a $\mathrm{p} 1$ was present.

The $\mathrm{p} 2$ is premolariform. The protoconid is the tallest and largest primary cuspid positioned slightly anterior to the center of the tooth. The paraconid is a distinct, relatively tall cuspid that is separated from the short paralophid by a small, but distinct notch. The protolophid extends posterolingually from the protoconid apex to an incipient metaconid (slight bulge) and then descends rapidly to terminate at the anterolingual edge of the talonid. The hypoconid is anteroposteriorly elongated and connected anteriorly to the protoconid forming a nearly straight, continuous lophid. The talonid basin is small and open at the posterolingual corner. A hypolophid is lacking.

Although the p3 is damaged, certain characters can still be discerned. It is submolariform. The paralophid extends from the protoconid in a tall, gentle arc to the anterolingual corner of the tooth. The protolophid is strong and extends as a slightly oblique lophid from the protoconid to join a tall metaconid. A slight swelling (incipient entoconid) is present on the lingual border of the talonid. The talonid is open posteriorly.

The p4 is submolariform. The paralophid is moderately well developed, descending in an arc from the protoconid apex to terminate just labial of the anterolingual corner of the trigonid. The protoconid is the tallest primary cusp and is connected to the metaconid by a strong, tall protolophid. The hypoconid is anteroposteriorly elongated and connected anteriorly to the posterior wall of the trigonid by a relatively straight, tall metalophid (= cristid 

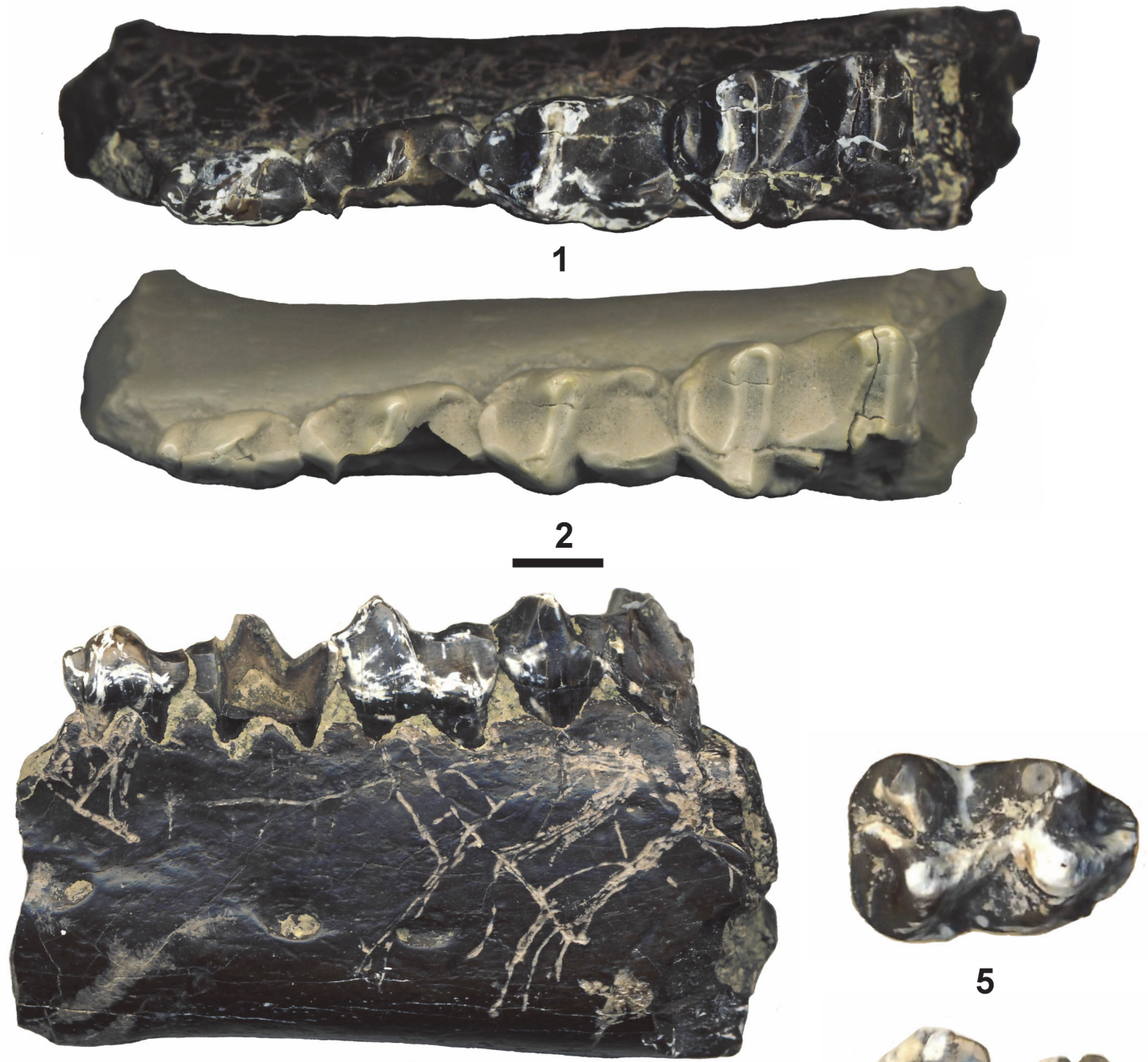

5
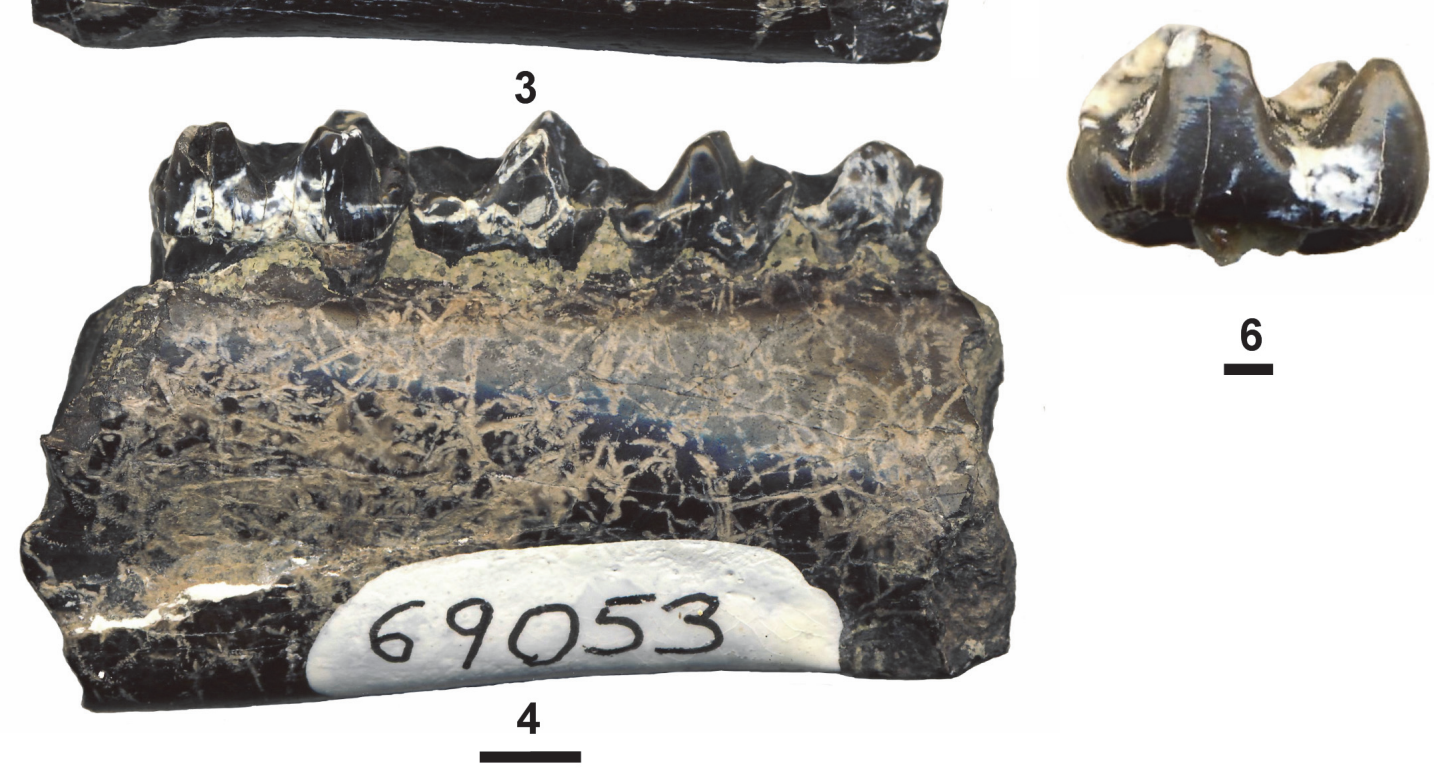

6

FIGURE 13. Perissodactyla from TBM. 1-4, Triplopus sp., cf. T. obliquidens, partial left dentary with alveolus for p1, p2, partial p3, p4 and partial m1 (UCM 69053 with 1, 3-4 original specimen, 2 cast showing detail better) in occlusal (12), labial (3) and lingual (4) views. 5-6, Epihippus sp., cf. E. gracilis, Rp3 (SDSNH 110408) in occlusal (5) and lingual (6) views. Scale bars for 1-2 and 3-4 equals $5 \mathrm{~mm}$. Scale bar for 5-6 equals $1 \mathrm{~mm}$. 
obliqua). A small, oval entoconid is present on the labial edge of the talonid. A hypolophid is lacking resulting in the talonid being open posteriorly.

The $\mathrm{m} 1$ has a rectangular occlusal outline. The protoconid, metaconid, hypoconid, and entoconid are tall and equal in height. The paralophid is well developed and extends from the protoconid as a wide, continuous, slight arc to terminate at the anterolingual corner of the trigonid. The protolophid and hypolophid are tall, complete lophids connecting the protoconid to the metaconid and the hypoconid to the entoconid, respectively, and are inclined slightly posteriorly and nearly parallel to each other. The metalophid is well developed, forming a nearly straight, tall lophid extending anteriorly from the hypoconid to terminate on the posterior wall of the trigonid, slightly below the protolophid. A very small hypoconulid is present, positioned centrally on a weak posterior cingulid. The occlusal morphology of the posterior half of the $\mathrm{m} 2$ is nearly identical to that of the $\mathrm{m} 1$ except that it has a slightly better developed, but still weak, hypoconulid.

The only specimen with an m3 is DMNH 75320 , where it is unerupted and buried within the alveolar crypt. Radiographs were taken of $\mathrm{DMNH}$ 75320. Although detailed occlusal morphology could not be discerned because of the mineralization of the enamel and surrounding bone, the radiographic outline of the $\mathrm{m} 3$ showed the bilophodont pattern and lack of a well-developed, protruding hypoconulid, characters that are typical of Triplopus.

Remarks. The taxonomic history of Triplopus and certain other middle Eocene tapiroid and rhinocerotoid taxa from the Bridger, Washakie, and Uinta formations is complicated. Cope (1873a, 1873b) described Hyrachyus implicatus based on two specimens, but neither were designated as a holotype; specimen number one (AMNH FM 5072) consists of a partial skull with partial (all teeth damaged) RP3-M3 and LP4-M3 from Cottonwood Creek, Bridger Formation, and specimen number two (AMNH FM 5078) consists of a partial skull with a partial P1, P2, partial P3, P4, and partial M13 and associated partial right dentary with Rp2-m3 from the Washakie Formation south of Bitter Creek. Cope (1884) transferred AMNH FM 5072 to Hyrachyus agarius Leidy, 1871, and restricted $H$. implicatus to AMNH FM 5078, making it the lectoholotype. Contrary to Cope (1884), Wood (1934) reidentified AMNH FM 5072 as representing $H$. affinis Marsh, 1871, which Radinsky (1967) synonymized with Hyrachyus modestus Leidy, 1870.
Wood (1934) erected a new genus Ephyrachyus based on AMNH FM 5078 along with a referred lower dentition (AMNH FM 12672) from the upper Bridger Formation (Bridger $\mathrm{D}, \mathrm{Br} 3$ ), making $E$. implicatus the type species. Radinsky (1967) synonymized Ephyrachyus with the early hyracodontid genus Triplopus, which made Triplopus cubitalis Cope, 1880, from the Washakie Formation the type species and transferred E. implicatus to Triplopus. Based on an upper dentition with the alveolus for P1 and P2-M3 (PU 10166), Scott (1883) described Desmatotherium guyotii, which he regarded as closely related to Hyrachyus Leidy, 1871. The provenance of the holotype of $D$. guyotii is uncertain and could be either the Washakie Formation or Bridger Formation (Scott, 1883; Granger, 1909; Matthew and Granger, 1925; Matthew in Osborn, 1909; Gazin, 1956; Radinsky, 1963). Radinsky (1963) believed the differences cited by Scott (1883) to differentiate $D$. guyotii from Hyrachyus are characters similar to those that define Helaletes Marsh, 1872b. Based on a partial maxilla with M1-3 (PU 10095), Osborn et al. (1878) described Hyrachyus intermedius from the Bridger Formation. Wood (1934) regarded $H$. intermedius as generically distinct from Hyrachyus and referred it to a new genus Chasmotheriodes, which he questionably considered a member of the Helaletidae. Radinsky (1963) synonymized Lophiodon nanus Marsh, 1871, with Helaletes boops Marsh, 1872b, as Helaletes nanus and regarded Chasmotheriodes and Desmatotherium as junior synonyms of Helaletes. Radinsky (1963) also regarded D. guyotii as a junior synonym of Helaletes intermedius and reassigned the lower dentition (AMNH FM 12672), previously assigned by Wood (1934) to $E$. implicatus from the upper Bridger Formation, to Helaletes intermedius, which was followed by Schoch (1984). Most recently, Colbert and Schoch (1998) resurrected Desmatotherium as a valid genus with $D$. intermedius as the type species and questionably regarded $D$. guyotii as a junior synonym of $D$. intermedius. Based on a partial upper dentition (PU 10403) from the Uinta Formation, Scott and Osborn (1887) erected a new genus and species, Prohyracodon intermedium, and, based on a partial lower dentition (PU 10402) from the Uinta Formation, named Hyrachyus obliquidens. Scott and Osborn (1889) later regarded these species as conspecific and also cogeneric with Triplopus, and transferred them to a single species as $T$. obliquidens. Peterson (1919) resurrected Prohyracodon and reassigned $T$. obliquidens to the genus as $P$. obliquidens, which was also followed by 
Wood (1927). Radinsky (1967) placed Prohyracodon back in synonymy with Triplopus and reassigned $P$. obliquidens back to Tripolpus. Wood (1927) erected the genus Eotrigonias, to which he assigned two new species, the type species $E$. rhinocerinus from the Uinta Formation and E. petersoni, from the Washakie Formation, and described a new species of Triplopus, T. grangeri, from the Uinta Formation. Radinsky (1963) placed Eotrigonias in synonymy with Triplopus, which transferred E. rhinocerinus to Triplopus. Radinsky (1967) also placed $E$. petersoni in synonymy with $T$. implicatus and $T$. grangeri in synonymy with $T$. obliquidens. Stock (1936) described a new species from the latest Uintan Strathearn Local Fauna of the Sespe Formation of California (see also Kelly, 1990; Kelly et al., 2012), which he questionably assigned to Triplopus, as T.? woodi. McCarroll et al. (1996) documented the occurrence of $T$. cubitalis and $T$. implicatus in the Washakie Formation, wherein these species are restricted the early Uintan middle unit of the Adobe Town Member. Most recently, Prothero (1998b) regarded Triplopus as the most common rhinocerotoid in the Uintan of North America with a restricted range from the early Uintan to the Duchesnean.

In summary, four species and one questionably referred species of Triplopus are currently recognized (Prothero, 1998b); T. cubitalis and T. implicatus from the Washakie Formation of Wyoming, $T$. obliquidens and $T$. rhinocerinus from the Uinta Formation of Utah, and T.? woodi from the Sespe Formation of California.

The lower teeth of UCM 69053 from the TBM are very similar in size to those of the only known lower dentition of Desmatotherium intermedius (AMNH FM 12672). However, they can be easily distinguished from those of $D$. intermedius by the following: 1) p1 present (absent in $D$. intermedius); 2) the p2 lacks an entoconid, p3 with a slight bulge (incipient entoconid) at the posterolingual corner of the tooth, and p4 with a low, very small, round entoconid (in $D$. intermedius, p2 with a small entoconid, p3 with a large entoconid, and p4 with a very large entoconid, latter nearly as tall as the hypoconid); 3 ) the p2 and p4 talonid widths (p3 broken in UCM 69053) significantly less transversely expanded relative to the trigonid widths ( $\mathrm{p} 2$ tra/trp $=0.97$ and $p 4$ tra/trp $=0.90$ in UCM 69053 versus p2 tra/trp $=0.72$ and p4 tra/trp $=0.79$ in D. intermedius); 4) p2 with distinct, tall paraconid, about $80 \%$ of the height of the protoconid (in D. intermedius, paraconid shelf-like and lower, about $40 \%$ of the height of the protoconid); 5) the p4-m1 paralophid slightly better developed and taller, extending anterolingually from the protoconid as a descending arc; 6) p4 metalophid extends anteriorly as a relatively straight ridge from the hypoconid to terminate on the posterior wall of the protoconid just lingual of the protoconid apex (in D. intermedius, p4 metalophid more obliquely orientated, extending anterolingually from the hypoconid to terminate further lingually on the posterior wall of the trigonid, resulting in V-shaped hypoconid occlusal outline); and 7 ) the $\mathrm{m} 1$ metalophid is well developed, extending from the hypoconid to the posterior wall of the trigonid, closing off the valley between the protoconid and hypoconid (in $D$. intermedius, $\mathrm{m} 1$ metalophid essentially lacking, only represented by a rapidly descending low ridge not extending to the posterior wall of the trigonid, resulting in an open valley between the protoconid and hypoconid). The lower teeth of UCM 69053 are also similar in size to those of Uintan Isectolophus annectans Scott and Osborn, 1887, but differ by the following (Troxell, 1922; Radinskyi, 1963, 1967; Schoch, 1983; Colbert and Schoch, 1998; Prothero, 1998b; Lucas et al., 2003): 1) relatively higher crowned (more hypsodont) resulting in greater lophodonty; 2) p2-4 less anteroposteriorly expanded relative to $\mathrm{m} 1$, especially p2 (p2 ap 10\% shorter relative to $\mathrm{m} 1$ ap); 3) p2 lacks distinct fold at junction of metalophid with protoconid; 4) p4-m1 labial cingulids more weakly developed; 5) p4-m1 metalophids better developed and straighter; and 6) m3 lacking a large, protruding hypoconulid.

All of the above dental characters that differentiate UCM 69053 from D. intermedius and $I$. annectans are also diagnostic for Triplopus (Radinsky, 1967; McCarroll et al., 1996; Prothero, 1998b), so the TBM specimens can be confidently assigned to the genus. Species of Triplopus are differentiated primarily by size (McCarroll et al., 1996; Prothero, 1998b). The lower teeth of the UCM 69053 are larger than those of $T$. cubitalis, slightly smaller than those of T. implicatus and Triplopus? woodi, much smaller than those of $T$. rhinocerinus, and within the observed size ranges for those of $T$. obliquidens (except $\mathrm{p} 2$, which is slightly smaller). However, until more complete dentitions including upper teeth from the TBM are available for further comparisons, UCM 69053 is only compared to $T$. obliquidens, as Triplopus sp., cf. T. obliquidens.

Family EQUIDAE Gray, 1821

Genus EPIHIPPUS Marsh, 1878

Epihippus sp., cf. E. gracilis (Marsh, 1871)

Figure 13.5-6, Table 3 
Referred specimen. From SDSNH Locality 5844: Rp3, SDSNH 110408.

Description. SDSNH 110408 has a forward projecting paralophid, a character that is typical of the p3 of Epihippus. It can be differentiated from the dp3 of Epihippus (MacFadden, 1980; Hanson, 1996; McCarroll et al., 1996) by being slightly wider relative to its length and by having a better developed paralophid (larger and more expanded anteriorly). In the p4 of Epihippus, the paralophid is slightly taller and relatively shorter than that of the p3, wherein it extends slightly less anterolingually from the protoconid to about the midline of the tooth and then turns sharply posteriorly, like those of $\mathrm{m} 1-3$.

SDSNH 110408 is fully molariform with the metaconid and entoconid well developed and about equal in size to the protoconid and the entoconid, respectively. The paralophid is a robust, relatively tall cristid extending lingually in a wide arc from the protoconid apex to the anterolingual base of the metaconid. The metaconid is expanded anteroposteriorly with a distinct metastylid present just posterior to its apex. A complete protolophid is present, connecting the protoconid to the metaconid. The posterior cingulid (postcristid) extends posterolingually from about the center of the hypolophid to the posterior base of the entoconid.

Remarks. The p3 of Epihippus is more molariform than that of Orohippus and further differs by the following (Granger, 1908; Stirton, 1940; Forstén, 1971; MacFadden, 1975, 1980, 1998; Hanson, 1996; McCarroll et al., 1996; Kelly and Murphey, 2016b): 1) a better developed paralophid (in Orohippus, paralophid lower and less transversely expanded); 2) the metaconid nearly equal in size to the protoconid (in Orohippus, metaconid significantly smaller than the protoconid); 3 ) the entoconid nearly equal in size to the hypoconid (in Orohippus, entoconid significantly smaller than the hypoconid); and 4) a tendency to bifurcate metaconid at its apex due to the presence of a small metastylid just posterior to the metaconid apex (in Orohippus, a distinct metastylid usually lacking). SDSNH 110408 agrees well with all of the above differentiating characters of the $\mathrm{p} 3$ of Epihippus and is assigned to the genus.

Two species of Epihippus are currently recognized from the Uintan; Epihippus gracilis (including E. parvus Granger, 1908), and Epihippus uintensis Marsh, 1875. A third species that is sometimes included in Epihippus is Duchesnehippus intermedius Peterson, 1931, from the Duchesnean (e.g., MacFadden, 1980, 1998; Hanson, 1996). How- ever, this species exhibits even further molarization of the lower premolars (especially p2), greater hypsodonty and increased size, which justifies its referral to a separate genus from Epihippus (Rasmussen et al., 1999; Kelly et. al., 2012; Kelly and Murphey, 2016b). Species of Epihippus are differentiated primarily by size, with $E$. uintensis being larger than E. gracilis. The Epihippus p3 from the TBM agrees well in size to those $E$. gracilis (Granger, 1908; MacFadden, 1980, table 1) and probably represents this species. However, until additional material of the TBM Epihippus is available to confirm its specific assignment, SDSNH 110408 is left in open nomenclature as Epihippus sp., cf. E. gracilis.

Order ARTIODACTYLA Owen, 1848

Family HOMACODONTIDAE Marsh, 1894

Genus HOMACODON Marsh, 1872a

Homacodon sp., cf. $H$. vagans Marsh, 1872a

Figure 14, Table 4

Referred specimen. From UCM 92189: partial Rp3, UCM 95810.

Description. The partial $p 3$ has the anterior portion of the crown broken off near the anterior half of the protoconid. It has a tall, central protoconid and a central posterior ridge with minor irregularities (bumps) that descends posteriorly from the protoconid apex to join a centrally positioned, distinct cuspid (hypoconulid?) at the posterior edge of the talonid. A second posterior ridge is present that is lower in height than the central posterior ridge. This second ridge rapidly descends posteriorly from the posterolingual edge of the protoconid then continues along the lingual border and then turns labial to join the central talonid cuspid. A third low, short ridge is present that extends labially from the central talonid cuspid to the labial edge of the tooth. A metaconid is lacking.

Remarks. Stucky (1998) briefly proposed that more than one species of Homacodon may be present in the Bridger Formation. However, besides relative size differences, he did not elaborate much on what other characters can be used to distinguish them, and his proposal has not yet been supported by a subsequent publication. The holotype of Homacodon vagans came from the Twin Buttes Member (Br3, Bridger D) at Henry's Fork (West, 1984; Stucky, 1998). Although broken, UCM 95810 agrees well in size and occlusal morphology with the p3 of $H$. vagans, including two posteriorly descending ridges from the protoconid (one centrally and one lingually positioned) that join a centrally positioned talonid cuspid and the absence of a metaconid. The $\mathrm{p} 3$ of $H$. vagans has 


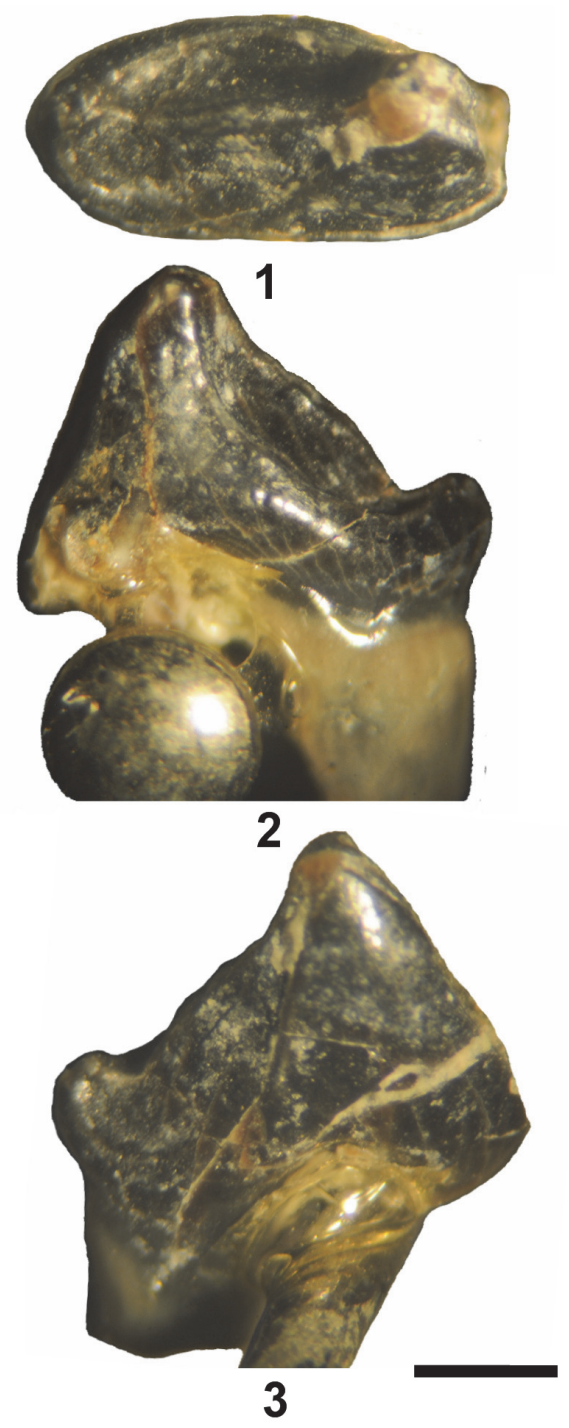

FIGURE 14. Homacodon sp., cf. H. vagans from TBM. Partial Rp3 (UCM 95810) in occlusal (1), lingual (2), and labial (3) views. Scale bar equals $1 \mathrm{~mm}$.

a small, but distinct paraconid present. Whether UCM 95810 possessed a paraconid cannot be determined because the anterior portion of the tooth is broken off. UCM 95810 probably represents $H$. vagans, but because its incomplete state does not allow further comparison, we refer it to Homacodon sp., cf. $H$. vagans.

Family OROMERYCIDAE Gazin, 1955 Genus MERYCOBUNODON Golz, 1976 Merycobunodon? walshi new species

Figure 15, Table 3-4

Holotype. RM1 or 2, UCM 67888.
Type locality. UCM 92189, $2 \mathrm{~m}$ above the base of the Turtle Bluff Member, Bridger Formation, Wyoming.

Distribution and age. Known only from type locality. Earliest Uintan (Ui1a).

Diagnosis. Merycobunodon? walshi differs from the M1-2 of Merycobunodon littoralis Golz, 1976, by the following: 1) more transverse occlusal outline (more rectangular rather than square, with ap shorter relative to tra); 2) primary cusps slightly less crescentic; 3 ) an incomplete lingual cingulum (does not extend across lingual base of protocone and hypocone); 4) an incipient entostyle between the protocone and hypocone; and 5) slightly smaller size. It differs from the M1-2 of species of Protylopus Wortman, 1898, by the following: 1) lower crowned with less crescentic primary cusps (more bunoselenodont); 2) weaker labial ribs on paracone and metacone; 3) weaker development of centrocrista and mesostyle; 4) slightly weaker enamel crenulations; and 5) smaller in size.

Etymology. Patronym for the late Stephen L. Walsh of the Department of Paleontology, San Diego Natural History Museum, California, in honor of his extensive contributions to our understanding of Eocene mammals.

Description. UCM 67888 consists of an upper molar, either M1 or M2, that is well worn and has a small portion of the enamel broken away from the anterior border of the paracone and the posterolabial wall of the metaconule. It has a transversely expanded occlusal outline with bunoseleodont primary cusps. The paracone is nearly equal in size to the metacone and both have weakly developed labial ribs. The protocone is the largest primary cusp and the metaconule is large, only slightly smaller than the protocone, and positioned at the posterolingual corner of the tooth. The centrocrista between the paracone and metacone is moderately developed with a distinct mesostyle at its center. The postmetacrista is moderately strong, extending from the metacone posteriorly to join a small metastyle. The enamel covering the preparacrista is broken away, but a ridge on the underlying dentine indicates that its development was about equal to that of the postmetacrista. The postprotocrista is merged lingually and labially with the premetaconule crista and a distinct inflection is present between their labial termini along with an isolated enamel islet positioned slightly anterior and labial of the inflection. The postmetaconule crista extends labially in a gentle arc from the metaconule to join with the metastyle. The labial cingulum is complete, extending from the parastyle 
TABLE 4. Comparison of dental characters of M1 or 2 of Merycobunodon? walshi to the M1-2s of other middle Eocene oromeryicids and homacodonts (Mercobunodon littoralis, Protylopus stocki, Protylopus annectans, Protylopus pearsonensis, Oromeryx plicatus, Malaquiferus tourteloti, Helohyus milleri, Antiacodon pygmaeus, Homacodon vagans, Bunomeryx montanus, Hylomeryx annectans, Mytonomeryx scotti, Pentacemylus progressus, Mesomeryx grangeri and Apriculus praeteritus). Shared characters are shown in bold.

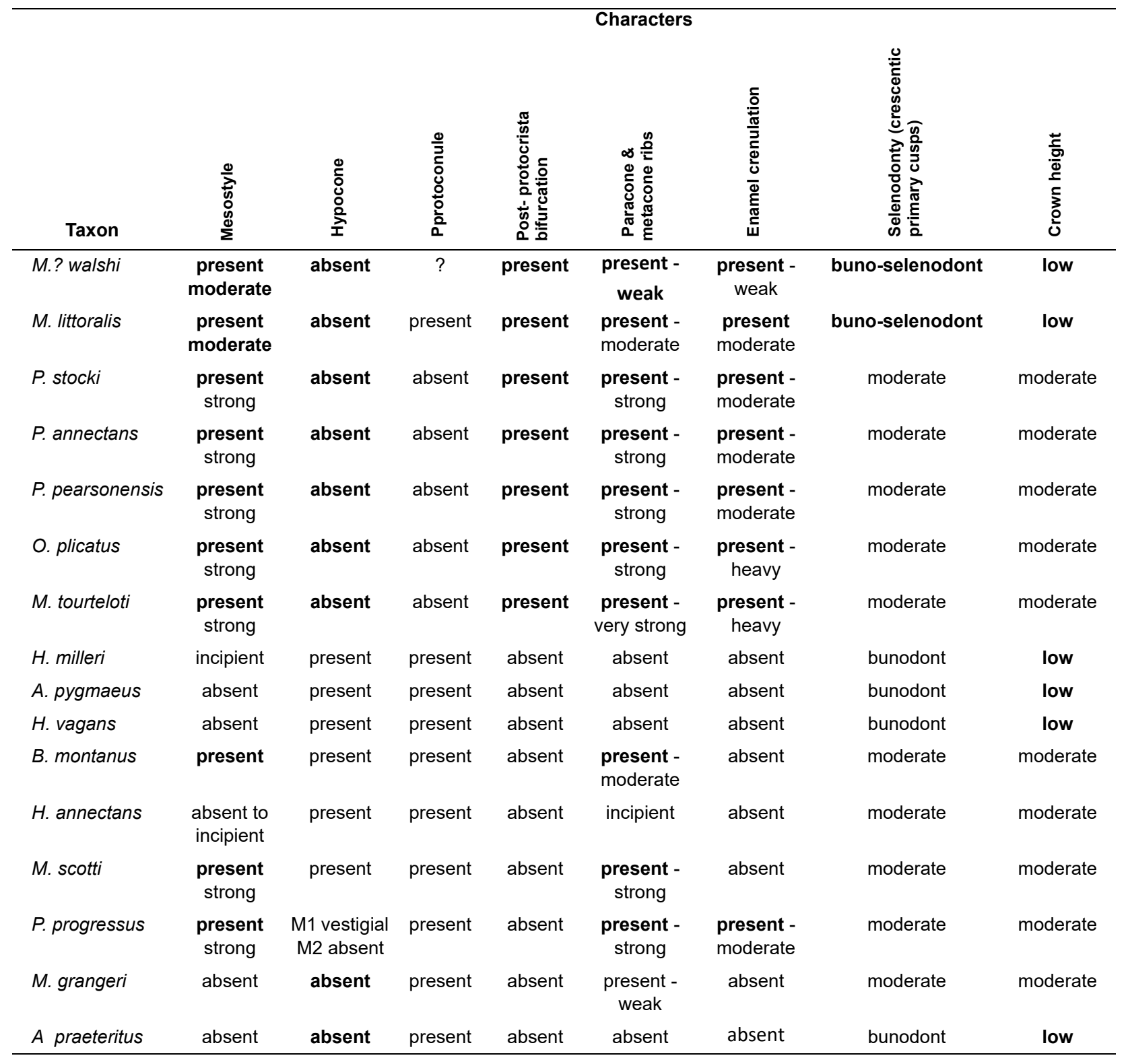

across the labial bases of the paracone and metacone to terminate at the metastyle. The anterior cingulum is moderately strong, extending labially from the anterolingual edge of the protocone to the parastyle. The lingual cingulum extends from the posterior wall of the protocone to the anterior wall metaconule with a central, cuspate swelling (incipient entostyle) present near its center. The enamel is finely crenulated. A hypocone is lacking.
Remarks. When the molar dental characters of UCM 67888 are compared to those of other small, middle Eocene artiodactyls, it exhibits the most similarity to those of the Oromerycidae (Table 4). However, the presence or absence of a small protoconule cannot be determined for UCM 67888 because of its advanced wear stage. In homacodonts, a distinct protoconule is present, which, even in advanced wear, can be identified by distinct indentations anteriorly and posteriorly along 


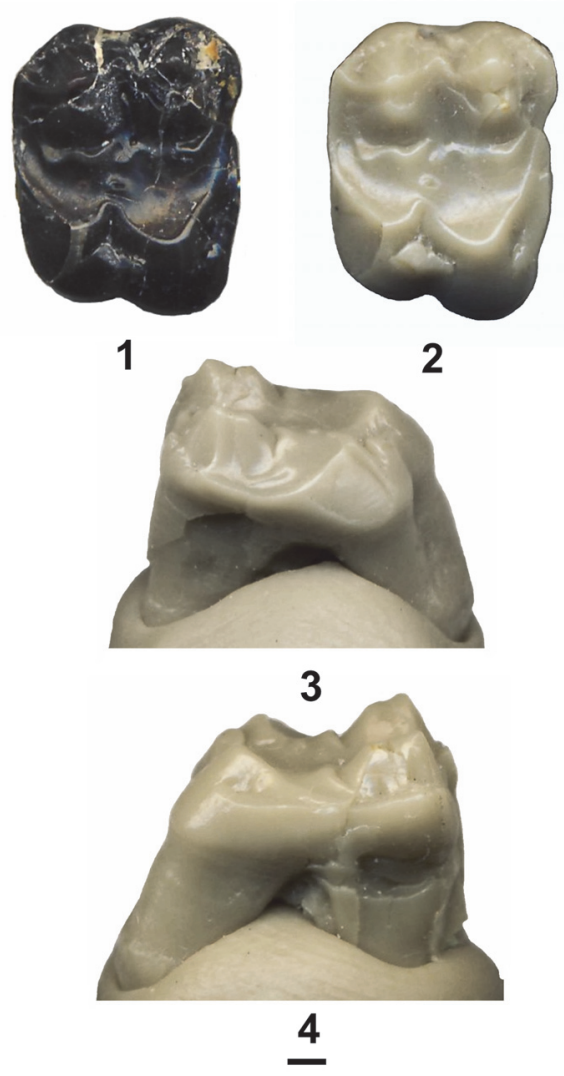

FIGURE 15. Merycobunodon? walshi new species from TBM. RM1 or 2 (UCM 67888, holotype, with 1 original specimen, 2-4 cast showing detail better) in occlusal (12), posterior (3), and anterior (4) views. Scale bar equals $1 \mathrm{~mm}$.

the preprotocrista that outline the position of the protoconule (Gazin, 1955; Prothero, 1998a; Stucky, 1998). In most homacodonts, the metaconule is moderately large and positioned labial of a distinct hypocone, whereas in UCM 67888 , a hypocone is not present and the metaconule is greatly enlarged forming a primary cusp positioned at the posterolingual corner of the tooth, like those of the Oromerycidae (Gazin, 1955; Prothero, 1998a; Stucky, 1998). The primitive oromerycid Merycobunodon littoralis from the early Uintan (Ui1b) of southern California is only known from a small number of upper cheek teeth including a dP4, an associated, moderately worn P4-M1 and an associated, unworn M1-2 (Golz, 1976). In M. littoralis, a small, but distinct, protoconule is present on the unworn M1-2, but in the referred specimen with a moderately worn $\mathrm{M} 1$, the protoconule is almost completely obliterated by wear (Golz, 1976). In UCM 67888, there is no indentation along the anterior border of the preprotocrista indicating that a distinct protoconule was present, but along the worn labial border of the anterior crescent outline there is a slight, convexity just posterior of the level of the paracone apex. However, whether this convexity represents a remnant of a protoconule cannot be determined because in well worn upper molars of Protylopus, which lack a protoconule, a similar convexity may also occur due to advanced wear of the protocone. In UCM 67888, the postprotocrista and premetaconule crista are merged lingually and labially due to wear, but there is a distinct lingual inflection between their labial termini along with an oval, isolated enamel islet positioned lingually and slightly anteriorly of the inflection. The inflection represents the remnant of the labial portion of the valley between the postprotocrista and premetaconule crista. The enamel islet appears to represent the remnant of the bifurcation of the postprotocrista and the anterior border of the premetaconule crista. A similar precursor to this enamel islet can also be observed in the bifurcation of the postprotocristae of moderately worn teeth of Protylopus and Oromyerx plicatus (Gazin, 1955, plates 13-15). Thus, it appears that UCM 67888 possessed a bifurcated postprotocristae, which is diagnostic for the Oromerycidae.

UCM 67888 exhibits the following shared characters with Merycobunodon and Protylopus (Table 4): 1) mesostyle present; 2) hypocone absent; 3) enlarged, posterolingually positioned metaconule; 4) postprotocrista bifurcation; 5) paracone and metacone ribs; and 6) crenulated enamel. UCM 67888 is definitely specifically distinct from all other known middle Eocene oromeryicids and homacodontids. Of all recognized oromerycids, UCM 67888 is most similar to the M12 of Merycobunodon by being low crowned and bunoseleodont. UCM 67888 could represent a new oromeryicid genus. However, without additional cheek teeth to better characterize it, including ones that are not as heavily worn, we cannot establish enough diagnostic characters to generically separate it from Merycobunodon. Furthermore, all of the differences between UCM 67888 and the M1-2 of $M$. littoralis listed above in the diagnosis only rise to the level of specific separation. Therefore, UCM 67888 is questionably assigned to Merycobunodon, as M.? walshi. In this systematic scenario, earliest Uintan M.? walshi could have given rise to early Uintan Merycobunodon littoralis, which then gave rise to middle to late Uintan Protylopus.

\section{DISCUSSION}

The type area of the Bridger Formation in the Bridger Basin consists of three members (in 
TABLE 5. Taxa lists of mammals of Uintan biochron Ui1a from TBM and the basal Tertiary Conglomerate Local Fauna (BTC) of lower member of the Devil's Graveyard Formation, Texas, along with taxa from lower in Bridger Formation $(\mathrm{Br} 2$ or $\mathrm{Br} 3)$ that are holdovers in the TBM and BTC, and taxa that range-through to Ui1b or later. Superscripts in the table indicate the reference numbers. References: 1, Leidy (1872b); 2, Marsh (1872b); 3, Matthew (1909); 4, Troxell (1923a); 5, Wilson (1937); 6, McKenna and Simpson (1959); 7, Wood (1959); 8, Wood (1973); 9, Robinson (1968a); 10, Szalay (1969); 11, Szalay (1976); 12, West (1974); 13, Gazin (1976); 14, Krishtalka (1976b); 15, Lillegraven et al. (1981); 16, West and Hutchinson (1981); 17, Wilson and Schiebout (1984); 18, West (1982); 19, Wilson (1984); 20, Wilson (1986); 21, Krishtalka, personal communication in Wilson (1986); 22, McCarroll et al. (1996); 23, Walsh (1996b); 24, Asher et al. (2002); 25, Turnbull (2002); 26, Williams and Kirk (2008); 27, Gunnell et al. (2008a); 28, Gunnell et al. (2009); 29, Mihlbachler (2008); 30, Murphey and Dunn (2009); 31, Campisano et al. (2014); 32, Kelly and Murphey (2016a); 33, this paper. FAD = first appearance datum. Index species = taxa restricted to Ui1a. $\mathrm{N}=$ number of taxa.

\begin{tabular}{|c|c|c|c|c|}
\hline Designation & $\mathbf{N}$ & TBM Taxa & $\mathbf{N}$ & BTC Taxa \\
\hline \multirow[t]{5}{*}{ Index species } & 5 & Hemiacodon engardae 30 & 0 & \\
\hline & & Nyctitherium gunnelli 33 & & \\
\hline & & Entomolestes westgatei33 & & \\
\hline & & Elymys? emryi 32 & & \\
\hline & & Merycobunodon? walshi 33 & & \\
\hline \multirow[t]{15}{*}{ Species FAD } & 15 & Nyctitherium gunnelli33 & 4 & Prolapsus juntionalis 8 \\
\hline & & Entomolestes westgatei33 & & Prolapsus sp. 8 \\
\hline & & Sespedectinae, genus undet. 33 & & Pareumys boskeyi 8 \\
\hline & & unnamed lipotyphlan sp. 33 & & Leptoreodon pusillus 19 \\
\hline & & Hemiacodon engardae 30 & & \\
\hline & & Microparamys sp. 32 & & \\
\hline & & new cylindrodont or ailuravine sp. 32 & & \\
\hline & & cf. Pareumys sp. 32 & & \\
\hline & & sciuravid sp. A 32 & & \\
\hline & & Metanoiamys sp. 32 & & \\
\hline & & Elymys? emryi 32 & & \\
\hline & & Wickia sp., cf. W. brevirhinus 33 & & \\
\hline & & Triplopus sp., cf. T. obliquidens 33 & & \\
\hline & & Epihippus sp., cf. E. gracilis 33 & & \\
\hline & & Merycobunodon? walshi 33 & & \\
\hline
\end{tabular}

ascending order); the Blacks Fork Member, the Twin Buttes Member, and the Turtle Bluff Member (TBM). The Blacks Fork and Twin Buttes members contain mammalian faunas of the Blackforkian (biochron Br2) and Twinbuttean (biochron Br3) subages of the Bridgerian North American Land Mammal age. The TBM has been designated as the stratotype for the earliest Uintan biochron Ui1a of the Uintan North American Land Mammal age (Gunnell et al., 2009). As such, documenting the taxonomic composition of the TBM further clarifies our understanding of the Bridgerian-Uintan transition.
Gunnell et al. (2009) listed two index species for the Ui1a; Hemiacodon engardae and Oromerycidae, new genus and species (= Merycobunodon? walshi new species, this paper). Kelly and Murphey (2016a) described a new dipodoid, Elymys? emryi, from the TBM, which is also a Ui1a index species restricted to the TBM. With the discovery of Nyctitherium gunnelli and Entomolestes westgatei, a total of five Ui1a index species can for now be confidently recognized from the TBM (Table 5). Six other taxa (Sespedectinae, genus undetermined, unnamed lipotyphlan sp., cf. Pareumys sp., sciruavid sp. A, Metanoiamys sp., and Microparamys sp.) 
TABLE 5 (continued).

\begin{tabular}{|c|c|c|c|c|}
\hline Designation & $\mathbf{N}$ & TBM Taxa & $\mathbf{N}$ & BTC Taxa \\
\hline \multirow{26}{*}{$\begin{array}{l}\text { Taxa also known } \\
\text { from } \mathrm{Br} 2 \text { or } \mathrm{Br} 3\end{array}$} & 26 & Apatemys bellulus $4,13,33$ & 14 & Scenopagus priscus 21 \\
\hline & & Apatemys rodens 4,33 & & Scenopagus sp. 21 \\
\hline & & Uintasorex parvulus 3 & & Entomolestes? sp. 21 \\
\hline & & Microsyops annectans 10 & & Centetodon pulcher 21 \\
\hline & & Notharctus robustior $1,28,32$ & & Nyctitherium velox 21 \\
\hline & & Trogolemur myodes 3 & & cf. Pantolestes sp. 21 \\
\hline & & Omomys carteri 11 & & Microsyops annectans 18 \\
\hline & & Washakius insignis 11 & & Omomys carteri 18, 25 \\
\hline & & Scenopagus priscus 6 & & Notharctus tenebrosus 18, 25 \\
\hline & & Scenopagus curtidens 3,6 & & Microparamys minutus 8 \\
\hline & & Centetodon bemicophagus 15 & & Thisbemys plicatus 8 \\
\hline & & Centetodon pulcher 15 & & Hyopsodus paulus 18 \\
\hline & & Nyctitherium velox 9,14 & & Hyrachyus? sp., cf. H. modestus 17 \\
\hline & & Pontifactor bestiola 12 & & Helohyus sp. 18 \\
\hline & & unnamed apternodontid sp. 24 & & \\
\hline & & Viverravus gracilis 2, 3 & & \\
\hline & & Paramys sp., cf. P. delicatior 16 & & \\
\hline & & Microparamys minutus 5 & & \\
\hline & & Thisbemys corrugatus 7 & & \\
\hline & & Sciuravus nitidus 4 & & \\
\hline & & Tillomys senex 4 & & \\
\hline & & Tillomys? parvidens 4 & & \\
\hline & & Taxymys lucaris 4 & & \\
\hline & & Hyopsodus lepidus 33 & & \\
\hline & & Uintatherium anceps 33 & & \\
\hline & & Homacodon sp., cf. H. vagans 33 & & \\
\hline \multirow{11}{*}{$\begin{array}{l}\text { Range-through to } \\
\text { Ui1b or later }\end{array}$} & 11 & Uintasorex parvulus 28 & 11 & Microsyops annectans 20 \\
\hline & & Microsyops annectans 31 & & Omomys carteri 23,27 \\
\hline & & Notharctus robustior 22 & & Ourayia uintensis 18, 28 \\
\hline & & Omomys carteri 23 & & Macrotarsius sp. 18, 26 \\
\hline & & Scenopagus priscus 28 & & Microparamys minutus 31 \\
\hline & & Scenopagus curtidens 28 & & Thisbemys plicatus 8,28 \\
\hline & & Tillomys senex 28 & & Prolapsus juntionalis 8, 28 \\
\hline & & Uintatherium anceps 25 & & Pareumys boskeyi 8,28 \\
\hline & & Wickia brevirhinus 29 & & Triplopus implicatus 17, 28 \\
\hline & & Epihippus gracilis 28 & & Helohyus sp. 28 \\
\hline & & Triplopus obiquidens 28 & & Leptoreodon pusillus 19 \\
\hline
\end{tabular}


from the TBM probably represent new species restricted to the TBM (Kelly and Murphey, 2016a; this paper), and thus potentially additional Ui1a index species, but assigning formal names to them has been deferred until additional material of each is available to better characterize them. Along with the above species, the first appearances of Metanoiamys, Triplopus and Epihippus occur in the TBM, genera that are generally regarded as having their first appearances in the Uintan (e.g., Prothero, 1998b; Flynn, 2008; MacFadden, 1998; Robinson et al., 2004; Gunnell et al., 2009). Assuming our referral of the brontothere from high in the TBM section is correct, the first appearance of Wickia also occurs in the TBM. Although the marsupials of the TBM have not yet been formally described, four taxa are present, which we will document in a future report. Currently, at least 26 mammal species in the TBM can be recognized as holdovers from lower in the Bridger Formation of which 10 are range-through species into Ui1b or later (Table 5). In summary, the mammals of the TBM include at least five index species (probably more), the first appearances of five genera and at least 15 species, and at least 26 species that are holdovers from lower in the Bridger Formation.

Flynn (1986) proposed a new subage, the Shoshonian, for the earliest Uintan based on transitional faunas primarily from the Bone Bed A (Horizon D) of the type section of the Tepee Trail Formation of Wyoming and what he regarded as correlative faunas from the lower Adobe Town Member of the Washakie Formation of Wyoming and the Friars and Mission Valley Formations of San Diego County, California. The Shoshonian has been controversial and has not been accepted by most recent investigators (e.g., Walsh, 1996a; Robinson et al., 2004). Robinson et al. (2004) recognized a single biochron for the early Uintan, Ui1. Subsequently, Gunnell et al. (2009) proposed dividing the Ui1 into two biochrons, Ui1a and Ui1b. Gunnell et al. (2009) regarded the fauna from the TBM as representing the oldest transitional Uintan interval and assigned it and the Basal Tertiary Local Fauna of the Devil's Graveyard Formation of Texas along with possibly all of the informal unit $A$ of the eastern Uinta Basin and the lower part of unit B of the western Uinta Basin of Uinta Formation, Utah, to biochron Ui1a. Gunnell et al. (2009) did not designate a stratotype section for biochron Ui1b, but referred the following sections to it: 1) the Washakie Formation of the Sand Wash Basin of Colorado; 2) the middle unit of the Adobe Town Member of the Washakie Formation of Wyoming;
3) the lowermost Tepee Trail Formation of the East Fork Basin of Wyoming; 4) the Friars Formation and the upper part of Member B of the Santiago Formation of southern California; 5 ) the portion of the lower member of the Devil's Graveyard Formation yielding the Whistler Squat Local Fauna of Texas; and 6) tentatively all or a portion of the informal units $A$ and $B 1$ of the Uinta Formation of the eastern part of the Uinta Basin and the lowermost part of unit B in the western part of the Uinta Basin, Utah. Thus, the areas referred by Flynn (1986) to the Shoshonian were subsumed into the Ui1a and Ui1b of Gunnell et al. (2009).

The Ui1a is now better characterized with at least five index species, and probably more, along with at least 15 taxa with first appearances in the stratotype section of the TBM (Table 5). However, the fauna of the TBM also includes a large number of Bridgerian holdover taxa and is lacking certain characteristic later Uintan taxa including Amynodon Marsh, 1877, and seleonodont artiodactyls (Gunnell et al., 2009; Campisano et al., 2014). These facts strongly support Gunnell et al.'s (2009) recognition of an earliest Uintan Ui1a biochron for the stratotype section of the TBM.

Wilson (1986) documented the faunas from the Devil's Graveyard Formation (DGF) of Texas. Two local faunas are recognized from the lower member of the DGF; the Basal Tertiary Local Fauna (Ui1a) from Junction (TMM Locality 41443), 0.6 miles east of Junction (TMM Locality 41444) in the basal Tertiary conglomerate and the laterally equivalent Hen Egg Mountain localities in the lower member of the DGF; and the Whistler Squat Local Fauna (Ui1b) from stratigraphically higher in the lower member of the DGF (Wilson, 1986; Walton, 1992; Gunnell et al., 2009; Campisano et al., 2014). Recently, Campisano et al. (2104) reevaluated the geochronology and taxonomy of the fauna from the Whistler Squat Quarry wherein they provided high precision ${ }^{40} \mathrm{Ar} /{ }^{39} \mathrm{Ar}$ dates of $45.04 \pm$ $0.10 \mathrm{Ma}$ for the lower tuff and $44.88 \pm 0.04 \mathrm{Ma}$ for upper tuff at the quarry. They also noted that the Whistler Squat Quarry is $\sim 2$ Ma younger than the Hen Egg Mountain localities based on an ${ }^{40} \mathrm{Ar} /{ }^{39} \mathrm{Ar}$ date of $46.80 \pm 0.08 \mathrm{Ma}$ (corrected, see also Miggins, 2009) for a basalt that overlies the localities on the southeast side of Hen Egg Mountain.

Gunnell et al. (2009) regarded the fauna from the basal Tertiary conglomerate $(=$ Basal Tertiary Local Fauna of Walton, 1992) as correlative with the TBM fauna and assigned it to biochron Ui1a. Similar to the TBM fauna, the Basal Tertiary Local Fauna also contains a large number of Bridgerian 
holdover taxa and is lacking Amynodon (Table 5). However, there are minor faunal differences between them. The TBM fauna contains a larger number of typical Bridgerian hold over taxa and has a proportionally smaller number of typical Bridgerian taxa that range-through to the Ui1b or later. Although Wilson (1984) referred three teeth from the basal Tertiary conglomerate at TMM Locality 41443 to the selenodont artiodactyl Leptoreodon pusillus, Gunnell et al. (2009) did not include it in their account of the Ui1a taxa. After years of collecting in the TBM, no seleondont artiodactyls have been discovered, which could be a result of paleoenviromental/geographical factors or the possibility that they had not yet evolved. In addition, cf. Pareumys sp. from the TBM appears to be slightly less derived than Pareumys boskeyi of the Basal Tertiary and Whistler Squat local faunas and could be ancestral to P. boskeyi (Kelly and Murphey, 2016a). The above facts suggest the possibility that the TBM fauna could be slightly older than the Basal Tertiary Local Fauna.

Murphey et al. (1999) reported an ${ }^{40} \mathrm{Ar} /{ }^{39} \mathrm{Ar}$ date of $47.13 \pm 0.45 \mathrm{Ma}$ (corrected) for a tuff that occurs $8 \mathrm{~m}$ below the base of the TBM (= the Basal E tuff of Murphey and Evanoff, 2007; see also Smith et al., 2003). Smith et al. (2008) provided an ${ }^{40} \mathrm{Ar} / 39 \mathrm{Ar}$ date of $47.45 \pm 0.15 \mathrm{Ma}$ (corrected, see Smith et al., 2010; Tsukui, 2016) for the Sage Creek Mountain tuff (SCMT), reported to occur in the TBM at about $44 \mathrm{~m}$ above the base (= Basal $\mathrm{E}$ limestone) and $14 \mathrm{~m}$ below the unconformably overlying Oligocene Bishop Conglomerate. Kelly and Murphey (2016a) incorrectly stated that the SCMT of Smith et al. (2008) was equivalent to the Basal E tuff of Murphey and Evanoff (2007). Based on four single-grain zircon analyses, Tsukui (2016) provided ${ }^{206} \mathrm{~Pb} / 238 \mathrm{U}$ dates for the SCMT at 47.192 $\pm 0.068,47.287 \pm 0.038,47.344 \pm 0.041$, and $47.381 \pm 0.057 \mathrm{Ma}$. Because of the small sample size of zircons (four) whose population could not be rigorously defined, Tsukui (2016) selected the youngest single zircon analysis as the best approximation of the depositional age for the SCMT. Tsukui and Clyde (2012) determined that the SCMT is of normal magnetic polarity, which they assigned to Chron C21n of the Global Polarity Time Scale. As noted above, a basalt overlying the Hen Egg Mountain localities, which are laterally equivalent to the basal Tertiary conglomerate localities in the DGF, was ${ }^{40} \mathrm{Ar} /{ }^{39} \mathrm{Ar}$ dated at $46.80 \pm$ $0.08 \mathrm{Ma}$. The new ${ }^{40} \mathrm{Ar} / 39 \mathrm{Ar}$ date and ${ }^{206} \mathrm{~Pb} / 238 \mathrm{U}$ dates for the SCMT (Smith et al., 2008, 2010;
Tsukui, 2016) indicate an age of about 47.4547.19 Ma for the TBM fauna, which also suggests that it might be slightly older than the Basal Tertiary Local Fauna.

Additional data on the geochronology of the TBM are being analyzed and will be presented in our third report on the mammals from the TBM, including magnetostratigraphy and ${ }^{206} \mathrm{~Pb} / 238 \mathrm{U}$ dating of the "tuffaceous white sandstone bed" and DMNH Locality 4673 (Figure 1) in the stratotype section on Cedar Mountain. These new data will further clarify the age of the TBM fauna relative to that of Basal Tertiary Local Fauna and the Bridgerian-Uintan transition. Until then, we follow Gunnell et al. (2009) and regard the TBM fauna and its correlative, the Basal Tertiary Local Fauna, as the principal faunas characterizing the Ui1a.

\section{ACKNOWLEDGMENTS}

We thank the U.S. Bureau of Land Management for supporting our research by providing permits to complete our field work over the years. We are grateful to B. Breithaupt of the Wyoming BLM for facilitating the curation of TBM specimens at the DMNS. We are greatly indebted to T.A. Deméré and K.A. Randall of the SDNHM, L. Ivy and J. Sertich of the DMNS, T. Culver and J. Eberle of the UCM, and J. Ming, R. O'Leary, and A. Gishlick of the $\mathrm{AMNH}$, for their considerate assistance in procuring loans of specimens for this study and assistance with locality and specimen numbers. Special thanks are extended to P. Robinson, E. Evanoff, P. Monaco, the late D. Engard, and all of the UCM students and volunteers who assisted with the recovery of the fossils from UCM Locality 92189; and P. Sena, M. Madsen, S. Madsen, H. Finalyson, and $\mathrm{T}$. Temme, who assisted with quarrying and hauling and wet screening of matrix samples of the more recently discovered TBM localities. Our greatest gratitude goes to our late friend and colleague S.L. Walsh of the SDNMH for his participation in the TBM field work, wet screening, heavy liquid separation, and fossil identifications; as well as his many contributions to middle Eocene mammalian paleontology, biostratigraphy and biochronology. J. Bloch of the Florida Museum of Natural History provided helpful comments during the preparation of this report. We appreciate the constructive reviews by G. Gunnell of the Division of Fossil Primates, Duke Lemur Center, and J. Westgate of Lamar University, which significantly improved the final paper. 


\section{REFERENCES}

Abel, O. and Cook, H.J. 1925. A preliminary study of the early mammals in a new fauna from Colorado. Proceedings of the Colorado Museum of Natural History, 5:33-36.

Archibald, J.D. 1998. Archaic ungulates ("Condylartha"), p. 292-329. In Janis, C.M., Scott, K.M., and Jacobs, L.L. (eds.), Evolution of Tertiary mammals of North America, Volume 1: terrestrial carnivores, ungulates and ungulatelike mammals. Cambridge University Press, New York.

Asher, R.J., McKenna, M.C., Emry, R.J., Tabrum, A.R., and Kron, D.G. 2002. Morphology and relationships of Apternodus and other extinct, zalambdodont, placental mammals. Bulletin of the American Museum of Natural History, 273:1-117.

Beard, K.C. and Dawson, M.R. 2009. Early Wasatchian mammals of the Red Hot Local Fauna, uppermost Tuscarhoma Formation, Lauderdale County, Mississippi. Annals of Carnegie Museum, 78:193-243.

Bown, T.M. 1982. Geology, paleontology, and correlation of Eocene volcaniclastic rocks, southeast Absaroka Range, Hot Springs County, Wyoming. USGS Professional Paper 1201-A:1-75.

Bown, T.M. and Schankler, D. 1982. Geology and mammalian paleontology of the Sand Creek facies, lower Willwood Formation (lower Eocene), Washakie County, Wyoming. Geological Survey of Wyoming Memoir, 2:1-151.

Bryant, H.N. 1996. Explicitness, stability, and universality in the phylogenetic definition and usage of taxon names: a case study of the phylogenetic taxonomy of the Carnivora (Mammalia). Systematic Biology, 45:174-189.

Burnett, G.T. 1830. Illustrations of the Quadrupeda, or Quadrapeds, being the arrangement of the true fourfooted beasts indicated in outline. Quarterly Journal of Science, Literature and Art, 1829:336-353.

Butler, P.M. 1988. Phylogeny of the insectivores, p. 117141. In Benton, M.J. (ed.), The Phylogeny of the Tetrapods, Volume 2, Clarendon Press, Oxford.

Campisano, C.J., Kirk, E.C., Townsend, K.E.B., and Deino, A.L. 2014. Geochronological and taxonomic revisions of the middle Eocene Whistler Squat Quarry (Devil's Graveyard Formation, Texas) and implications for the early Uintan in Trans-Pecos Texas. PLoS ONE, 9:e101516. doi:10.1371/journal.pone.0101516

Christiansen, M.G. and Stucky, R.K. 2013. Revision of the Wind River faunas, early Eocene of central Wyoming. Part 15. New Nyctitheriidae (?Lipotyphla) with analysis of the relationships of North American taxa. Denver Museum of Nature and Science Annals, 3:116.

Cifelli, R.L. 1993. Early Cretaceous mammal from North America and the evolution of marsupial dental characters. Proceedings of the National Academy of Sciences of the USA, 90:9413-9416.
Cifelli, R.L. and Muizon, C. 1998. Tooth eruption and replacement pattern in early marsupials. Comptes Rendus de l'Académie des Sciences, Série 2, Sciences de la Terre et des Planètes, 326:215-220.

Cifelli, R.L., Rowe, T.B., Luckett, W.P., Banta, J., Reyes, R., and Howes, R.I. 1996. Fossil evidence for the origin of marsupial pattern of tooth replacement. Nature, 379:715-718.

Colbert, M.W. and Schoch, R.M. 1998. Tapiroidea and other moropomorphs, p. 569-582. In Janis, C.M., Scott, K.M., and Jacobs, L.L. (eds.), Evolution of Tertiary mammals of North America, Volume 1: terrestrial carnivores, ungulates and ungulatelike mammals. Cambridge University Press, New York.

Cope, E.D. 1873a. On some Eocene mammals obtained by Hayden's geological survey of 1872. Palaeontological Bulletin, 12:5-6.

Cope, E.D. 1873b. On the osteology of the extinct tapiroid Hyrachyus. Proceedings of the American Philosophical Society, 13:212-224.

Cope, E.D. 1873c. Third notice of extinct Vertebrata from the Tertiary of the Plains. Palaeontological Bulletin, 16:1-8.

Cope, E.D. 1875. Systematic catalogue of Vertebrata of the Eocene of New Mexico collected in 1874. Geographical Explorations and Surveys West of the 100th Meridian. U.S. Government Printing Office, Washington, D.C.

Cope, E.D. 1879. On the extinct species of Rhinocerotidae of North America and their allies. Bulletin of the U.S. Geological Survey, 5:227-237.

Cope, E.D. 1880. A new genus of tapiroids. American Naturalist, 14:382-383.

Cope, E.D. 1881. A new type of Perissodactyla. American Naturalist, 15:1017-1020.

Cope, E.D. 1884. The Vertebrata of the Tertiary formations of the West. Report of the U.S. Geological Survey of the Territories, 3:1-1009.

Dashzeveg, D. and Hooker, J.J., 1997. New ceratomorph perissodactyls (Mammalia) from the middle and late Eocene of Mongolia: their implications for phylogeny and dating. Zoological Journal of the Linnaean Society, 120:105-138.

Delson, E. 1971. Fossil mammals of the early Wasatchian Powder River local fauna, Eocene of northwestern Wyoming. Bulletin of the American Museum of Natural History, 146:305-364.

Eaton, J.G. 1982. Paleontology and correlation of Eocene volcanic rocks in the Carter Mountain area, Park County, southeastern Absaroka Range, Wyoming. Contribution to Geology, University of Wyoming, 21:153-194.

Emry, R.J. 1990. Mammals of the Bridgerian (middle Eocene) Elderberry Canyon local fauna of eastern Nevada. Geological Society of America Special Paper, 243:187-210.

Evanoff, E., Robinson, P., Murphey, P.C., Kron, D.G., Engard, E., and Monaco, P. 1994. An early Uintan fauna from Bridger E. Society of Vertebrate Paleon- 
tology, Abstracts with Programs Supplement, 14:24A.

Fisher von Waldheim, G. 1817. Adversaria zoological. Memoires Societe Imperiale des Sciences Naturelles, Moscow, 5:368-428. (In French)

Flower, W.H. 1867. On the development and succession of the teeth in the Marsupialia. Philosophical Transactions of the Royal Society, London, 157:631-641.

Flower, W.H. 1876. Professor Flower's Hunterian lectures on the relations of extinct to existing Mammalia, Part IV. Nature, 13:387-388.

Flynn, J.J. 1986. Correlation and geochronology of middle Eocene strata from the western United States. Palaeogeography, Palaeoclimatology, Palaeoecology, 55:335-406.

Flynn, J.J. 1991. Hyopsodus (Mammalia) from the Tepee Trail Formation (Eocene), northwestern Wyoming. American Museum Novitates, 3007:1-19.

Flynn, J.J. 1998. Early Cenozoic Carnivora ("Miacoidea"), p. 110-123. In Janis, C.M., Scott, K.M., and Jacobs, L.L. (eds.), Evolution of Tertiary mammals of North America, Volume 1: terrestrial carnivores, ungulates and ungulatelike mammals. Cambridge University Press, New York.

Flynn, J.J. and Galiano, H. 1982. Phylogeny of early Tertiary Carnivora, with a description of a new species of Protictis from the middle Eocene of northwestern Wyoming. American Museum Novitates, 2725:1-64.

Flynn, L.J. 2008. Eomyidae, p. 415-427. In Janis, C.M., Gunnell, G.F., and Uhen, M.E. (eds.), Evolution of Tertiary Mammals of North America, Volume 2, Small Mammals, Xenarthans, and Marine Mammals. Cambridge, Cambridge University Press.

Forstén, A.M. 1971. Early Tertiary vertebrate faunas, Vieja Group, Trans-Pecos Texas: Part 1, Epihippus from the Vieja Gropus Trans-Pecos Texas. PearceSellards Series, Texas Memorial Museum, 18:1-3.

Froehlich, D.J. 2002. Quo vadis Eohippus? the systematics and taxonomy of the early Eocene equids (Perissodactyla). Zoological Journal of the Linnaean Society, 134:141-256.

Gazin, C.L. 1955. A review of the upper Eocene Artiodactyla of North America. Smithsonian Miscellaneous Collections, 128:1-96.

Gazin, C.L. 1956. The geology and vertebrate paleontology of upper Eocene strata in the northeastern part of the Wind River Basin, Wyoming, Part 2, the mammalian fauna of the Badwater area. Smithsonian Miscellaneous Collections, 131:1-35.

Gazin, C.L. 1958. A review of the middle and upper Eocene primates of North America. Smithsonian Miscellaneous Collections, 144:1-98.

Gazin, C.L. 1968. A study of the Eocene condylathran mammal Hyopsodus. Smithsonian Miscellaneous Collections, 153:1-90.

Gazin, C.L. 1976. Mammalian faunal zones of the Bridger middle Eocene. Smithsonian Contributions to Paleobiology, 26:1-25.
Gingerich, P.D. 1974a. Stratigraphic record of early Eocene Hyopsodus and the geometry of mammalian phylogeny. Nature, 248:107-109.

Gingerich, P.D. 1974b. Size variability of the teeth of living mammals and the diagnosis of closely related sympatric fossil species. Journal of Paleontology, 48:895-903.

Gingerich, P.E. 1976. Paleontology and phylogeny: patterns of evolution at the species level in early Tertiary mammals. American Journal of Science, 276:1-28.

Gingerich, P.D. 1987. Early Eocene bats (Mammalia, Chiroptera) and other vertebrates in freshwater limestones of the Willwood Formation, Clark's Fork Basin, Wyoming. Contributions of the Museum of Paleontology, University of Michigan, 27:275-320.

Golz, D.J. 1976. Eocene Artiodactyla of southern California. Natural History Museum of Los Angeles County Science Bulletin, 26:1-85.

Granger, W.A. 1908. A revision of the American Eocene horses. Bulletin of the American Museum of Natural History, 24:221-264.

Granger, W.A. 1909. Faunal horizons of the Washakie Formation of southern Wyoming. Bulletin of the American Museum of Natural History, 26:13-23.

Gray, J.E. 1821. On the natural arrangement of vertebrose animals. London Medical Repository, 15:296310.

Gregory, W.K. 1910. The orders of mammals. Bulletin of the American Museum of Natural History, 27:1-524.

Gunnell, G.F. and Bartels, W.S. 1999. Middle Eocene vertebrates from the Uinta Basin, Utah, and their relationship with faunas from the southern Green River Basin, Wyoming, p. 427-442. In Gillette, D.D. (ed.), Vertebrate Paleontology in Utah. Miscellaneous Publication 99-1. Utah Geological Survey, Utah.

Gunnell, G.F., Bown, T.M., Bloch, J.I., and Boyer, D.M. 2008a. "Proteutheria," p. 63-81. In Janis, C.M., Gunnell, G.F., and Uhen, M.E. (eds.), Evolution of Tertiary Mammals of North America, Volume 2, Small Mammals, Xenarthans, and Marine Mammals. Cambridge University Press, Cambridge.

Gunnell, G.F., Bown, T.M., Hutchison, J.H., and Bloch, J.I. 2008b. Lipotyphla, p. 89-125. In Janis, C.M., Gunnell, G.F., and Uhen, M.E. (eds.), Evolution of Tertiary Mammals of North America, Volume 2, Small Mammals, Xenarthans, and Marine Mammals. Cambridge University Press, Cambridge.

Gunnell, G.F., Murphey, P.C., Stucky, R.K., Townsend, K.E., Robinson, P., Zonneveld, J.-P., and Bartels, W.S. 2009. Biostratigraphy and biochronology of the latest Wasatchian, Bridgerian, and Uintan North American Land Mammals "Ages," p. 279-330. In Albright, L.B. III (ed.), Papers on Geology, Vertebrate Paleontology, and Biostratigraphy in Honor of Michael O. Woodburne. Museum of Northern Arizona Bulletin 65. Museum of Northern Arizona, Flagstaff.

Haeckel, E. 1866. Generelle Morphologie der Organismen: Allgemeine Grundzuge der Organischen For- 
men-Wissenschaft, Mechanisch Begrundet durch die von Charles Darwin Reformierte Descendenz-Theorie 1\&2. Georg Reimer, Berlin. (In German)

Hanson, C.B. 1996. Stratigraphy and vertebrate faunas of the Bridgerian-Duchesnean Clarno Formation, north-central Oregon, pp. 206-239. In Prothero, D.R. and Emry, R.J. (eds.), The Terrestrial Eocene-Oligocene Transition in North America. Cambridge University Press, Cambridge.

Hough, J. 1956. A new insectivore from the Oligocene of the Wind River Basin, Wyoming, with notes on taxonomy of the Oligocene Tenrecoidea. Journal of Paleontology, 30:531-541.

Jepsen, G.L. 1934. A revision of the American Apatemyidae and the description of a new genus, Sinclairella, from the White River Oligocene of South Dakota. Proceedings of the American Philosophical Society, 74:287-305.

Jepsen, G.L. 1966. Early Eocene bat from Wyoming. Science, 154:1333-1339.

Kelly, T.S. 1990. Biostratigraphy of Uintan and Duchesnean land mammal assemblages from the middle member of the Sespe Formation, Simi Valley, California. Contributions to Science, 419:1-42.

Kelly, T.S. and Murphey, P.C. 2016a. Mammals from the earliest Uintan (middle Eocene) Turtle Bluff Member, Bridger Formation, southwestern Wyoming, Part 1: Primates and Rodentia. Palaeontologia Electronica 19.2.24A:1-55 palaeo-electronica.org/content/2016/ 1518-earliest-uintan-mammals.

Kelly, T.S. and Murphey, P.C. 2016b. New records of Epihippus (Equidae) and a rhinocerotoid perissodactyl from the middle Eocene Santiago Formation of southern California. Paludicola, 11:8-30.

Kelly, T.S., Murphey, P.C., and Walsh, S.L. 2012. New records of small mammals from the middle Eocene Duchesne River Formation, Utah, and their implications for the Uintan-Duchesnean North American Land Mammal Age transition. Paludicola, 8:194-237.

Koenigswald, W.V., Rose, K.D., Grande, B.L., and Martin, R.D. 2005. First apatemyid skeleton from the lower Eocene Fossil Butte Member, Wyoming (USA), compared to the European apatemyid from Messel, Germany. Palaeontographica Abteilung A, 272:149169.

Korth, W.W. 1994. Middle Tertiary marsupials (Mammalia) from North America. Journal of Paleontology, 68:376-397.

Korth, W.W. 2008. Marsupialia, p. 39-47. In Janis, C.M, Gunnell, G.F., and Uhen, M.E. (eds.), Evolution of Tertiary Mammals of North America, Volume 2, Small Mammals, Xenarthans, and Marine Mammals. Cambridge University Press, Cambridge.

Krishtalka, L. 1975. Systematics and relationships of early Tertiary Lipotyphla (Mammalia, Insectivora) of North America. Unpublished PhD dissertation, Texas Tech University, Lubbock, Texas, USA.

Kristhtalka, L. 1976a. Early Tertiary Adapisoricidae and Erinaceidae (Mammalia, Insectivora) of North Amer- ica. Bulletin of Carnegie Museum of Natural History, 1:1-40.

Krishtalka, L. 1976b. North American Nyctitheriidae (Mammalia, Insectivora). Annals of Carnegie Museum, 46:7-28.

Krishtalka, L. 1979. Paleontology and geology of the Badwater Creek area, central Wyoming. Part 18. Revision of late Eocene Hyopsodus. Annals of Carnegie Museum, 48:377-389.

Krishtalka, L. and Setoguchi, T. 1977. Paleontology and geology of the Badwater Creek area, central Wyoming. Part 13. the late Eocene Insectivora and Dermoptera. Annals of the Carnegie Museum, 46:71-99.

Krishtalka, L. and Stucky, R.K. 1983. Paleocene and Eocene marsupials of North America. Annals of Carnegie Museum, 52:229-263.

Krishtalka, L. and West, R.M. 1977. Paleontology and geology of the Bridger Formation, southern Green River Basin, southwestern Wyoming, Part 2, the Bridgerian insectivore Entomolestes grangeri. Contributions in Biology and Geology, 14:1-11.

Kuiper, K.F., Deino, A., Hilgen, F.J., Krijgsman, W., Renne, P.R., and Wijbrans, J.R. 2008. Synchronizing rock clocks of Earth history. Science, 320:500-504.

Leidy, J. 1870. Remarks on a collection of fossils from the western Territories. Proceedings of the Academy of Natural Sciences, Philadelphia, 22:109-110.

Leidy, J. 1871. Report on vertebrate fossils from the Tertiary formations of the West, p. 340-370. In Hayden, F.V. (ed.), Preliminary Report of the U.S. Geological Survey of Wyoming and Portions of Contiguous Territories (being a Second Annual Report of Progress). Government Printing Office, Washington.

Leidy, J. 1872a. On some new species of fossil mammals from Wyoming. Proceedings of the Academy of Natural Science, Philadelphia, 1872:169.

Leidy, J. 1872b. Remarks on fossils from Wyoming. Proceedings of the Academy of Natural Sciences, Philadelphia, 24:19-21.

Leidy, J. 1873. Contributions to the extinct vertebrate fauna of the Western Territories. Report of the U.S. Geological Survey of the Territories, 1:1-358.

Lillegraven, J.A. 1976. Didelphids (Marsupialia) and Uintasorex (?Primates) from later Eocene sediments of San Diego County, California. Transactions of the San Diego Society of Natural History, 18:85-112.

Lillegraven, J.A., McKenna, M.C., and Krishtalka, L. 1981. Evolutionary relationships of middle Eocene and younger species of Centetodon (Mammalia, Insectivora, Geolabididae) with a description of the dentition of Ankylodon (Adapisoricidae). University of Wyoming Publications, 45:1-115.

Lopatin, A.V. 2006. Early Paleogene insectivore mammals of Asia and establishment of the major groups of Insectivora. Paleontological Journal, 40:205-405.

Lucas, S.G., Holbrook, L.T., and Emry, R.J., 2003. Isectolophus (Mammalia, Perissodactyla) from the Eocene of the Zaysan Basin, Kazakstan and its bio- 
chronological significance. Journal of Vertebrate Paleontology, 23:238-243.

Lucas, S.G. and Schoch, R.M. 1998. Dinocerata, p. 284291. In Janis, C.M., Scott, K.M., and Jacobs, L.L. (eds.), Evolution of Tertiary Mammals of North America, Volume 1: Terrestrial Carnivores, ungulates and Ungulatelike mammals. Cambridge University Press, New York.

MacFadden, B.J. 1975. Cladistic analysis of primitive equids, with notes on other Perissodactyla. Systematic Zoology, 25:1-14.

MacFadden, B.J. 1980. Eocene Perissodactyla from the type section of the Tepee Trail Formation of northwestern Wyoming. Contributions to Geology, University of Wyoming, 18:135-143.

MacFadden, B.J. 1998. Equidae, p. 537-559. In Janis, C.M., Scott, K.M., and Jacobs, L.L. (eds.), Evolution of Tertiary mammals of North America, Volume 1: terrestrial carnivores, ungulates and ungulatelike mammals. Cambridge University Press, New York.

Manz, C.L. and Bloch, J.I. 2015. Systematics and phylogeny of Paleocene-Eocene Nyctitheriidae (Mammalia, Eulipotyphla?) with description of a new species from the late Paleocene of the Clark's Fork Basin, Wyoming. Journal of Mammalian Evolution, 22:307-342. doi:10.1007/s10914-014-9284-3

Marsh, O.C. 1871. Notice of some new fossil mammals from the Tertiary formation. American Journal of Science, Series 3, 2:15-19.

Marsh, O.C. 1872a. Preliminary description of new Tertiary mammals, Part II. American Journal of Science, Series 3, 4:122-128.

Marsh, O.C. 1872b. Preliminary description of new Tertiary mammals. American Journal of Science, Series 3, 4:202-224.

Marsh, O.C. 1873. On the gigantic fossil mammals of the order Dinocerata. American Journal of Science, 5:117-122.

Marsh, O.C. 1875. Notice of new Tertiary mammals, IV. American Journal of Science, Series 3, 9:239-250.

Marsh, O.C. 1877. Notice of some new vertebrate fossils. American Journal of Science, Series 3, 14:249256.

Marsh, O.C. 1878. The introduction and succession of vertebrate life in America. Popular Science Monthly, 7:513-527, 672-697.

Marsh, O.C. 1886. Dinocerata, a monograph of an extinct order of gigantic mammals. U.S. Geological Survey Monograph, 10:1-237.

Marsh, O.C. 1894. Description of Tertiary artiodactyles. American Journal of Science, 48:259-274.

Matthew, W.D. 1909. The Carnivora and Insectivora of the Bridger Basin, middle Eocene. American Museum of Natural History Memoirs, 9:289-567.

Matthew, W.D. 1918. A revision of the lower Eocene Wasatch and Wind River faunas. Part V. Insectivora (continued), Glires, Edentata. Bulletin of the American Museum of Natural History, 38:565-657.
Matthew, W.D. 1921. Stehlinius, a new Eocene insectivore. American Museum Novitates, 14:1-5.

Matthew, W.D. 1929. Preoccupied names. Journal of Mammalogy, 10:171.

Matthew, W.D. and Granger, W. 1925. New ungulates from the Ardyn Obo Formation of Mongolia with faunal list and remarks on correlation. American Museum Novitates, 195:1-11.

McCarroll, S.M., Flynn, J.J., and Turnbull, W.D. 1996. The mammalian faunas of the Washakie Formation, Eocene age, of southern Wyoming, Part III. the perissodactyls. Fieldiana Geology New Series, 33:1-38.

McGrew, P.O. 1959. The geology and paleontology of the Elk Mountain and Tabernacle Butte area, Wyoming. Bulletin of the American Museum of Natural History, 117:117-176.

McGrew, P.O. and Sullivan, R. 1970. The stratigraphy and paleontology of the Bridger A. Contributions to Geology, University of Wyoming, 9:66-85.

McKenna, M.C. 1960a. Fossil Mammalia from the early Wasatchian Four Mile fauna, Eocene of northwest Colorado. University of California Publications of the Department of Geological Sciences, 37:1-130.

McKenna, M.C. 1960b. The Geolabidinae, a new subfamily of early Cenozoic erinaceoid insectivores. University of California Publications of the Department of Geological Sciences, 37:131-164.

McKenna, M.C. 1963. Primitive Paleocene and Eocene Apatemyidae (Mammalia, Insectivora) and the primate-insectivore boundary. American Museum Novitates, 2160:1-39.

McKenna, M.C. and Haase, F. 1992. Marsholestes, a new name for the Eocene insectivoran Myolestes Matthew, 1909, not Myolestes Brèthes, 1904. Journal of Vertebrate Paleontology, 12:256.

McKenna, M.C., Robinson, P., and Taylor, D.W. 1962. Notes on the Eocene Mammalia and Mollusca from Tabernacle Butte, Wyoming. American Museum Novitates, 2102:1-12.

McKenna, M.C. and Simpson, G.G. 1959. A new insectivore from the middle Eocene of Tabernacle Butte, Wyoming. American Museum Novitates, 1952:1-12.

Miggins, D.P. 2009. Temporal and geochemical insights related to volcanic and plutonic activity within Big Bend National Park, Texas. Unpublished PhD Thesis, University of Texas, El Paso, Texas, USA.

Mihlbachler, M.C. 2008. Species taxonomy, phylogeny, and biogeography of the Brontotheriidae (Mammalia: Perissodactla). Bulletin of the American Museum of Natural History, 311:1-475.

Murphey, P.C. 2001. Stratigraphy, fossil distribution, and depositional environments of the upper Bridger Formation (middle Eocene) of southwestern Wyoming, and the taphonomy of an unusual Bridger microfossil assemblage. Unpublished PhD Thesis, University of Colorado, Denver, Colorado, USA.

Murphey, P.C. and Dunn, R.H. 2009. Hemiacodon engardae, a new species of omomyid primate from the earliest Uintan Turtle Bluff Member of the Bridger 
Formation, southwestern Wyoming, USA. Journal of Human Evolution, 57:123-130.

Murphey, P.C. and Evanoff, E. 2007. Stratigraphy, fossil distribution, and depositional environments of the upper Bridger Formation (middle Eocene), southwestern Wyoming. Wyoming State Geological Survey, Report of Investigations, 57:1-107.

Murphey, P.C., Lester, A., Bohor, B., Robinson, P., Evanoff, E., and Larson, E. 1999. ${ }^{40} \mathrm{Ar} / 39 \mathrm{Ar}$ dating of volcanic ash deposits in the Bridger Formation (middle Eocene), southwesternWyoming. Geological Society of America Abstracts with Programs, 31:233.

Nievelt, A.F.H. and Smith, K.K. 2005. Tooth eruption in Monodelphis domestica and its significance for phylogeny and natural history. Journal of Mammalogy, 86:333-341.

Novacek, M.J. 1976. Insectivora and Proeutheria of the later Eocene (Uintan) of San Diego County, California. Contributions in Science, 283:1-52.

Novacek, M.J. 1980. Crypholestes, a new name for the early Tertiary insectivore (Mammalia) Cryptolestes Novacek, 1976. Journal of Paleontology, 54:1135.

Novacek, M.J. 1985. The Sespedectinae, a new subfamily of hedgehog-like insectivores. American Museum Novitates, 2822:1-24.

Novacek, M.J., Bown, T.M., and Schankler, D. 1985. On the classification of the early Tertiary Erinaceomorpha (Insectivora, Mammalia). American Museum Novitates, 2813:1-22.

Osborn, H.F. 1902. American Eocene primates, and the supposed rodent family Mixodectidae. Bulletin of the American Museum of Natural History, 16:169-214.

Osborn, H.F. 1908. New or little known titanotheres from the Eocene and Oligocene. Bulletin of the American Museum of Natural History, 24:599-617.

Osborn, H.F. 1909. Cenozoic mammal horizons of western North America, with faunal lists of the Tertiary Mammalia of the West by W.D. Matthew. U.S. Geological Survey Bulletin, 361:1-138.

Osborn, H.F., Scott, W.B., and Speir, F. 1878. Paleontological report of the Princeton Scientific Expedition of 1877. Contributions of the Museum of Geology and Archeology, Princeton College, 1:1-107.

Owen, R. 1848. Description of teeth and proportions of jaws of two extinct anthrocotheroid quadrupeds (Hyopotamus vecitanus and Hyop. bovinus) discovered by the Marchioness of Hastings in the Eocene deposits of the NW coast of the Isle of Wight with an attempt to develop Cuvier's idea of the classification of pacyderms by the number of their toes. Quarterly Journal of the Geological Society of London, 4:104141.

Peterson, O.A. 1919. Report upon the material discovered in the upper Eocene of the Uinta Basin by Earl Douglas in the years 1908-1909, and by O.A. Peterson in 1912. Annals of Carnegie Museum, 12:40168.

Peterson, O.A. 1931. New species from the Oligocene of the Uinta. Annals of Carnegie Museum, 21:61-78.
Prothero, D.R. 1998a. Oromerycidae, p. 426-430. In Janis, C.M., Scott, K.M., and Jacobs, L.L. (eds.), Evolution of Tertiary Mammals of North America, Volume 1: Terrestrial Carnivores, Ungulates and Ungulatelike Mammals. Cambridge University Press, New York.

Prothero, D.R. 1998b. Hyracodontidae, p. 589-594. In Janis, C.M., Scott, K.M. and Jacobs, L.L. (eds.), Evolution of Tertiary Mammals of North America, Volume 1: Terrestrial Carnivores, Ungulates and Ungulatelike Mammals. Cambridge University Press, New York.

Radinsky, L.R. 1963. Origin and early evolution of North American Tapiroidea. Peabody Museum of Natural History, Yale University Bulletin, 17:1-106.

Radinsky, L.R. 1967. A review of the rhinocerotoid family Hyracodontidae (Perissodactyla). Bulletin of the American Museum of Natural History, 136:1-45.

Rasmussen, D.T., Hamblin, A.H., and Tabrum, A.R. 1999. The mammals of the Eocene Duchesne River Formation, p. 421-427. In Gillette, D.D. (ed.), Vertebrate Paleontology in Utah. Utah Geological Survey, Miscellaneous Publication 99-1. Utah Geological Survey, Salt Lake City.

Robinson, P. 1966a. Fossil Mammalia of the Huerfano Formation, Eocene, of Colorado. Peabody Museum of Natural History Bulletin, 21:1-85.

Robinson, P. 1966b. Paleontology and geology of the Badwater Creek area, central Wyoming. Part 3. late Eocene Apatemyidae (Mammalia: Insectivora) from the Badwater area. Annals of Carnegie Museum, 38:317-322.

Robinson, P. 1968a. Nyctitheriidae (Mammalia, Insectivora) from the Bridger Formation of Wyoming. Contributions to Geology, University of Wyoming, 7:129138.

Robinson, P. 1968b. Talpavus and Entomolestes (Insectivora, Adapisoricidae). American Museum Novitates, 2339:1-7.

Robinson, P., Gunnell, G.F., Walsh, S.L., Clyde, W.C., Storer, J.E., Stucky, R.K., Froehlich, D.J., Villafranca, I.F., and McKenna, M.C. 2004. Wasatchian through Duchesnean biochronology, p. 106-155. In Woodburne, M.O. (ed.), Late Cretaceous and Cenozoic Mammals of North America. Columbia University Press, New York.

Rose, K.D. 1981. The Clarkforkian Land-Mammal age and mammalian faunal composition across the Paleocene-Eocene boundary. University of Michigan, Paper in Paleontology, 26:1-196.

Rose, K.D. 2006. The Beginning of the Age of Mammals. John Hopkins University Press, Baltimore.

Rose, K.D., Chew, A.E., Dunn, R.H., Kraus, M.J., Fricke, H.C., and Zack, S.P. 2012. Earliest Eocene mammalian fauna from the Paleocene-Eocene Thermal Maximum at Sand Creek Divide, southern Bighorn Basin, Wyoming. University of Michigan, Papers in Paleontology, 36:1-122.

Russell, L.S. and Wickenden, R.T.D. 1933. An upper Eocene vertebrate fauna from Saskatchewan. Trans- 
actions of the Royal Society of Canada, Series 3, 27:53-65.

Schoch, R.M. 1983. A new species of Isectolophus (Mammalia, Tapiroidea) from the middle Eocene of Wyoming. Postilla, 188:1-4.

Schoch, R.M. 1984. Two unusual specimens of Helaletes in the Yale Peabody Museum collections and some comments on the ancestry of the Tapiridae (Perissodactyla, Mammalia). Postilla, 193:1-20.

Scott, W.B. 1883. On Desmatotherium and Dilophodon, two new Eocene lophiodonts. Contributions of the $E$. M. Museum of Geology and Archeology, Princeton College Bulletin, 3:46-53.

Scott, W.B. and Jepsen, G.L. 1936. The mammalian fauna of the White River Oligocene. Part 1. Insectivora and Carnivora. Transactions of the American Philosophical Society New Series, 28:1-153.

Scott, W.B. and Osborn, H.F. 1887. Preliminary report on the vertebrate fossils of the Uinta Formation, collected by the Princeton Expedition of 1886. Proceedings of the American Philosophical Society, 24:255264.

Scott, W.B. and Osborn, H.F. 1889. The mammalian fauna of the Uinta Formation. Transactions of the American Philosophical Society, New Series, 16:461572.

Secord, R. 2008. The Tiffanian Land-Mammal Age (middle and late Paleocene) in the northern Bighorn Basin, Wyoming. University of Michigan, Papers in Paleontology, 35:1-192.

Setoguchi, T. 1975. Paleontology and geology of the Badwater Creek area, central Wyoming. Part 11. late Eocene marsupials. Annals of Carnegie Museum, 45:263-275.

Sigé, B. 1991. Morphologie dentaire lactéale d'un Chiroptère de l'Éocène inférieur-moyen d'Europe. Geobios, 13:231-236.

Sigé, B. 1997. Les mammifères insectivores des nouvelles collection de Sossis et sites associés (Eocène Supérieur, Espagne). Geobios, 30:91-113.

Sigé, B., Habersetzer, J., and Storch, G. 1998. The deciduous dentition and dental replacement in the Eocene bat Palaeochiropteryx tupaiodon from Messel: the primitive condition and beginning of specialization of milk teeth among Chiroptera. Lethaia, 31:349-358.

Silcox, M.T., Bloch, J.I., Boyer, D.M., and Houde, P. 2010. Cranial anatomy of Paleocene and Eocene Labidolemur kayi (Mammalia: Apatotheria), and the relationships of Apatemyidae to other mammals. Zoological Journal of the Linnean Society, 160:773825.

Simpson, G.G. 1928. A new mammalian fauna from the Fort Union of southern Montana. American Museum Novitates, 297:1-15.

Simpson, G.G. 1929. A collection of mammals from Bear Creek, Montana. Annals of Carnegie Museum, 19:115-122.
Smith, M.E., Carroll, A.R., and Singer, B.S. 2008. Synoptic reconstruction of a major ancient lake system: Eocene Green River Formation, western United States. Geological Society of America Bulletin, 120:54-84.

Smith, M.E., Chamberlain, K.R., Singer, B.S., and Carroll, A.R. 2010. Eocene clocks agree; coeval 40Ar/ ${ }^{39} \mathrm{Ar}, \mathrm{U}-\mathrm{Pb}$, and astronomical ages from the Green River Formation. Geology, 38:527-530.

Smith, M.E., Singer, B., and Carroll, A. 2003. ${ }^{40} \mathrm{Ar} /{ }^{39} \mathrm{Ar}$ geochronology of the Eocene Green River Formation, Wyoming. Geological Society of America Bulletin, 115:549-565.

Smith, T. 1995. Présence du genre Wyonycteris (Mammalia, Lipotyphla) à la limite Paléocène-Eocène en Europe. Comptes Rendus Académie des Sciencies, 321:923-930.

Smith, T., Habersetzer, N.B., Simmons, N.B., and Gunnell, G.F. 2012. Systematics and paleobiogeography of early bats, p. 67-104. In Gunnell, G.F. and Simmons, N.B. (eds.), Evolutionary History of Bats: Fossils, Molecules and Morphology. Cambridge University Press, Cambridge.

Smith, T., Rana, R.S., Missiaen, P., Rose, K.D., Sahni, A., Singh, H., and Singh, L. 2007. High bat (Chiroptera) diversity in the early Eocene of India. Naturwissenschaften, 94:1003-1009.

Stirton, R.A. 1940. Phylogeny of North American Equidae. University of California Publications, Bulletin of the Department of Geological Sciences, 25:165-198.

Stock, C. 1935. Insectivora from the Sespe uppermost Eocene, California. Proceedings of the National Academy of Science, 21:214-219.

Stock, C. 1936. Perissodactyla of the Sespe Eocene, California. Proceedings of the National Academy of Sciences of the USA, 22:260-265.

Storer, J.E. 1984. Mammals of the Swift Current Creek Local Fauna. Natural History Contributions, Saskatchewan Culture and Recreation Museum of Natural History, 7:1-158.

Storer, J.E. 1996. The marsupials of the Lac Pelletier lower fauna, middle Eocene (Duchesnean) of Saskatchewan. Journal of Vertebrate Paleontology, 16:770-774.

Stucky, R.K. 1998. Eocene bunodont and bunoseleondont Artiodactyla ("dichobunids"), p. 358-374. In Janis, C.M., Scott, K.M., and Jacobs, L.L. (eds.), Evolution of Tertiary mammals of North America, Volume 1: terrestrial carnivores, ungulates and ungulatelike mammals. Cambridge University Press, New York.

Szalay, F.S. 1969. Mixodectidae, Microsyopidae, and the insectivore-primate transition. Bulletin of the American Museum of Natural History, 140:195-330.

Szalay, F.S. 1976. The systematics of the Omomyidae (Tarsiiformes, Primates): taxonomy, phylogeny and adaptations. Bulletin of the American Museum of Natural History, 156:157-450. 
Trouessart, E.-L. 1879. Catalogue des mammiféres vivants et fossiles. Revue et Magazine de Zoologie (Paris), 6:219-285.

Troxell, E.L. 1922. The status of Homogalax, with two new species. American Journal of Science Series 5, 3:288-292.

Troxell, E.L. 1923a. The Eocene rodents Sciuravus and Tillomys. American Journal of Science, 5:383-396.

Troxell, E.L. 1923b. The Apatemyidae. American Journal of Science, 5:503-506.

Tsukui, K. 2016. Chronology and faunal evolution of the middle Eocene Bridgerian North American Land Mammal "Age": achieving high precision geochronology. Unpublished PhD Thesis, Columbia University, New York, USA.

Tsukui, K. and Clyde, W.C. 2012. Fine-tuning the calibration of the early to middle Eocene geomagnetic polarity time scale: paleomagnetism of radioisotopically dated tuffs from Laramide foreland basins: Geological Society of America Bulletin, 124:870-885.

Turnbull, W.D. 2002. The mammalian faunas of the Washakie Formation, Eocene age, of southern Wyoming. Part IV. the uintatheres. Fieldiana Geology, 47:1-189.

Walsh, S.L. 1996a. Theoretical biochronology, the Bridgerian/Uintan boundary, and the "Shoshonian subage" of the Uintan, p. 52-74. In Prothero, D.R. and Emry, R.J. (eds.), The Terrestrial Eocene-Oligocene Transition in North America. Cambridge University Press, New York.

Walsh, S.L. 1996b. Middle Eocene mammalian faunas of San Diego County, California, p. 75-119. In Prothero, D.R. and Emry, R.J. (eds.), The Terrestrial EoceneOligocene Transition in North America. Cambridge University Press, New York.

Walsh, S.L. 1998. Notes on the anterior dentition and skull of Proterixoides (Mammalia: Insectivora: Dormaaliidae), and a new dormalliid genus from the early Uintan (middle Eocene) of southern California. Proceedings of the San Diego Society of Natural History, 34:1-26.

Walton, A.H. 1992. Magnetostratigraphy and the ages of Bridgerian and Uintan faunas in the lower and middle members of the Devil's Graveyard Formation, TransPecos Texas, p. 74-87. In Prothero, D.R. and Berggren, W.A. (eds.), Eocene-Oligocene Climatic and Biotic Evolution. Princeton University Press, Princeton, New Jersey.

Weitzel, K. 1949. Neue Wirbeltiere (Rodentia, Insectivora, Testudinata) aus den Mittleleozän von Messel bei Darmstadt. Abhandlungen Senckenbergische Naturforschenden Gesellschaft, 480:1-24.

West, R.M. 1973a. Geology and mammalian paleontology of the New Fork-Big Sandy area, Sublette County, Wyoming. Fieldiana Geology, 29:1-193.

West, R.M. 1973b. Review of the North American Eocene and Oligocene Apatemyidae (Mammalia: Insectivora). Special Publications of the Museum, Texas Tech University, 3:1-42.
West, R.M. 1974. New North American middle Eocene nyctithere (Mammalia, Insectivora). Journal of Paleontology, 48:983-987.

West, R.M. 1979. Paleontology and geology of the Bridger Formation, southern Green River Basin, southwestern Wyoming. Part 3. Notes on Hyopsodus. Contributions in Biology and Geology, Milwaukee Public Museum, 25:1-52.

West, R.M. 1982. Fossil mammals from the lower Buck Hill Group, Eocene of Trans-Pecos Texas. PearceSellards Series, 35:1-20.

West, R.M. 1984. Paleontology and geology of the Bridger Formation, southern Green River Basin, southwestern Wyoming, Part 7, Survey of Bridgerian Artiodactyla, including description of a skull and partial skeleton of Antiacodon pygmaeus. Contributions in Biology and Geology, Milwaukee Public Museum, $56: 1-47$

West, R.M. and Hutchison, J.H. 1981. Paleontology and geology of the Bridger Formation, southern Green River Basin, southwestern Wyoming, Part 6, the fauna and correlation of Bridger $\mathrm{E}$. Contributions in Biology and Geology, Milwaukee Public Museum, 46:1-8.

West, R.M. and Dawson, M.R. 1975. Eocene fossil Mammalia from the Sand Wash Basin, northwestern Moffat County, Colorado. Annals of Carnegie Museum, 45:231-253.

Wheeler, J.A. 1961. Revision of the Uintatheres. Peabody Museum of Natural History Bulletin, 14:1-93.

Williams, B.A. and Kirk, E.C. 2008. New Uintan primates from Texas and their implications for North American patterns of species richness during the Eocene. Journal of Human Evolution, 55:927-941.

Wilson, J.A. 1984. Vertebrate faunas 49 to 36 million years ago and additions to the species of Leptoreodon (Mammalia: Artiodactyla) found in Texas. Journal of Vertebrate Paleontology, 4:199-207.

Wilson, J.A. 1986. Stratigraphic occurrence and correlation of early Tertiary vertebrate faunas, Trans-Pecos Texas: Agua Fria-Green Valley areas. Journal of Vertebrate Paleontology, 6:350-373.

Wilson, J.A. and Schiebout, J.A. 1984. Early Tertiary vertebrate faunas, Trans-Pecos Texas: Ceratomorpha less Amynodontidae. Pearce-Sellards Series, 39:147.

Wilson, R.W. 1937. Two new Eocene rodents from the Green River Basin, Wyoming. American Journal of Science, 34:447-456.

Wood, A.E. 1959. The geology and paleontology of the Elk Mountain and Tabernacle Butte area, Wyoming, Rodentia. Bulletin of the American Museum of Natural History, 117:157-169.

Wood, A.E. 1973. Eocene rodents, Pruett Formation, southwest Texas: their pertinence to the origin of the south American Caviomorpha. Pearce-Sellards Series, 20:1-41. 
Wood, H.E. 1927. Some early Tertiary rhinoceroses and hyracodonts. Bulletins of American Paleontology, 13:165-249.

Wood, H.E. 1934. Revision of the Hyrachyidae. Bulletin of the American Museum of Natural History, 67:181295.
Wortman, J.L. 1898. The extinct Camelidae of North America and some associated forms. Bulletin of the American Museum of Natural History, 10:93-142.

Wortman, J.L. and Matthew, W.D. 1899. The ancestry of certain members of the Canidae, the Viverridae and Procyonidae. Bulletin of the American Museum of Natural History, 12:109-139. 